\title{
ARE THE CHARACTERISTICS OF MOTHERS AND CHILD CARE PRACTITIONERS PREDICTIVE OF THEIR EARLY LITERACY AND NUMERACY PRACTICES?
}

\author{
A thesis submitted to \\ the Faculty of Graduate Studies and Research \\ in Partial Fulfillment of the requirements for the degree
}

Masters of Arts

By

Carla Sowinski

Department of Psychology

Carleton University

September 22, 2009

(C2009 Carla Sowinski 


$\begin{array}{ll}\begin{array}{l}\text { Library and Archives } \\ \text { Canada }\end{array} & \begin{array}{l}\text { Bibliothèque et } \\ \text { Archives Canada }\end{array} \\ \begin{array}{l}\text { Published Heritage } \\ \text { Branch }\end{array} & \begin{array}{l}\text { Direction du } \\ \text { Patrimoine de l'édition }\end{array} \\ \begin{array}{l}\text { 395 Wellington Street } \\ \text { Ottawa ON K1A ON4 } \\ \text { Canada }\end{array} & \begin{array}{l}\text { 395, rue Wellington } \\ \text { Ottawa ON K1A ON4 } \\ \text { Canada }\end{array}\end{array}$

Your file Votre refférence

ISBN: 978-0-494-58424-8

Our file Notre référence

ISBN: 978-0-494-58424-8

NOTICE:

AVIS:

The author has granted a nonexclusive license allowing Library and Archives Canada to reproduce, publish, archive, preserve, conserve, communicate to the public by telecommunication or on the Internet, loan, distribute and sell theses worldwide, for commercial or noncommercial purposes, in microform, paper, electronic and/or any other formats.

The author retains copyright ownership and moral rights in this thesis. Neither the thesis nor substantial extracts from it may be printed or otherwise reproduced without the author's permission.

L'auteur a accordé une licence non exclusive permettant à la Bibliothèque et Archives Canada de reproduire, publier, archiver, sauvegarder, conserver, transmettre au public par télécommunication ou par l'Internet, prêter, distribuer et vendre des thèses partout dans le monde, à des fins commerciales ou autres, sur support microforme, papier, électronique et/ou autres formats.

L'auteur conserve la propriété du droit d'auteur et des droits moraux qui protège cette thèse. $\mathrm{Ni}$ la thèse ni des extraits substantiels de celle-ci ne doivent être imprimés ou autrement reproduits sans son autorisation.
In compliance with the Canadian Privacy Act some supporting forms may have been removed from this thesis.

While these forms may be included in the document page count, their removal does not represent any loss of content from the thesis.
Conformément à la loi canadienne sur la protection de la vie privée, quelques formulaires secondaires ont été enlevés de cette thèse.

Bien que ces formulaires aient inclus dans la pagination, il n'y aura aucun contenu manquant.

\section{Canadä}




\begin{abstract}
Do the characteristics of practitioners and mothers predict their reported literacy and numeracy practices? Canadian mothers $(N=131)$ and child care practitioners $(N=376)$ caring for preschoolers completed surveys. Children's book exposure and mothers' academic expectations predicted mothers' literacy and numeracy practices. Mothers' literacy attitudes also predicted literacy practices, but numeracy attitudes only weakly predicted some numeracy practices. Professional development, beliefs about child care, and beliefs about children's capabilities predicted practitioners' literacy practices overall; their expectations predicted basic literacy practices only. Professional development, beliefs about children's capabilities, and expectations predicted practitioners' numeracy practices overall; their beliefs about child care predicted advanced numeracy practices only. Thus, both parent and practitioner characteristics predicted their reported literacy and numeracy practices; expectations stood out as a significant predictor for both groups. In future, adult characteristics should be taken into consideration in studies of their literacy and numeracy practices with children.
\end{abstract}




\section{Acknowledgements}

I think it would be difficult to complete a Master of Arts degree without a lot of support. I feel very happy (and lucky) to have been supported every step along the way, and I offer my sincere thanks to my friends and family who helped me through.

Thank you to Jo-Anne LeFevre for supporting and guiding me, and for being all that an advisor should be.

To Derek: Thanks for all of the things that you have done for me as I worked on this project, and for all of your encouragement. There really is no way for me to adequately express how much your support means to me; all I can say is Thank You. 


\section{Table of Contents}

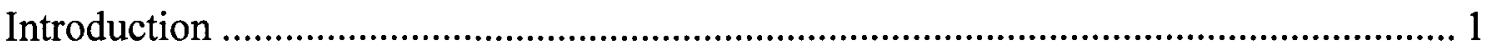

Why are Early Literacy and Numeracy Important? .................................................. 2

Literacy and reading achievement. .................................................................. 2

Numeracy and math achievement. ...................................................................... 2

Research on the Early Literacy and Numeracy and the Home Environment.................. 3

Why Mothers and ELCC Practitioners?

Background Research......................................................................................... 6

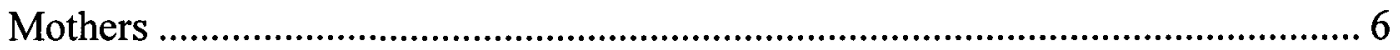

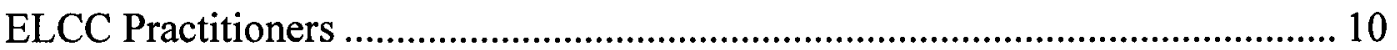

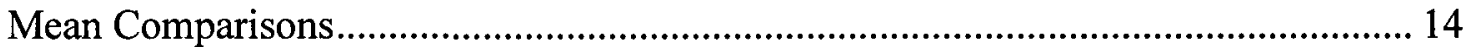

A Comparison of Mothers and Practitioners................................................................ 14

The Current Project ............................................................................................... 15

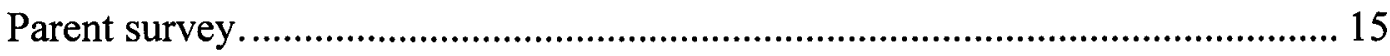

Early Learning Survey. .................................................................................... 16

Summary of Hypotheses ................................................................................... 18

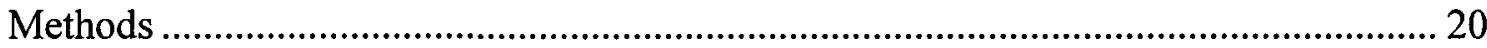

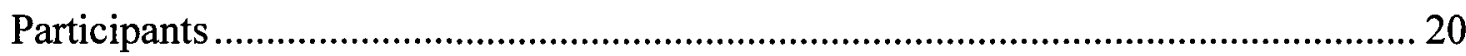

Procedure

Parent Questionnaire .................................................................................... 21

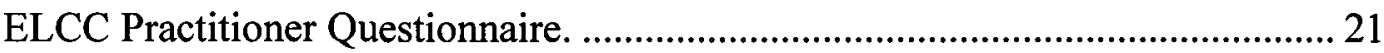

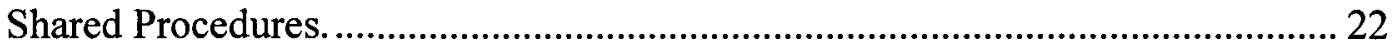




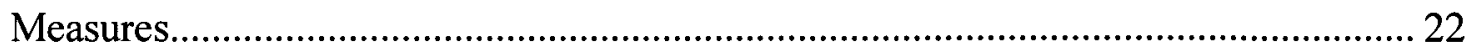

Parent Questionnaire ……............................................................................... 22

Practitioner Questionnaire................................................................................. 24

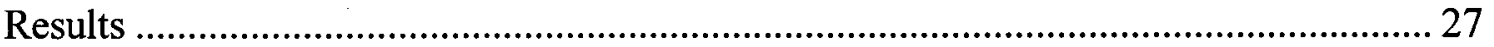

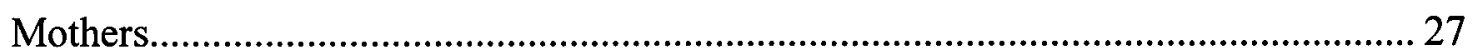

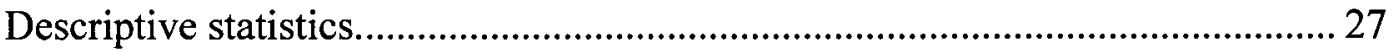

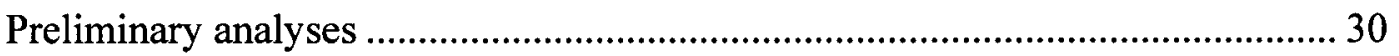

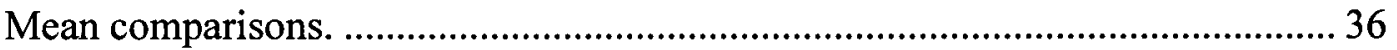

Correlates of mothers' literacy practices................................................................. 36

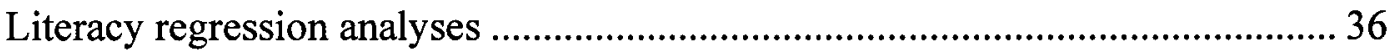

Numeracy practices principle components analysis. ............................................. 39

Correlates of mothers' numeracy practices............................................................. 41

Regression analyses three types of numeracy practices......................................... 41

Summary of Models to Predict Maternal Numeracy and Literacy Practices........ 44

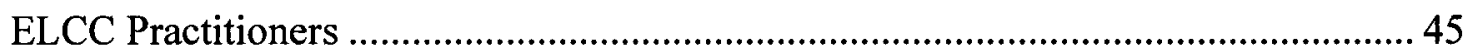

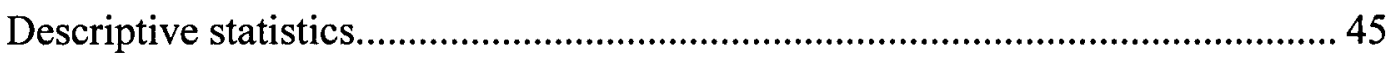

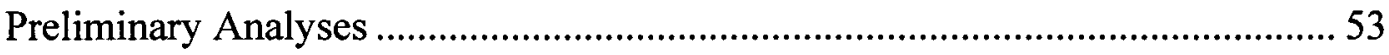

Correlates of ELCC practitioner practices. ............................................................. 66

Regression models for ELCC practitioners........................................................6

A comparison of models to predict ELCC practitioner practices. .......................... 74

Descriptive comparison of mothers and ELCC practitioners..................................... 75

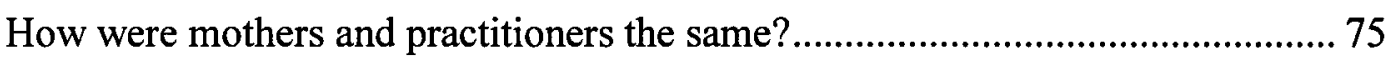

How were mothers and practitioners different? .................................................... 77 


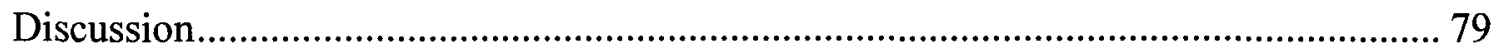

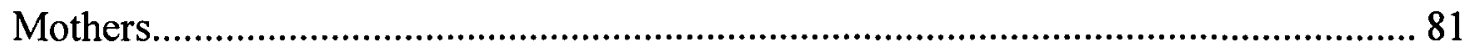

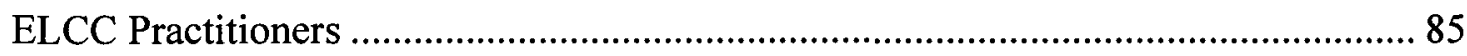

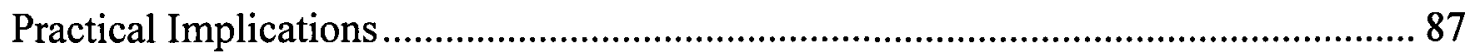

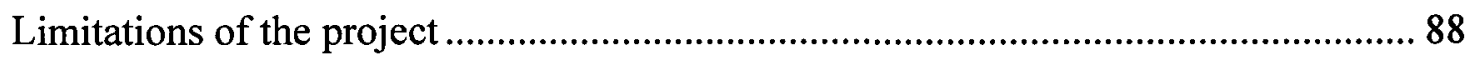

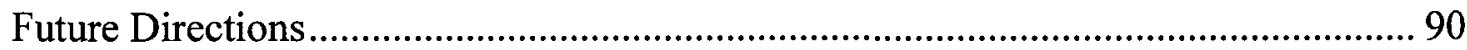

Other variables to consider in future research......................................................90

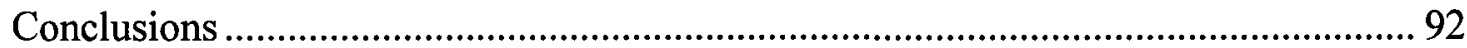

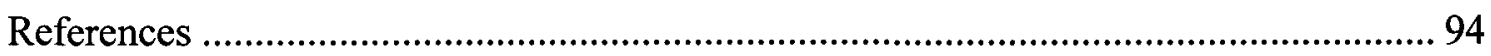




\section{List of Tables}

Table 1. Summary of Hypotheses...................................................................... 19

Table 2 Summary of Descriptive Statistics for Mothers' Expectations. ....................... 31

Table 3 Summary of Descriptive Statistics for Mothers' Literacy and Numeracy

Attitudes. 32

Table 4 Summary of Descriptive Statistics for Mothers' Numeracy Practices.............. 34

Table 5 Summary of Descriptive Statistics for Mothers' Literacy Practices. ............... 35

Table 6 Correlations Among Parent Characteristics and Their Reported Literacy and

Numeracy Practices.................................................................................... 37

Table 7 Standardized Coefficients and $R^{2}$ for All Regression Models Predicting

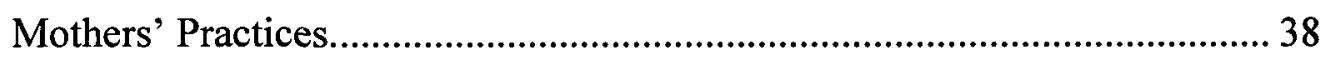

Table 8 Rotated Factor Loadings for Three Extracted Numeracy Components. .......... 40

Table 9 Correlations Among Parent Characteristics and Three Types of Numeracy

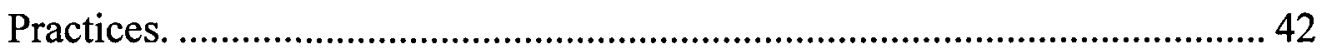

Table 10 Characteristics of ELCC Practitioners........................................................... 46

Table 11 Summary of Descriptive Statistics for ELCC Practitioners' Expectations..... 54

Table 12 Summary of Descriptive Statistics for ELCC Practitioners' Beliefs About

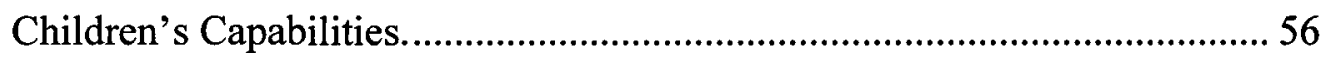

Table 13 Summary of Descriptive Statistics for ELCC Practitioners' Literacy Practices.

Table 14 Rotated Factor Loadings for ELCC Practitioners' Literacy Practices. .......... 58 
Table 15 Summary of Descriptive Statistics for ELCC Practitioners' Numeracy

Practices.

Table 16 Rotated Factor Loadings for ELCC Practitioners' Numeracy Practices........ 62

Table 17 Practices Means by Beliefs About Child Care Cluster Groups...................... 65

Table 18 Correlations Among ELCC practitioner Variables .......................................... 67

Table 19 Standardized Coefficients and $R^{2}$ for Regression Models Predicting ELCC

Practitioners' Practices.

Table 20 Correlations Among ELCC Practitioner Predictors and Outcomes and

Professional Development, Experience and Education.

Table 21 Summary of Regression Models Predicting ELCC Practitioners' Practices

with Professional Development Included.

Table 22 Summary of Supported Hypotheses.

80 


\section{List of Figures}

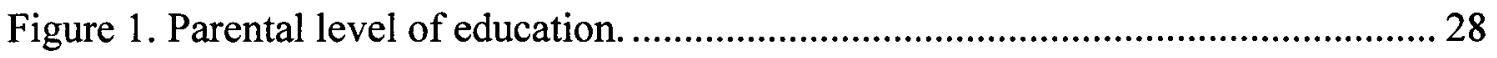

Figure 2. Percentage of mothers working within each industry category. ...................... 29

Figure 3. ELCC practitioners' experience in the field and in current position. .............. 47

Figure 4. The percentage of children in child care programs within each disadvantaged

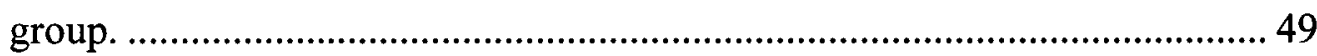

Figure 5. ELCC practitioner awareness of professional development events.................50

Figure 6. Frequency of professional development events by topic. ............................... 52

Figure 7. A graphical depiction of means on belief items grouped by cluster................ 64 


\section{List of Appendices}

Appendix A: Parent Survey ………………………............................................... 103

Appendix B: Early Learning and Child Care Practitioner Survey …………………... 110

Appendix C: ELCC Practitioner Program Philosophies................................................. 119

Appendix D: Ethics Approval ............................................................................... 120 


\section{Introduction}

When children enter kindergarten, they vary in numeracy and literacy knowledge (Aunola, Leskinen, Lerkkanen, \& Nurmi, 2004; Desoete \& Gregoire, 2006; Jordan, Kaplan, Locuniak, \& Ramineni, 2007; Lonigan, Burgess \& Anthony, 2000; McCardle, Scarborough \& Catts, 2001; Scarborough \& Dobrich, 1994). These individual differences suggest that children have already acquired some literacy and numeracy skills before they begin formal education. In the current project, it is assumed that children's early experiences at home and in the child care setting contribute to their literacy and numeracy development. The goal of the current project is to examine parent and early learning and child care (ELCC) practitioner characteristics, (e.g., expectations and attitudes), in relation to their reports of literacy and numeracy activities.

Literacy is the ability to read, write and use language in everyday settings. Before children learn to read and write, assessments of their early literacy skills usually focus on knowledge of letter sound correspondence, vocabulary, phonological awareness, and letter naming ability because research has shown that these factors are related to learning to read (Perlman \& Fletcher, 2008; Sénéchal \& LeFevre, 2002). Numeracy is meant to be analogous to literacy. Early numeracy is thought to be the foundation for mathematical knowledge, just as early literacy is thought to be the foundation for reading and writing (Gersten \& Chard, 1999; Jordan, Kaplan, Oláh \& Locuniak, 2006). Numeracy can be used to describe one's ability to use numbers and quantities in various ways in everyday life activities, such as shopping, comparing, estimating, and budgeting. Before children can do symbolic arithmetic, assessments of early numeracy focus on knowledge of the 
formal symbolic number system (e.g., Arabic digits, counting vocabulary) as well as an understanding of quantity.

This project focuses on both literacy and numeracy practices. Traditionally, more research has focused on literacy than numeracy. For this reason, literacy research guides the numeracy research proposed here. Although relations between home literacy practices and children's literacy outcomes are fairly well understood; relatively less is known about the relations between home numeracy practices and children's numeracy outcomes. Very little is known about the practices of ELCC practitioners, however, the current project seems a natural extension from past research focused on the home environment, given the amount of time that many young children spend in child care.

\section{Why are Early Literacy and Numeracy Important?}

Literacy and reading achievement. Early literacy is important because it is a precursor to reading. Differences in early literacy achievement can be detected in kindergarten, and lower achievement in early literacy has been linked to lower achievement in reading in primary school (Lonigan et al., 2000; McCardle et al., 2001; Scarborough \& Dobrich, 1994). Scarborough (1998) found that reading achievement in primary school predicted reading achievement in Grade 8. Duncan et al. (2007) also found that school-entry reading was a strong predictor of academic achievement up until ages 13-14. Thus, early literacy is important because researchers have consistently found links between early literacy and subsequent reading and school achievement.

Numeracy and math achievement. Early numeracy is important because it is considered to be a precursor to mathematical understanding. Individual differences in math achievement are present when children enter kindergarten (Aunola et al., 2004; 
Desoete \& Grégoire, 2006; Jordan et al., 2007). Furthermore, these differences predict children's mathematical achievement in later grades. For example, Aunola et al. (2004) found that children with low math achievement in preschool also had low achievement in Grade 2. Although children's rank order within the class remained stable, results indicated that the low-achieving children fell further and further behind. Moreover, Duncan et al. (2007) found that math performance at school entry was the strongest predictor of academic performance in math and reading at ages 8, 10 and 13-14, even after controlling for family factors, attention, socioemotional and cognitive skills (see also Jordan et al., 2007; Kurdek \& Sinclair, 2001). Thus, the evidence suggests that early numeracy skills prepare children to achieve both specifically in mathematics, and generally in school overall.

In sum, children's early literacy and numeracy skills are important because they lay the foundation for the development of more complex skills, such as reading and advanced mathematical knowledge. Ultimately, the goal of early education is to educate children effectively, thus creating functionally literate and numerate adults.

\section{Research on the Early Literacy and Numeracy and the Home Environment}

The relations between home literacy practices and early literacy achievement have been well established in past research (see Evans \& Shaw, 2008 for a review). For example, Sénéchal et al. (1998) found that parents' reports of their literacy practices (e.g., teaching children to print and read words) uniquely predicted kindergarten children's written language skills (early literacy achievement) after controlling for other variables. Similarly, Sénéchal (2006) found that kindergarten-age children whose parents reported teaching them the sounds of letters and reading were more knowledgeable of the alphabet 
and displayed better reading fluency in Grade 4. Thus, parents' literacy practices before Grade 1 are related to their children's academic performance (Evans \& Shaw, 2008). In contrast, research on parents' home numeracy practices and children's numeracy outcomes is sparse. LeFevre et al. (2009) examined the relations between parents' reports of home numeracy experiences and children's mathematical skills. Frequent participation in numerical games was correlated with higher levels of math knowledge, whereas frequent participation in math games and applications (applying math in everyday life) was correlated with higher levels of math fluency (speeded solutions of single-digit addition). Hierarchical regression revealed that home numeracy experiences accounted for a small portion of unique variance in math knowledge, and a larger portion of unique variance in math fluency, even after controlling for other factors, such as socio-economic status (SES) and vocabulary. LeFevre, Polyzoi, Skwarchuk, Fast and Sowinski (In Press) found that, for both Canadian and Greek children, parents' reported frequency of home numeracy practices was a significant predictor of children's numeracy scores, suggesting that parent's home practices are important to the development of numerical concepts. Overall, these results suggest that home numeracy activities contribute to children's numeracy outcomes.

In general, previous research supports the hypothesized links between parents' literacy practices and children's literacy outcomes; there is also some support for the hypothesized links between parents' home numeracy practices and children's numeracy outcomes. Thus the current project was designed to determine what characteristics of mothers might predict their literacy and numeracy practices. 
The current project extends from research on home experiences to include child care experiences as well. Numeracy interventions conducted within Head Start programs in the United States suggest that early child care experiences are related to children's numeracy outcomes (for an example see Clements \& Sarama, 2007). Little to no research has focused specifically on the beliefs, attitudes and expectations of child care practitioners in relation to their practices. This is somewhat surprising given that approximately half of all Canadian children five years of age or younger spend some of their time in the care of individuals other than their parents (Bushnik, 2006). Given the significant portion of time that many children spend in out-of-home child care, it is important to examine the characteristics of ELCC practitioners, as well as the literacy and numeracy experiences that they provide the children in their care. Given that the current project does not assess children's literacy or numeracy achievement, subsequent research is necessary to determine whether or not child care experiences are predictive of children's numeracy and literacy outcomes.

\section{Why Mothers and ELCC Practitioners?}

I chose to examine the characteristics of mothers and practitioners because these people are primarily responsible for the early learning experiences of young children. This study focuses on mothers instead of parents because survey respondents were almost exclusively mothers, despite the fact that fathers were also invited to participate. I hypothesized that practitioners and mothers would be similar because both groups are striving to provide children with learning opportunities to prepare them for success in school and later in life. Specifically, I hypothesized that mother and practitioner expectations and attitudes would predict their practices in a similar manner-the higher 
their expectations and the more positive their attitudes, the more likely they would be to engage in literacy and numeracy practices. Furthermore, I chose to compare mothers and ELCC practitioners because, to my knowledge, no other research has examined the characteristics of mothers and practitioners in relation to their numeracy and literacy practices, especially not from a Canadian perspective.

\section{Background Research}

The current study examines parent and practitioner expectations and attitudes, as well as practitioner beliefs. It is important to note that these variables could all be categorized as "beliefs." For the purposes of this study, I have operationalized specific beliefs in ways described below.

Maternal education, academic expectations, literacy and numeracy attitudes and book exposure will be examined as predictors of their reported literacy and numeracy practices. Practitioner expectations, literacy and numeracy attitudes, beliefs about child care, and beliefs about children's capabilities will be examined as predictors of their reported literacy and numeracy practices. Practitioner level of education, experience and professional development will also be considered as predictors. The following section reviews the existing research on these topics.

\section{Mothers}

Parental socio-economic status and overall academic success. In general, children from less advantaged families (i.e., lower levels of SES) perform less well than their high-SES peers on measures of math achievement and fluency (Arnold \& Doctoroff, 2003; Campbell, Pungello, Miller-Johnson, Burchinal, \& Ramey, 2001; Clements 2004; Ginsburg, Lee \& Boyd, 2008; Jordan et al., 2007; Siegler \& Ramani, 2008; Young- 
Loveridge, 1989). Similarly, low-SES children are more at risk for reading problems and have less phonological awareness and letter knowledge prior to school-entry (Whitehurst \& Lonigan, 1998). For this reason, maternal SES, as measured by maternal education, was included as a predictor of mothers' practices. I hypothesized that higher levels of maternal education would be predictive of higher reported frequencies of literacy and numeracy practices.

Expectations. In this study, parent expectations refer to the level of achievement that mothers expect to their children to attain and specifically how important it is for children to possess specific skills by the time they begin Grade 1. Past research on parents' expectations has generally shown that children do well academically when parent expectations are high, and they provide sufficient learning support to their children (Galper, Wigfield, \& Seefeldt, 1997). Specifically, some research has focused on parental expectations in relation to their literacy practices. For example, DeBaryshe (1995) found that parental expectations were strongly related to maternal practices such as shared book reading and quality of interactions during book reading in a sample of mothers of fouryear olds. Hess, Holloway, Dickson and Price (1984) found that maternal expectations were predictive of children's scores on a measure of reading readiness, demonstrating that parental expectations have also been linked to children's outcomes (see also Galper et al., 1997).

More recently, researchers have hypothesized a positive relation between parental expectations and numeracy practices and outcomes, however the findings in support of these hypothesis have been somewhat mixed. LeFevre, Clarke and Stringer (2002) and Musun-Miller and Blevins-Knabe (1998) found that parent expectations were positively 
correlated with their reports of numeracy practices. Huntsinger, Jose, Liaw, and Ching (1997) found that parents' child-specific math expectations were related to parents' practices, as well as to children's math performance. On the other hand, LeFevre et al. (In Press) found that parental expectations did not predict numeracy practices or numeracy outcomes for Greek parents and children. For the Canadian children in LeFevre et al.'s study, parent expectations were a significant predictor of numeracy outcomes, but they did not predict numeracy practices.

In summary, parents' expectations are positively related to their literacy and numeracy practices, as well as to children's outcomes, although the evidence is sparse and the relations are generally modest. In the current project, measures of children's literacy and numeracy achievement were not available. Instead, the focus was on the relation between parent expectations and reported practices. I hypothesized that mothers with higher academic expectations would also report higher frequencies of literacy and numeracy practices.

Attitudes. In this study, attitudes refer to mothers' personal feelings towards math and literacy. Attitudes are often assessed by asking individuals whether or not they enjoy mathematics or writing and whether or not they were good at mathematics or reading in school. Like parental expectations, the evidence linking parental attitudes and practices is somewhat mixed. Weigel, Martin and Bennett (2006) found that parents' own reading enjoyment and writing practices were predictive of their children's literacy outcomes (print knowledge, expressive and receptive language); however, the authors did not examine these variables as predictors of parent practices. Blevins-Knabe, Berghout, Musun, Eddy and Jones (2000) asked parents to report their own enjoyment of engaging 
in reading and math activities with children, and examined how math attitudes were related to practices. Parents were more likely to engage in math activities when they reported enjoying reading. LeFevre et al. (In Press) found that parents' math attitudes were predictive of Canadian and Greek parents' practices, and for Canadian parents, math attitudes were also predictive of children's numeracy outcomes. In contrast, LeFevre et al. (2009) did not find any statistically significant relations between parents' math attitudes and other variables, such as children's math outcomes. Despite the somewhat mixed findings linking attitudes and practices, I conclude that there is sufficient evidence to justify examining maternal attitudes as a predictor of their literacy and numeracy practices. For this study, I hypothesized that mothers with more positive attitudes towards literacy and numeracy would report providing more literacy and numeracy practices, respectively.

Book exposure. In this study, book exposure was operationalized as a combination of how frequently mothers read to their children, as well as the number of children's books in the home. Weigel et al. (2006) combined book exposure with other parent practices, and found that this composite variable was predictive of both print knowledge (i.e., early literacy skill) and receptive vocabulary in preschool children. In studies by Sénéchal and colleagues (Sénéchal, LeFevre, Hudson and Lawson, 1996; Sénéchal, LeFevre, Thomas \& Daley, 1998), parent reports of how frequently they taught their child to decode letters predicted children's phonological awareness and decoding skills (early reading skills). In contrast, book exposure predicted children's language skills such as vocabulary and listening comprehension (but not their early reading skills), suggesting that book exposure is related to some child outcomes. In the current study, I 
hypothesized that mothers' reports of book exposure would predict higher frequencies of other literacy practices.

More recently, book exposure has been examined as a predictor of parents' numeracy practices. Despite the fact that LeFevre et al. (In Press) did not find relations between reports of book exposure and the numeracy practices of Greek or Canadian parents, book exposure was predictive of numeracy outcomes in the Greek children. Also, as part of a movement in early education to see children's literatures as a vehicle for teachers to cover numeracy concepts, Anderson, Anderson and Shapiro (2004) have examined shared book reading as an opportunity for parents to discuss numerical concepts. Based on these findings, I hypothesized that book exposure would predict higher frequencies of reported numeracy practices.

\section{ELCC Practitioners}

Expectations. Just as with mothers, in this study practitioner expectations referred to the level of academic achievement they expect children to attain before entering Grade 1. To my knowledge, little research has included practitioners' expectations as predictors of their practices. Blevins-Knabe et al. (2000) found that home care providers had lower expectations for math skills than social, literacy, and language skills. In a second study, home child care practitioners engaged in numeracy activities infrequently, suggesting that practitioners' expectations may be related to their numeracy practices. Research with teachers suggests that their expectations influence children's academic outcomes (Gill \& Reynolds, 1999). There is also evidence to suggest that teachers interact with students differently based on their specific expectations for that child, suggesting some link between expectations and practices. However, in this study I was concerned with 
practitioners' overall expectations, across children. Specifically, I hypothesized that higher expectations would be predictive of higher reported frequencies of literacy and numeracy practices.

Attitudes. In this study, attitudes referred to practitioners' personal feelings towards math and literacy. Practitioners were only asked about their writing and mathematics avoidance. Weigel et al. (2006) found that child care providers' own writing practices and reading enjoyment were predictive of children's literacy outcomes (e.g., print knowledge and expressive language), however, these variables were not examined as predictors of caregivers' practices. Blevins-Knabe et al. (2000) found that child care providers reported more frequent engagement in math activities when they also reported enjoyment of math and reading. Thus, there is some evidence to suggest that practitioner attitudes are related to their practices. Within practitioners, I hypothesized that positive literacy and numeracy attitudes would be predictive of higher reported frequencies of literacy and numeracy practices, respectively.

Beliefs about children's capabilities. To clarify, practitioner expectations were operationalized as importance placed on knowing specific academic skills by the time a child enters Grade1 (e.g., Count to 100; Know all 26 alphabet letters). For beliefs about children's capabilities, practitioners selected the age when most children are capable of specific milestones, such as distributing 8 candies between 2 people, and using invented spelling to print words. Thus, expectations asked what children should know by Grade 1 , and capabilities asked when children know specific things (e.g., before 4; 4 until 5, 5 until 6 or Age 6 and up). Weigel et al. (2006) found that child care providers' beliefs were predictive of literacy outcomes in preschool children (e.g., print knowledge, receptive and 
expressive language). Other researchers have identified teacher beliefs as a predictor of their behaviours (Pajares, 1992). Little research has focused on practitioner beliefs about children's capabilities in relation to their practices, however. Although there is evidence to suggest that young children are capable of a variety of numeracy and literacy tasks (Ginsburg et al., 2008), practitioners and teachers sometimes underestimate children's capabilities (Anderson, Anderson \& Thauberge, 2008; Greenes, Ginsburg \& Balfanz, 2004; Warfield, Wood \& Lehman, 2005; Young-Loveridge, 1989). Although there is little existing evidence on which to base hypotheses, it seems reasonable to think that practitioners will only engage in activities that they think children are capable of. Thus, practitioner beliefs about children's capabilities are expected to show a negative relation with their practices. I hypothesize that ELCC practitioners who believe children are capable of activities at younger ages overall will report higher frequencies of literacy and numeracy practices than practitioners that do not think children are capable of these activities until older ages overall.

Beliefs about child care. Research by Wang, Elicker, McMullen, and Mao (2008) and Stipek and Byler (1997) suggests that practitioners tend to engage in practices that are consistent with their beliefs. Stipek and Byler (1997) found that practitioners tended to believe that child care should be either basic skills or child-centered in approach. In their study, practitioners with child-centered beliefs were very concerned with providing developmentally appropriate activities that the children initiated themselves. Practitioners with a basic skills orientation tended to believe that child care should include direct instruction designed to prepare children academically for school. Stipek and Byler also found that teachers were more likely to engage in numeracy and literacy activities when 
they believed that numeracy and literacy skill development were important goals of child care. Thus, in Stipek and Byler's research, the types of activities practitioners engaged in were in line with their beliefs. Based on this, the practitioner questionnaire contained questions designed to assess their beliefs about child care. I hypothesized that practitioners who believe that child care should include academic preparation would report higher frequencies of literacy and numeracy practices than practitioners that do not believe child care should include direct instruction.

Education, experience, and professional development. Howe and Jacobs (1995) found that practitioner training was related to the quality of child care, which in turn was related to children's development outcomes. Similarly, Green, Peterson and Lewis (2006) examined ELCC practitioner characteristics in relation to their language and literacy practices and found that practitioner confidence in their training was predictive of literacy practices. Hence, the education or training experience of practitioners may be related to their practices. I hypothesized that practitioners with more training would report higher frequencies of literacy and numeracy practices.

Practitioner practices. Few researchers have examined practices in the child care setting (see Ginsburg \& Amit, 2008). Green et al. (2006) investigated literacy practices in child care settings. Results indicated that practitioners engaged in a variety of early literacy activities. No similar research on early numeracy was found. Thus, to my knowledge, this is one of the first studies to examine early literacy and numeracy practices of Canadian early learning and child care practitioners. 


\section{Mean Comparisons}

Musen-Miller and Blevins-Knabe (1998; Blevins-Knabe et al. 2000) found that child care providers and parents place less importance on numeracy skills in comparison to literacy skills. Although the questions asked in their studies differed from the one asked in the current study, I hypothesized that mothers and practitioners would have more positive attitudes towards literacy than towards numeracy.

In terms of practices, Blevins-Knabe et al. (2000) examined the frequencies of math and literacy activities at home and in home child care settings. Child care providers and parents were very similar in their responses in terms of high frequency and low frequency activities. Overall, the frequency of math activities was quite low. Layzer, Goodson and Moss (1993) also found that numeracy practices occurred much less frequently than literacy practices when they observed preschool classrooms. Based on these findings, I hypothesized that both mothers and practitioners would report lower frequencies of numeracy than literacy practices

\section{A Comparison of Mothers and Practitioners}

Although mothers and practitioners cannot be compared directly, descriptive comparisons can be made. I hypothesized that the practices of both mothers and practitioners would be predicted by their expectations and attitudes. I also hypothesized that both mothers and practitioners would have more positive literacy than numeracy attitudes, and that literacy practices would be reported more frequently than numeracy practices. Thus, results will determine whether or not mothers and practitioners are similar or different in these regards. 


\section{The Current Project}

A survey was designed to gather information about mothers' level of education, expectations, attitudes, book exposure and practices. Mothers were recruited from daycare and preschool programs in Winnipeg, Manitoba. Another survey was designed to gather information about ELCC practitioners' expectations, attitudes, beliefs about child care, beliefs about children's capabilities, professional development, and practices. Practitioners from across Canada completed this survey.

Parent survey. The parent survey used in the present research evolved through a series of studies conducted by LeFevre and colleagues (http://www.carleton.ca/cmi). In their longitudinal project, mothers completed two different versions of a survey designed to assess children's home numeracy experiences (LeFevre et al., 2009; LeFevre et al., In Press). LeFevre et al. (2009) administered the parent survey to parents of kindergarten, Grade 1 and Grade 2 children. They found that home activities, especially numeracy games, were a modest but unique predictor of children's math knowledge (a KeyMath composite score). They also found that home activities, (teaching number skills, numeracy games and numeracy applications) predicted children's math fluency, as measured by response time on single-digit addition. LeFevre et al. (In Press) administered a revised version of this survey to Greek and Canadian parents of kindergarten-age children and found links between parental reports and children's math outcomes. The findings of these two previous studies, plus information from similar projects on early literacy experiences (e.g., LeFevre et al., 2002; Sénéchal \& LeFevre, 2002), were used to refine and improve the survey used in the present research. In particular, effort was made 
to ensure that the survey adequately assessed both early numeracy and early literacy experiences, and included both advanced and basic practices. All practices were designed to be age appropriate practices suitable for the home.

Maternal SES was assessed by asking mothers to indicate their highest level of education. Mothers' expectations were assessed by asking mothers how important it is for children to reach certain literacy and numeracy benchmarks prior to starting Grade 1 . The expectations items were taken from parent questionnaires, where they have been used in past research (LeFevre et al., 2002; 2009). Maternal attitudes were assessed by collecting information on mothers' math and literacy avoidance and enjoyment, as well their own math and literacy performance in school, and the amount of time spent writing or doing math in their current job. The amount that mothers exposed their children to books was assessed by asking mothers to report how frequently they read to their children, as well as the number of children's books in the home. Finally, mothers provided information about their practices by indicating how frequently they engaged in literacy and numeracy activities with their children.

Early Learning Survey. The ELCC practitioner survey was developed and implemented by a team of academic researchers in collaboration with the Canadian Child Care Federation (CCCF), and funded by the Canadian Council on Learning. The practitioner questionnaire was designed to survey members of the CCCF. The CCCF is a Canada-wide organization whose members include over 11,000 early learning and child care practitioners.

Practitioners indicated their level of education, as well as their attendance of professional development workshops. Practitioners also indicated their years of 
experience in the child care field. Practitioner expectations were assessed by having practitioners rate how important it is for children to reach certain literacy and numeracy benchmarks prior to starting Grade 1. Items were taken from past parent questionnaires (LeFevre et al., 2002; 2009). Practitioner attitudes towards literacy and numeracy were assessed by asking them about their writing and math avoidance.

To obtain information about practitioners' beliefs about child care they were asked to rate their agreement with a list of statements designed to assess whether or not activities should be adult or child-initiated and whether the primary goal of child care is to prepare children academically or socioemotionally for school. Practitioner beliefs about children's capabilities were assessed by asking practitioners to identify the age that most children are capable of various activities. This question was developed for this survey. Literacy statements were taken from Millard and Waese's (2007) Language and Literacy Milestones, and some more advanced literacy activities were added. Questions on counting, comparing and ordering, geometry, and early arithmetic were developed by one of the research collaborators based on the findings from past research.

To assess practitioner practices, a list of early numeracy and literacy activities was developed based on the existing research on parent and practitioner practices (Bracken \& Fischel, 2006; Charlesworth et al., 1993; Stipek \& Byler, 1997, 2004; Vartuli, 1999). These practices were designed to be developmentally appropriate and suitable for the child care setting. Practitioners rated how frequently they engaged in basic and advanced literacy and numeracy activities. Some socioemotional practices were also included to make the list representative of the early child care experience. 


\section{Summary of Hypotheses}

A summary of hypotheses is presented in Table 1. To review, I hypothesized that both mothers and practitioners would report more positive attitudes towards literacy than numeracy, and that they would report lower frequencies of literacy than numeracy practices. Education or experience, attitudes, and expectations were hypothesized to be predictive of literacy and numeracy practices in both mothers and practitioners. Book exposure was also hypothesized to predict mothers' practices, whereas practitioner beliefs about child care and children's capabilities were also hypothesized to predict their practices. 
Table 1.

Summary of Hypotheses.

\begin{tabular}{|c|c|c|c|c|}
\hline Hypotheses & \multicolumn{2}{|c|}{ Mothers } & \multicolumn{2}{|c|}{ Practitioners } \\
\hline \multicolumn{5}{|l|}{$\begin{array}{l}\text { Comparisons between literacy and } \\
\text { numeracy }\end{array}$} \\
\hline $\begin{array}{l}\text { Attitudes towards literacy will be more } \\
\text { positive than those towards numeracy }\end{array}$ & \multicolumn{2}{|c|}{$\sqrt{ }$} & \multicolumn{2}{|c|}{$\sqrt{ }$} \\
\hline $\begin{array}{l}\text { Literacy practices will be reported } \\
\text { more frequently than numeracy } \\
\text { practices }\end{array}$ & \multicolumn{2}{|c|}{$\checkmark$} & \multicolumn{2}{|c|}{$\sqrt{ }$} \\
\hline Potential Predictors of Reported Practices & Num & Lit & Num & Lit \\
\hline Education or experience & $\sqrt{ }$ & $\sqrt{ }$ & $\sqrt{ }$ & $\sqrt{ }$ \\
\hline Academic expectations & $\sqrt{ }$ & $\sqrt{ }$ & $\sqrt{ }$ & $\sqrt{ }$ \\
\hline Attitudes towards literacy or numeracy & $\sqrt{ }$ & $\sqrt{ }$ & $\sqrt{ }$ & $\sqrt{ }$ \\
\hline Book Exposure & $\sqrt{ }$ & $\sqrt{ }$ & $\mathrm{n} / \mathbf{a}$ & $\mathrm{n} / \mathrm{a}$ \\
\hline Beliefs about child care & $\mathrm{n} / \mathrm{a}$ & $\mathrm{n} / \mathrm{a}$ & $\sqrt{ }$ & $\sqrt{ }$ \\
\hline Beliefs about children's capabilities & $\mathrm{n} / \mathbf{a}$ & $\mathrm{n} / \mathrm{a}$ & $\sqrt{ }$ & $\sqrt{ }$ \\
\hline
\end{tabular}

Note. A check mark indicates that this hypothesis was proposed, not that it was supported. Num = numeracy practices; Lit = literacy practices. 


\section{Methods}

\section{Participants}

The current study utilized archival data from two recent surveys: one that surveyed mothers of four-year-olds residing in Winnipeg, Manitoba and another that surveyed early learning and child care (ELCC) practitioners from across Canada, Mothers $(N=137)$ of preschool children completed the parent questionnaire. All items necessary for further analyses were included in a missing values analysis. Little's MCAR test was not significant, $\chi^{2}(1250, N=137)=1268.83, p=.35$, suggesting that any missing data was missing completely at random, thus permitting case-wise deletion. Three cases were deleted for missing $15 \%$ of data or more. Three other participants missing all of the data necessary to compute the book exposure variable were also deleted. For the remaining cases, each missing value was imputed with the regression mean for that particular item. The size of the final parent sample was $N=131$.

Although 768 practitioners completed the practitioner survey, only the data from the practitioners caring for preschoolers $(N=444)$ was analyzed for the current project. This was done to ensure that mothers and practitioners were providing responses based on children of the same age. All cases missing data on entire measurement scales necessary for analyses ( $n=57)$, or missing such substantial portions of data that imputation seemed inappropriate $(n=11)$ were deleted. The size of the final practitioner 
sample was $N=376$. No one item was missing more than $5 \%$ of its data, and each missing value was imputed with the regression mean for that particular item ${ }^{1}$.

\section{Procedure}

Parent Questionnaire. Most of the recruitment for the parent questionnaire was done through preschools and child care centres in Winnipeg. Approximately 75 preschools and child care centres were contacted to participate, and of these 30 agreed to participate. At first, consent letters for parents were dropped off at the participating locations and surveys were provided once parents had consented to participate. However, later on in the data collection consent forms and surveys were given out together in an attempt to increase participation rates. Additionally, parents were recruited at a preschool wellness picnic held in Winnipeg called the Teddy Bear Picnic. Information packages were also sent to a Kindercamp program in Winnipeg. Some mothers participated through an emailed link to the online survey. More than 1000 consent forms and survey packages were distributed altogether. Most mothers completed a paper version of the survey, however some accessed an online version of the survey via a link to the web survey tool, SurveyMonkey. Data collection was done in the spring and summer of 2008.

ELCC Practitioner Questionnaire. The practitioner survey took 15-20 minutes to complete. Most ELCC practitioners completed the survey online via the web survey application, SurveyMonkey $(\mathrm{n}=288)$. Another 88 participants completed a paper version of the survey at early learning conferences. Online participants were recruited by email and through a link to the survey on the Canadian Child Care Federation's webpage.

\footnotetext{
${ }^{1}$ For example, the regression mean for Practice 5 would be imputed for any missing Practice 5 . The regression mean is the mean plus the residual from a randomly chosen case.
} 
Participants were also recruited at conferences for child care practitioners in Winnipeg and Vancouver. Data collection was done during the spring of 2008.

Shared Procedures. Both mothers and practitioners gave their informed consent before beginning their respective surveys. The informed consent provided a description of the purpose of the study, and explained that responses would remain anonymous and confidential. The contact information for investigators was provided for anyone with ethical concerns or problems with the survey. An incentive draw was held to encourage participation; at the end of the online survey, participants were provided with a separate link to the prize draw in an effort of maintain anonymity.

The online survey displayed a progress bar at the top of every page, and an Exit Survey button was displayed at all times. Next Page and Previous Page buttons were also displayed on each page. The survey pages were designed to minimize scrolling. The paper version of the survey was modified to some extent to fit the paper and to replace web-specific features with printed items.

\section{Measures}

\section{Parent Questionnaire}

Demographic information. Mothers provided a variety of demographic information including maternal age, level of education and occupation of each parent, employment status of the responding parent, whether or not the parent qualified for a subsidy, language spoken in the home, and age of other children (see Appendix A for more information). Birth date of the child and the school the child was to attend the next year were also collected to facilitate locating the children and administering child measures at a later time. 
Mothers' expectations. To assess what mothers expect children to know prior to formal schooling, mothers rated how important it is for children to achieve a list of 13 literacy and numeracy benchmarks before starting Grade 1. This list of expectations was very similar to the list of expectations included on the practitioner questionnaire. One difference was that the practitioner questionnaire had 7 items instead of 13 . The items on the parent questionnaire were more advanced than items on the practitioner questioner. The parent questionnaire included items, such as: "Count to 1000," "Know multiplying," and "Read chapter books." The expectations question on the parent questionnaire differed from the practitioner questionnaire in an attempt to increase variability within the measure, because a preliminary examination of the question indicated that most practitioners rated all of the benchmarks as very important. The rating scale on the parent questionnaire was also somewhat different from the practitioner questionnaire; response options ranged from Unimportant (-1) to Extremely important (3), whereas the practitioner questioner response items ranged from Very unimportant (-2) to Very important (2).

Mothers' attitudes. To assess attitudes towards numeracy and literacy, mothers rated their agreement with statements that they avoid situations involving mathematics and writing. In addition, mothers also rated their agreement with statements about whether they were good at math and literacy in school, whether they find math and writing enjoyable, and whether or not their job involves a lot of math or writing. Response options range from Strongly disagree (-2) to Strongly agree (2). Math and literacy avoidance items were reverse coded (e.g., disagreement with avoiding math or writing reflects a more positive attitude, and is scored 1 instead of -1). 
Mothers' practices. A list of 28 numeracy and literacy activities thought to be appropriate in the home setting was developed. The practices section of the survey began with the question: "How often do you do the following activities with your child?" Response options were: Rarely or Never (0), Monthly (1), Weekly (2), Several days per week (3), and Most days per week (4). Items included: "I help my child to read words," "I help my child learn simple sums," and "I help my child weigh, measure and compare things." See Appendix A for a complete list of items.

Book exposure. Mothers also reported how many days a week they read to their child at bedtime and at other times during the day. Response options included: Never (0) to More than 7 (8). Mothers also indicated how many children's books were available in the home. Response options were: 0-25 (1), 26-50 (2), $51-75$ (3), 76-100 (4), 100-199 (5), and 200 or more (6). These measures indicated the amount of book exposure children receive at home.

Some other questions designed to assess children's preferences for activities and parent practices in specific scenarios were also included in this questionnaire as part of a larger study, and will not be analyzed here.

\section{Practitioner Questionnaire}

Program characteristics. Practitioners answered questions about their current work situation such as: role in the program (e.g. administrator vs. practitioner working directly with children), percent of time working directly with children, program philosophy, program location, and percentage of disadvantaged children attending the program (See Appendix B for more details). 
Practitioner characteristics. Practitioners provided demographic information about themselves, such as gender, age, number of years working in the child care field, and number of years in the current position.

Practitioner education and training. Practitioners provided their level of education. They were also asked, in the last 2 years, how frequently they had attended PD workshops on early literacy, social skills, numeracy, health and safety, and combined numeracy and literacy; selecting from Not at all (1) to Three times or more (4). Practitioners also rated their agreement of awareness of professional development events on early numeracy and early literacy in their local area from Strongly agree (2) to Strongly disagree (-2). As a measure of their perceptions, practitioners rated their agreement that they felt sufficiently knowledgeable about early numeracy and literacy.

Practitioner expectations. To assess their expectations, practitioners rated how important it is for children to achieve a list of 7 literacy and numeracy benchmarks before starting Grade 1. Benchmarks included items such as: "Count to 10," "Know all 26 alphabet letters," and "Know simple sums (e.g. 2+2)." Response options ranged from Very unimportant (-2) to Neither unimportant nor important (0) to Very important (2).

Practitioner attitudes. To assess practitioner attitudes towards numeracy and literacy, practitioners were asked to rate their agreement with statements that they often avoid situations involving mathematics and situations involving writing. Response options ranged from Strongly disagree (2) to Strongly agree (-2). These items were reverse coded so that a positive score indicated positive literacy or numeracy attitudes. This was done to keep practitioner attitude scores consistent with maternal attitude scores. 
Practitioner beliefs about child care. Practitioners also completed 10 questions which were designed to tap their beliefs about child care. Practitioners rated their agreement with belief statements such as "Teaching children about letters, sounds and words is part of my job," "Social and emotional growth is the primary goal of an early childhood program," and "Four and five year olds should be introduced to the basics of addition and subtraction." Response options ranged from Strongly disagree (-2), to Neither disagree nor agree (0), to Strongly agree (2).

Practitioner beliefs about children's capabilities. To assess practitioner beliefs about children's capabilities they were asked to select the age that children are capable of achieving a variety of numeracy and literacy activities. Sixteen activities were listed, and response options were: Before age 4 (1), Age 4 until Age 5 (2), Age 5 until Age 6 (3), and Age 6 and up (4). Items included: "Knows how to fairly distribute 8 candies between 2 people," "Uses invented spelling to print words" and "Knows that 2 and 2 are 4."

Practitioner practices. To assess the frequency of literacy and numeracy activities in the child care setting, a list of 25 practices was developed; it included literacy, numeracy and socioemotional practices. The practices section of the survey began with the question: "How often did you do the following activities with the children in your care?" Response options were Never (0), Not with this age group (1), Sometimes, but not last month (2), At least once in the last month (3), At least once last week (4), and Most days last week (5). Items included: "I asked children about quantities (e.g., how many are there?)," "I encouraged activities involving adding, subtracting or measuring," and "I used alphabet books and/alphabets to teach letters." See Appendix B for a complete list of items. 


\section{Results}

\section{Mothers}

Descriptive statistics. Surveys were completed by 131 mothers of preschool-age children. Mothers ranged in age from 22-51 years ( $M=35$ years, $S D=4.7$ years). Almost all mothers indicated that they spoke English in the home (94\%); two mothers spoke French in the home (1.5\%), one mother spoke Filipino/Tagalog at home (.7\%) and 5 mothers (3.7\%) did not complete this question. Mothers also indicated the number of children they had: $12 \%$ had one child, $66 \%$ had two children, $20 \%$ had three children, and $2 \%$ had four children. Mothers reported that $56 \%$ of the preschool-age children were male and $44 \%$ were female.

Mothers specified their own level of education, as well as the level of education of the other parent; this information is provided in Figure 1. For both parents, it was most common to have a university degree. Each mother selected her work industry from a list of options; she also selected the work industry of the other parent (see Figure 2). According to mothers' reports, approximately half (48\%) of mothers were employed full time, $32 \%$ were employed part time, and the remaining $20 \%$ were unemployed. Approximately $8 \%$ of mothers reported qualifying for a daycare subsidy; $10 \%$ of mothers did not respond to this question.

This sample is thought to be fairly representative of English speaking mothers in Winnipeg, Manitoba; containing mothers from a range of education levels, work industries, and family composition. 
Figure 1. Parental level of education.

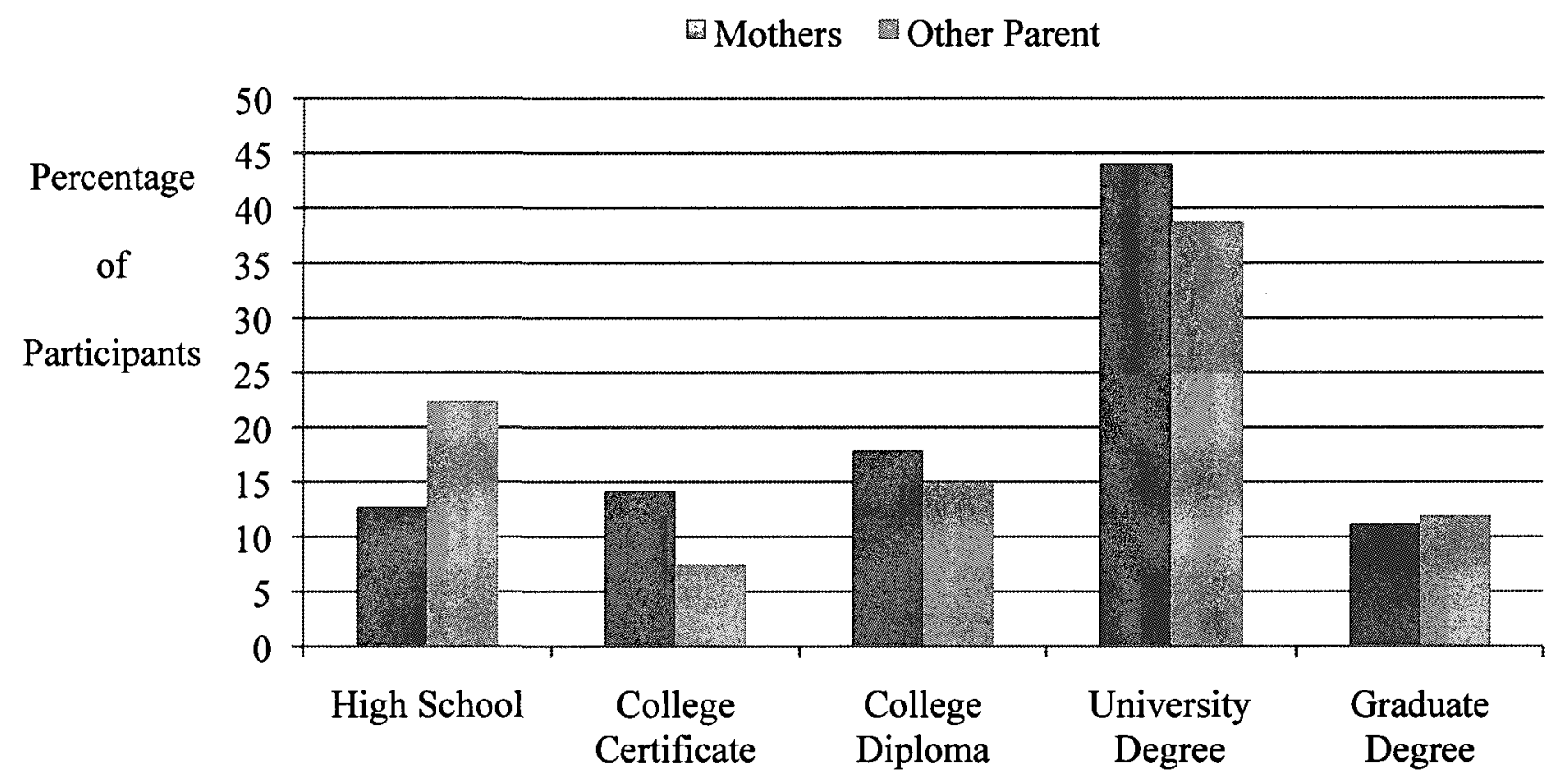

Education Level 
Figure 2. Percentage of parents working within each industry category.

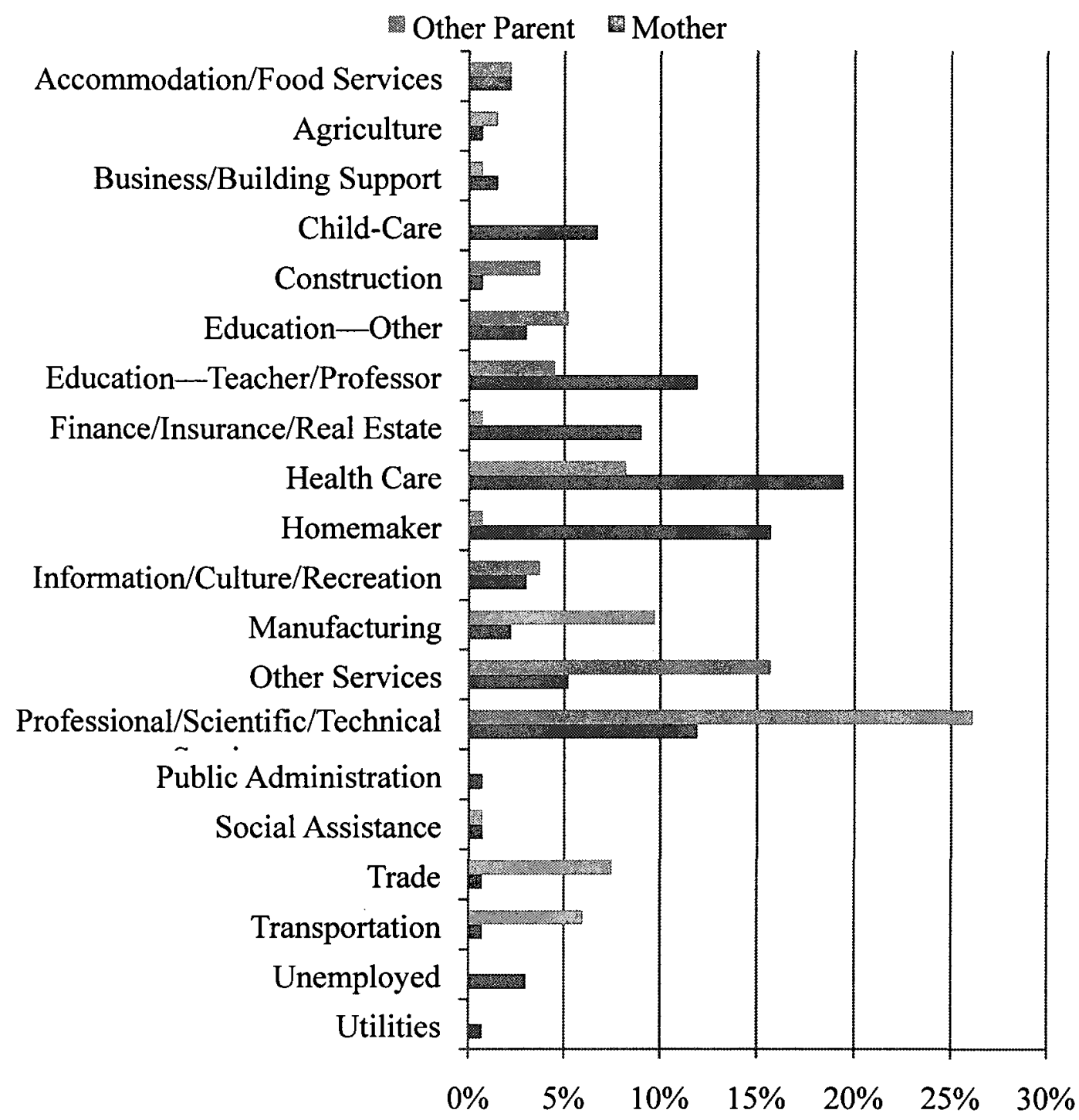

Percentage of Respondents 


\section{Preliminary analyses}

Expectations. Descriptive statistics for expectations are presented in Table 2. Each expectation item was examined for normality. Four items contained almost no variability—almost all mothers rated the items "Count to 10 " and "Know some alphabet letters" as Extremely Important (3) and almost all mothers rated the items "Read chapter books" and "Count to 1000" as Unimportant (-1) to know before Grade 1, therefore these items were removed from further analyses. The observed internal reliability of the expectation scale was Cronbach's $\alpha=.90$ ( 9 items). An arithmetic mean was computed by summing the expectation items and dividing by the number of items. This composite expectation variable had a mean of $1.58(S D=.77)$, indicating that on average mothers felt that expectation items were Important (1) to Very Important (2) to know by Grade 1.

Attitudes. Descriptive statistics for parent attitudes are presented in Table 3. The items "My job involves a lot of reports and writing" and "My job involves a lot of mathematics" were deleted from the literacy and numeracy scales because doing so improved their internal reliabilities. The observed internal reliability of the literacy attitudes scale was Cronbach's $\alpha=.66$; ( 3 items), which is a less than is ideal. The observed internal reliability of the numeracy attitudes scale was Cronbach's $\alpha=.85$ (3 items). For both numeracy and literacy attitudes, an arithmetic mean was created with the remaining 3 items in each scale. The mean for the literacy attitudes composite variable was $.93(S D=.77)$, indicating that on average mothers had relatively positive attitudes towards literacy $(1=$ Agree $)$. The mean for the numeracy attitudes composite variable was $.65(S D=1.07)$, indicating that on average mothers also had positive attitudes towards numeracy $(1=$ Agree $)$. 
Table 2

Summary of Descriptive Statistics for Mothers' Expectations.

\begin{tabular}{|c|c|c|c|c|c|}
\hline Item & Min & $\operatorname{Max}$ & Mean & $S D$ & $\begin{array}{c}\text { Included in } \\
\text { expectations } \\
\text { composite } \\
\text { mean }\end{array}$ \\
\hline \multicolumn{6}{|l|}{ Literacy } \\
\hline Know some alphabet letters & 1 & 3 & 2.66 & .63 & No \\
\hline Print his/her name & 0 & 3 & 2.52 & .78 & Yes \\
\hline Know all 26 alphabet letters & 0 & 3 & 2.45 & .89 & Yes \\
\hline Print all 26 alphabet letters & 0 & 3 & 2.11 & 1.02 & Yes \\
\hline Read a few words & -1 & 3 & 1.60 & 1.15 & Yes \\
\hline Read simple picture books & -1 & 3 & 1.41 & 1.23 & Yes \\
\hline Read chapter books & -1 & 3 & -.44 & .73 & No \\
\hline \multicolumn{6}{|l|}{ Numeracy } \\
\hline Count to 10 & 1 & 3 & 2.69 & .61 & No \\
\hline Know simple sums & -1 & 3 & 1.53 & 1.14 & Yes \\
\hline Count to 100 & -1 & 3 & 1.51 & 1.15 & Yes \\
\hline $\begin{array}{l}\text { Read printed numbers up to } \\
100\end{array}$ & -1 & 3 & 1.26 & 1.14 & Yes \\
\hline Count to 1000 & -1 & 3 & -.05 & 1.00 & No \\
\hline Know multiplying & -1 & 3 & -.18 & .82 & Yes \\
\hline
\end{tabular}

Note. $S D=$ Standard deviation; $\operatorname{Min}=$ Minimum; $\operatorname{Max}=$ Maximum . 
Table 3

Summary of Descriptive Statistics for Mothers' Literacy and Numeracy Attitudes.

\begin{tabular}{lcccc}
\hline Numeracy Items & Min & Max & Mean & $S D$ \\
\hline I avoid situations involving mathematics & -2 & 2 & .95 & 1.05 \\
$\begin{array}{l}\text { When I was in school, I was good at } \\
\text { mathematics }\end{array}$ & -2 & 2 & .55 & 1.36 \\
$\quad$ I find math enjoyable. & -2 & 2 & .46 & 1.24 \\
$\quad \begin{array}{l}\text { My job involves a lot of mathematics. } \\
\text { Literacy Items }\end{array}$ & -2 & 2 & .02 & 1.22 \\
\hline $\begin{array}{l}\text { I avoid situations involving writing }{ }^{1} . \\
\begin{array}{l}\text { When I was in school, I was good at } \\
\text { language and reading. }\end{array}\end{array}$ & -2 & 2 & 1.05 & .97 \\
$\begin{array}{l}\text { I find writing enjoyable. } \\
\begin{array}{l}\text { My job involves a lot of reports and } \\
\text { writing. }\end{array}\end{array}$ & -2 & 2 & 1.03 & .99 \\
\hline
\end{tabular}

Note. ${ }^{1}$ These items were reverse coded; ${ }^{2}$ Item was not included in composite mean. $S D=$ Standard Deviation; $\operatorname{Min}=$ Minimum; $\operatorname{Max}=$ Maximum. 
Numeracy and literacy practices. Two practice items, ("My child plays computer games that involve number/letters" and "I encourage my child to pretend while playing"), were removed from analyses because they were neither numeracy nor literacy practices. Table 4 contains descriptive statistics for maternal numeracy practices. Deleting the item "I ask my child to answer a question very quickly" improved the overall reliability of the numeracy practices scale; the final observed internal reliability was Cronbach's $\alpha=.87$, (14 items). An arithmetic mean was created with all remaining numeracy items. The mean for this numeracy practices composite variable was $2.2(S D=.76)$, indicating that, on average, mothers reported engaging in numeracy practices Weekly (2).

Table 5 contains descriptive statistics for maternal literacy practices. Deleting the item "We visit the library for children's books" improved the overall reliability of the literacy practices scale; the final observed internal reliability was Cronbach's $\alpha=.87$, (10 items). An arithmetic mean was created with all remaining literacy items. The mean for this literacy practices composite variable was $2.64(S D=.84)$, indicating that, on average, mothers reported engaging in most literacy activities Weekly (2) to Several days per week (3).

Book exposure. On average, mothers reported owning 100-199 (5) children's books $(M=4.62 ; S D=1.34)$. Mothers also reported how often they read to their children at bedtime $(M=5.96 ; S D=2.00)$ and at other times $(M=4.46 ; S D=2.21)$. Thus, on average, children were read to about 6 times a week at bedtime and 4 or 5 times a week at other times. A book exposure variable was created by summing the number of children's books, frequency of reading at bedtime, and frequency of reading at other times. The resulting book exposure variable had a mean of $15.1(S D=3.94)$. 
Table 4

Summary of Descriptive Statistics for Mothers' Numeracy Practices.

\begin{tabular}{|c|c|c|c|c|}
\hline Items & Min & Max & Mean & $S D$ \\
\hline I help my child to recite numbers in order. & 0 & 4 & 2.93 & 1.00 \\
\hline I teach my child to recognize printed numbers. & 0 & 4 & 2.92 & 1.04 \\
\hline I ask about quantities (e.g., How many spoons?). & 0 & 4 & 2.87 & 1.13 \\
\hline $\begin{array}{l}\text { I encourage the use of fingers to indicate how } \\
\text { many. }\end{array}$ & 0 & 4 & 2.67 & 1.34 \\
\hline $\begin{array}{l}\text { We sign counting songs (e.g., Five Little } \\
\text { Monkeys). }\end{array}$ & 0 & 4 & 2.31 & 1.22 \\
\hline We talk about time with clocks $\&$ calendars. & 0 & 4 & 2.31 & 1.37 \\
\hline We play board games or cards. & 0 & 4 & 2.27 & 1.01 \\
\hline We sort \& classify by color, shape and size. & 0 & 4 & 2.24 & 1.25 \\
\hline $\begin{array}{l}\text { We play games that involve counting, adding or } \\
\text { subtracting. }\end{array}$ & 0 & 4 & 2.16 & 1.16 \\
\hline I help my child learn simple sums (e.g., $2+2)$ & 0 & 4 & 2.05 & 1.33 \\
\hline $\begin{array}{l}\text { I encourage collecting (e.g. cards, stamps, } \\
\text { rocks). }\end{array}$ & 0 & 4 & 1.82 & 1.42 \\
\hline I encourage my child to do math in his/her head. & 0 & 4 & 1.78 & 1.47 \\
\hline $\begin{array}{l}\text { I ask my child to answer a question very } \\
\text { quickly. }\end{array}$ & 0 & 4 & 1.40 & 1.50 \\
\hline We time how fast an activity can be completed. & 0 & 4 & 1.39 & 1.36 \\
\hline $\begin{array}{l}\text { I help my child weigh, measure and compare } \\
\text { quantities. }\end{array}$ & 0 & 4 & 1.05 & 1.02 \\
\hline
\end{tabular}

Note. ${ }^{1}$ This item was not included in the numeracy practices composite variable. $S D=$ Standard deviation; Min = Minimum; Max = Maximum . 
Table 5

Summary of Descriptive Statistics for Mothers' Literacy Practices.

\begin{tabular}{|c|c|c|c|c|}
\hline Items & Min & Max & Mean & $S D$ \\
\hline $\begin{array}{l}\text { I ask questions when we read } \\
\text { together. }\end{array}$ & 0 & 4 & 2.99 & 1.15 \\
\hline $\begin{array}{l}\text { I teach my child to recognize printed } \\
\text { letters. }\end{array}$ & 0 & 4 & 2.92 & 1.13 \\
\hline I teach my child the sounds of letters. & 0 & 4 & 2.79 & 1.10 \\
\hline $\begin{array}{l}\text { I help my child to sing/recite the } \\
\text { alphabet. }\end{array}$ & 0 & 4 & 2.74 & 1.19 \\
\hline $\begin{array}{l}\text { I introduce new words and their } \\
\text { definitions to my child. }\end{array}$ & 0 & 4 & 2.72 & 1.27 \\
\hline I help my child to print words. & 0 & 4 & 2.65 & 1.25 \\
\hline $\begin{array}{l}\text { We identify words on signs (e.g., } \\
\text { Stop, Exit). }\end{array}$ & 0 & 4 & 2.54 & 1.25 \\
\hline I help my child read words. & 0 & 4 & 2.47 & 1.31 \\
\hline $\begin{array}{l}\text { We make up rhymes in songs (e.g., } \\
\text { Down by the Bay). }\end{array}$ & 0 & 4 & 2.37 & 1.31 \\
\hline $\begin{array}{l}\text { I ask my child to point to } \\
\text { words/letters when we read. }\end{array}$ & 0 & 4 & 2.16 & 1.39 \\
\hline $\begin{array}{l}\text { We visit the library for children's } \\
\text { books }{ }^{1} \text {. }\end{array}$ & 0 & 2 & .86 & .73 \\
\hline
\end{tabular}

Note. ${ }^{1}$ This item was not included in the literacy practices composite mean. $S D=$ Standard deviation; Min $=$ Minimum; Max $=$ Maximum . 
Mean comparisons. Paired-samples t-tests were conducted to determine whether or not mothers differed in their literacy versus numeracy practices and attitudes. As hypothesized, mothers reported significantly higher frequencies of literacy than numeracy practices $(2.63$ vs. 2.20$) ; t(130)=9.74, \mathrm{p}<.001$. Mothers also reported more positive literacy than numeracy attitudes (.93 vs. .65$) ; t(130)=2.33, \mathrm{p}<.05$.

Correlates of mothers' literacy practices. All bivariate correlations between maternal education, expectations, literacy and numeracy attitudes, book exposure, and literacy and numeracy practices are presented in Table 6. Expectations and book exposure were significantly correlated with both literacy and numeracy practices, however, maternal education was not correlated with either practice. Mothers' literacy attitudes were correlated with their literacy practices, whereas their numeracy attitudes were not correlated with their numeracy practices.

Literacy regression analyses ${ }^{2}$. Using the enter method, multiple regression was conducted with maternal education, expectations, literacy attitudes, and book exposure entered as predictors of literacy practices (see Table 7 for model summary). All predictors were significant, except for maternal education, thus supporting most of the hypotheses. Thus, mothers who provided their children with more book exposure, who had higher academic expectations, and who were more positive about literacy themselves also reported higher frequencies of home literacy activities.

\footnotetext{
${ }^{2}$ Prior to these and all other regression analyses, the data and its residuals were examined to ensure that they met the assumptions for linear regression. The data adequately complied with the assumptions of linearity, normality, homoscedasticity and independence; the assumption of existence is assumed to be intact. The data was also screened for potential outliers and influential cases.
} 


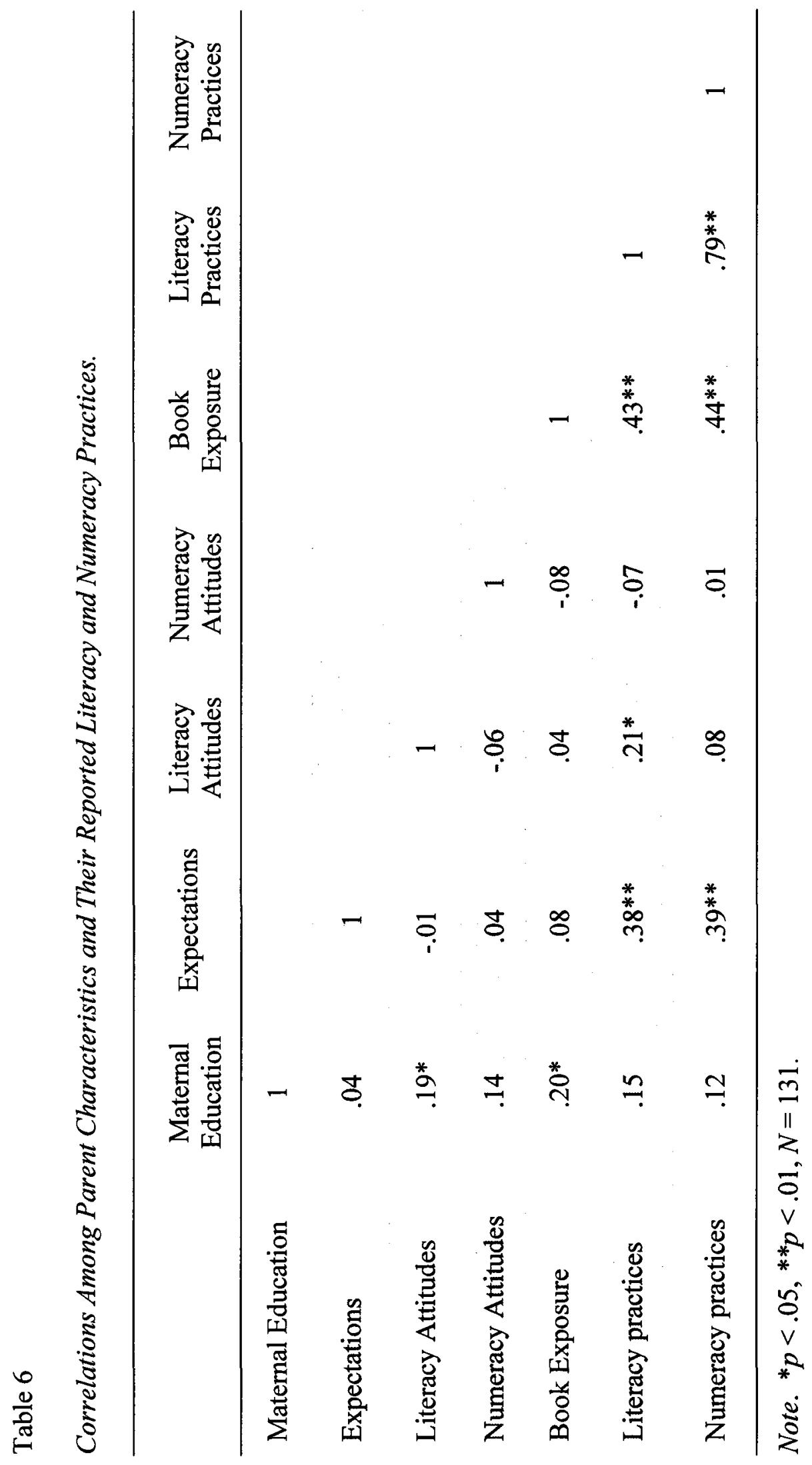




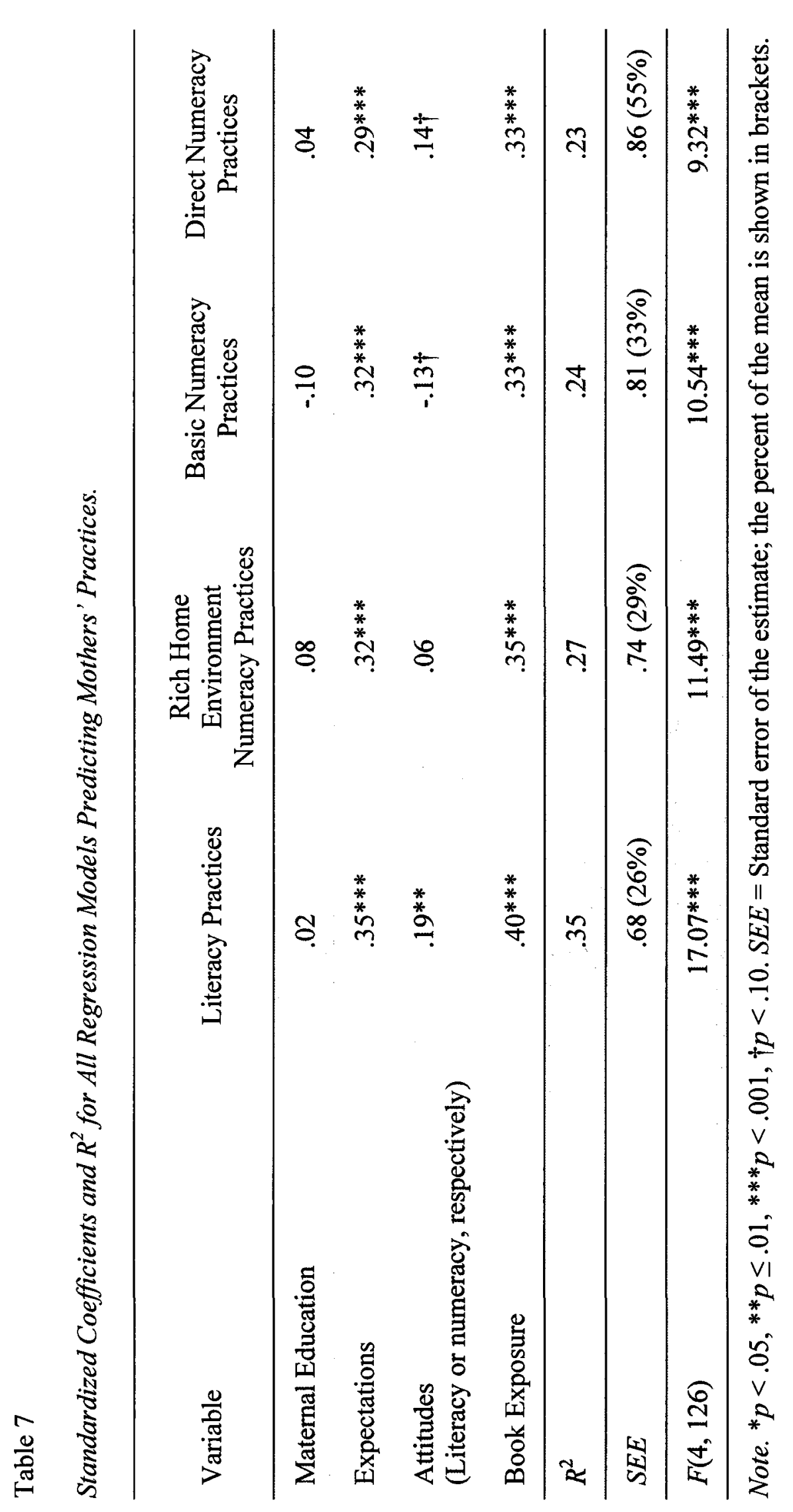


Numeracy practices principle components analysis. Given the lack of relationship between numeracy attitudes and numeracy practices, principle components analyses (PCA) were conducted to see if one or more extracted factors would show a relation to numeracy attitudes ${ }^{3}$. An orthogonal rotation (varimax) was applied, producing three components that accounted for $57 \%$ of the variance in numeracy practices (see Table 8 for rotated factor loadings). Component 1 was named rich home environment. The items loading highly on this component were activities containing numeracy content, but not focused on teaching mathematics (e.g., playing math games; talking about clocks and calendars). Component 2 was named basic numeracy because items loading on this factor are thought to promote rudimentary numeracy skills (e.g., reciting numbers in order; using fingers to show how many). Component 3 was named direct numeracy. The items loading on this component involved directly teaching mathematics (e.g., teaching simple sums), as well as weighing, measuring and comparing quantities. Items loading most highly on a given component were summed and divided by the number of items, thus creating an arithmetic mean. Means were used instead of factor scores because means better facilitate the comparison of literacy and numeracy practices. The three numeracy outcomes were never entered into a regression model together, thus their shared variance did not pose a multicollinearity problem. Rich home environment practices had a mean of $2.50(S D=.85)$, and basic numeracy practices had a similar mean of $2.43(S D=.92)$, indicating that, on average, mothers reportedly engaged in these

\footnotetext{
${ }^{3}$ Items to be entered in this PCA and into the exploratory factor analyses (EFA) conducted later were first screened for normality. For both the PCA and the EFA, data were also examined to ensure items were correlated, but not multicollinear, and thus sufficiently factorable. The Kaiser-Meyer-Olkin statistic also indicated that the sample sizes were adequate in each analysis.
} 
Table 8

Rotated Factor Loadings for Three Extracted Numeracy Components.

\begin{tabular}{|c|c|c|c|}
\hline \multirow[b]{2}{*}{ Item } & \multicolumn{3}{|c|}{ Component } \\
\hline & $\begin{array}{l}\text { Rich Home } \\
\text { Environment }\end{array}$ & $\begin{array}{c}\text { Basic } \\
\text { Numeracy }\end{array}$ & $\begin{array}{c}\text { Direct } \\
\text { Numeracy }\end{array}$ \\
\hline We play board games or cards. & .746 & .097 & .078 \\
\hline I ask about quantities. & .637 & .384 & .238 \\
\hline We talk about time with clocks \& calendars. & .630 & .030 & .248 \\
\hline $\begin{array}{l}\text { I teach my child to recognize printed } \\
\text { numbers. }\end{array}$ & .608 & .297 & .331 \\
\hline We sort and classify by color, shape and size. & .564 & .537 & .193 \\
\hline $\begin{array}{l}\text { We play games that involve counting, adding } \\
\text { or subtracting. }\end{array}$ & .534 & .332 & .448 \\
\hline I help my child to recite numbers in order. & .106 & .733 & .268 \\
\hline $\begin{array}{l}\text { I encourage use of fingers to indicate how } \\
\text { many. }\end{array}$ & .037 & .731 & .132 \\
\hline We sing counting songs. & .201 & .653 & .109 \\
\hline I encourage collecting. & .398 & .632 & -.034 \\
\hline I help my child learn simple sums. & .297 & .053 & .733 \\
\hline $\begin{array}{l}\text { I encourage my child to do math in his/her } \\
\text { head. }\end{array}$ & .363 & .077 & .728 \\
\hline $\begin{array}{l}\text { We time how fast an activity can be } \\
\text { completed. }\end{array}$ & -.126 & .353 & .676 \\
\hline $\begin{array}{l}\text { I help my child weigh, measure and compare } \\
\text { quantities. }\end{array}$ & .309 & .121 & .567 \\
\hline
\end{tabular}


activities Weekly (2) to Several days per week (3). Direct numeracy practices had a mean of $1.57(S D=.96)$, thus, on average, mothers engaged in these practices Monthly (1) to Weekly (2). One item ("We sort \& classify by color, shape and size"), loaded fairly equally on two components, therefore it was not included in either composite mean.

Correlates of mothers' numeracy practices. All bivariate correlations among predictors (maternal education, expectations, numeracy attitudes, book exposure) and numeracy outcomes (rich home environment, basic, and direct numeracy practices) are presented in Table 9. Despite the lack of correlation between numeracy attitudes and practices, the attitude variable was included as a predictor of the three types of numeracy outcomes. This was done to facilitate hypothesis testing and comparisons between models.

Regression analyses three types of numeracy practices. Multiple regression analyses were conducted to test the hypotheses that maternal education, expectations, numeracy attitudes and book exposure would predict reported numeracy practices.

Rich home environment. A linear regression model was fit to the data using the Enter method. Maternal education, expectations, numeracy attitudes, and book exposure were entered as predictors of rich home environment practices (see Table 7 for a model summary). Contrary to hypotheses, maternal education and numeracy attitudes did not predict rich home environment practices. However, as hypothesized, maternal expectations and book exposure were significant predictors of rich home environment practices. The higher mothers' academic expectations and the more they exposed their children to books, the more frequently mothers reported engaging in rich home environment practices. 


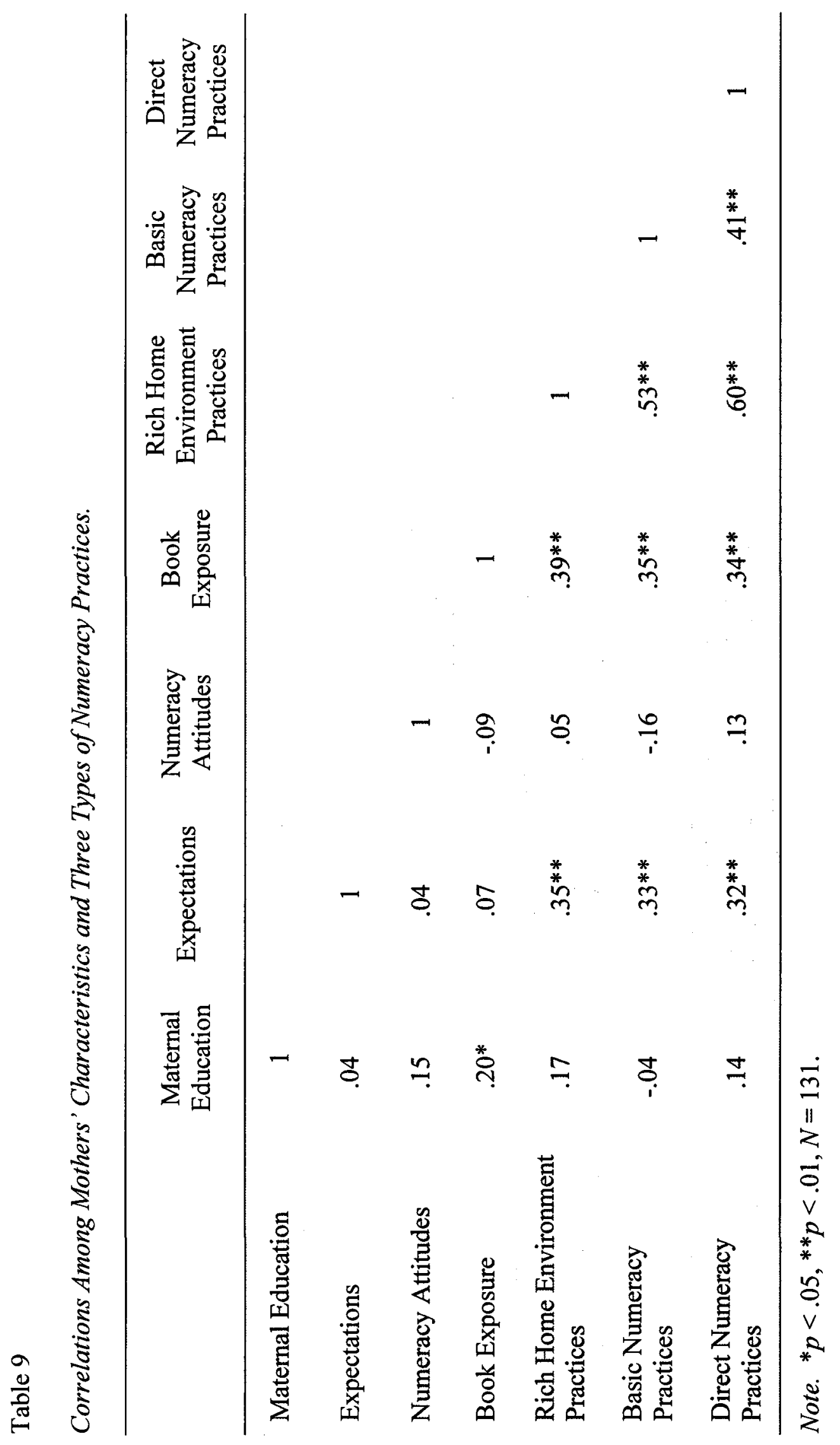


Basic numeracy practices. A linear regression model was fit to the data using the Enter method. Maternal education, expectations, numeracy attitudes, and book exposure were entered as predictors of basic numeracy practices (see Table 7 for model summary). Contrary to hypotheses, maternal education was not a significant predictor of basic numeracy practices. Mothers' expectations and book exposure significantly predicted basic numeracy practices as hypothesized. In other words, the higher mothers' academic expectations and the more that mothers exposed their children to books, the more often they reported engaging in basic numeracy activities with their children. Furthermore, the numeracy attitudes variable was a marginally significant predictor of basic numeracy practices, but the relationship was in the opposite direction from hypothesized. Mothers with more negative numeracy attitudes were more likely to engage in basic numeracy practices than were mothers with more positive numeracy attitudes.

Direct numeracy practices. A linear regression model was fit to the data. Maternal education, expectations, numeracy attitudes, and book exposure were entered as predictors of direct numeracy practices (see Table 7). Contrary to hypotheses, (but consistent with the other models of mothers' practices), maternal education was not a significant predictor of direct numeracy practices. Expectations and book exposure predicted direct numeracy practices as hypothesized. The higher mothers' academic expectations and the more they exposed their children to books, the more they reported engaging in direct numeracy activities with their children. The numeracy attitudes variable was also a marginally significant predictor of direct numeracy practices, and this time the direction of the relationship was consistent with hypotheses. Mothers with more positive numeracy attitudes reported higher frequencies of direct numeracy practices. 


\section{Summary of Models to Predict Maternal Numeracy and Literacy Practices.}

To facilitate comparison, Table 7 displays the standardized coefficients of predictors and $R^{2}$ values for all 4 (1 literacy, 3 numeracy) models predicting maternal practice outcomes. Of note are many similarities. Maternal education did not predict any of the four outcomes. Both maternal expectations and book exposure were significant predictors across all four outcomes. In fact, in each model the standardized coefficients for expectations and book exposure are very similar in magnitude, thus they had relatively equal weight in predicting the outcome in each model. Book exposure and expectations also have similar standardized coefficients across models, suggesting that these variables predict literacy and all numeracy practices to the same degree.

There are also some differences among the four models predicting parent practices. Maternal expectations, attitudes and book exposure accounted for more variance in literacy practices $(35 \%)$ than in numeracy practices $(25 \%$ on average). The predictive capability of maternal attitudes also differed across the four models. Literacy attitudes acted as a significant predictor of literacy practices, although this variable was a weaker predictor than both maternal expectations and book exposure. For numeracy outcomes, the pattern between attitudes and outcomes was more complex. The numeracy attitudes variable was not a significant predictor of rich home environment practices, and only a marginally significant predictor of other numeracy practices. Negative numeracy attitudes were predictive of basic numeracy practices, whereas positive numeracy attitudes were predictive of direct numeracy practices. These findings suggest that the predictability of numeracy attitudes may differ depending on the type of numeracy practices. 


\section{ELCC Practitioners}

Descriptive statistics. Almost all participants were female (96.5\%) and ranged in age from under 21 to over 61 , with a mean of 40.2 years of age $(S D=10.04)$. Participants were located across Canada, with the largest proportion located in Manitoba (see Table 10 for participants by province).

Most practitioners had earned either a college certificate (18.6\%) or diploma (45.7\%), but another substantial portion had obtained a university degree (24.2\%). Relatively few practitioners had only a high school diploma (7.2\%) or a graduate degree (4.3\%). This sample had ample experience working in the child care field-the mode for this variable was 15 years or more (see Figure 3 for information on practitioner experience).

Most practitioners worked either directly with children in a child care program $(34.3 \%)$ or as a director or administrator $(36.4 \%)$. About half of all practitioners $(50.8 \%)$ spent $100 \%$ of their time working directly with children, while the other half spent at least some of their time performing other duties. Practitioners reported that they worked in dedicated private facilities (35.1\%), in community centres (14.6\%), in schools (13.8\%), or within their own homes (16.9\%). Practitioners were asked about the philosophy of their programs. Responses to this item were very diverse, with the most common response being None (28.2\%). About 16\% of practitioners reported Emergent Curriculum and another $9.8 \%$ reported Academic-school preparation as their program philosophies (full details on Program Philosophy can be found in Appendix C). 
Table 10

Characteristics of ELCC Practitioners.

\begin{tabular}{lc}
\multicolumn{1}{c}{ Province } & Percentage \\
\hline Manitoba & 28.7 \\
Ontario & 16.0 \\
British Columbia & 15.7 \\
New Brunswick & 12.0 \\
Saskatchewan & 10.9 \\
Alberta & 5.9 \\
Nova Scotia & 4.8 \\
Québec & 2.4 \\
Prince Edward Island & 2.1 \\
Northwest Territories, Yukon \\
and Nunavut
\end{tabular}

Note . Missing cases $=1$. 
Figure 3. ELCC practitioners' experience in the field and in current position.

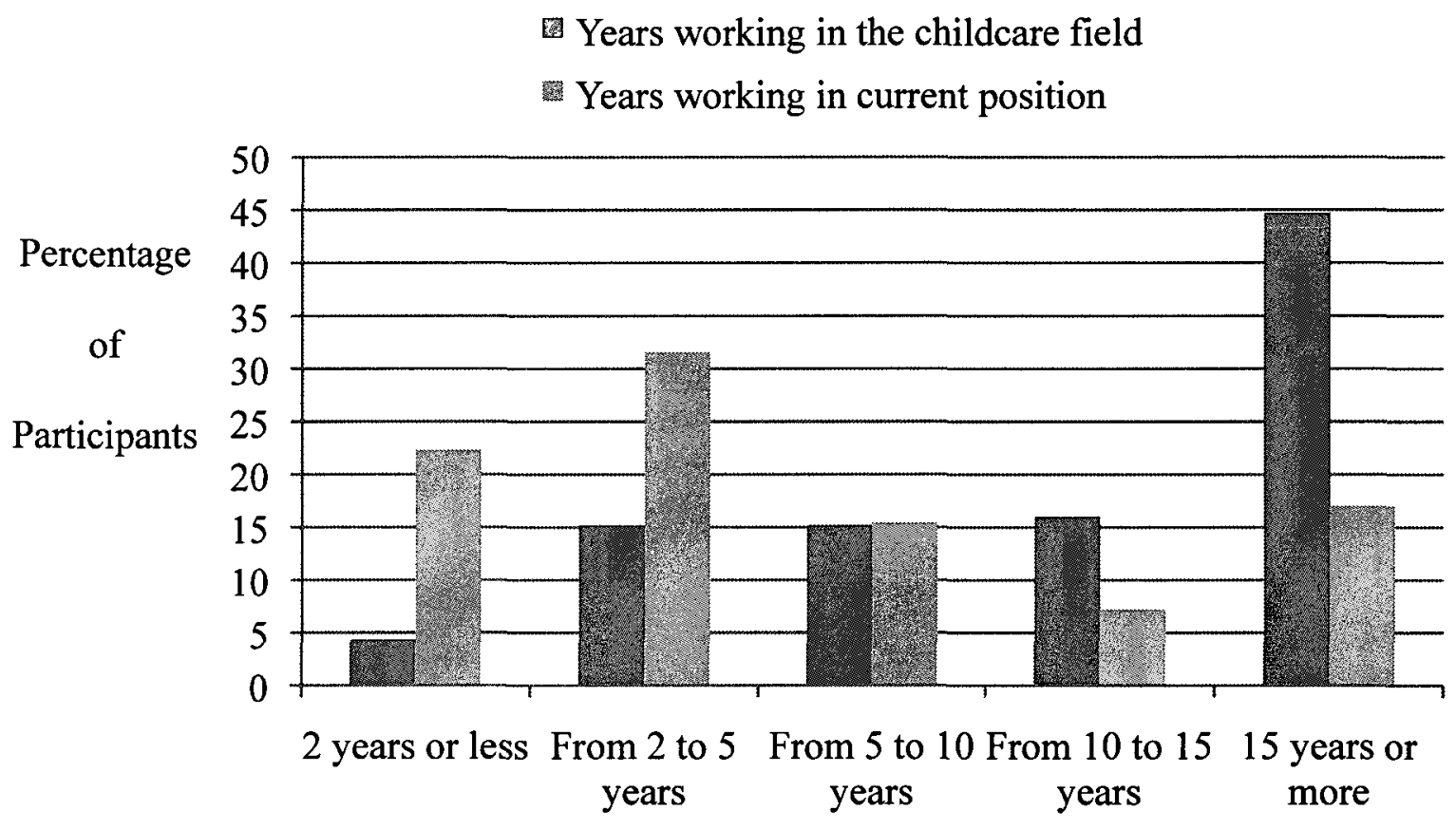


Practitioners indicated the number of children in their program that were classified as aboriginal, English as a second language (ESL), impoverished, government subsidized, or as special needs. Figure 4 provides a graphical depiction of participants' responses. Along the abscissa are the five disadvantaged categories. Along the ordinate is the percentage of participants, thus each bar shows the percentage of participants that selected that particular response. Participants indicated how many children were in each disadvantaged category by selecting from the categories: $1-25 \%, 26-50 \%, 51-75 \%$ or $76-$ $100 \%$. For all categories, the most common response was that these children constituted $1-25 \%$ of the children in the program. Thus, relatively few programs had a high proportion of disadvantaged or special needs children.

Figure 5 provides a graphical comparison of practitioner awareness of literacy versus numeracy professional development (PD) opportunities. Practitioners were asked to rate their agreement with the statements "I am aware of Professional Development events about early literacy/early numeracy in my local area." Along the abscissa are the response options for these questions: Strongly disagree, Disagree, Neither agree nor disagree, Agree and Strongly Agree. Along the ordinate is the percentage of participants, thus each bar shows the percentage of participants that selected that particular response. For literacy, it was most common for practitioners to agree that they were aware of PD events in their local area, but practitioners most commonly disagreed that they were aware of numeracy PD events. 


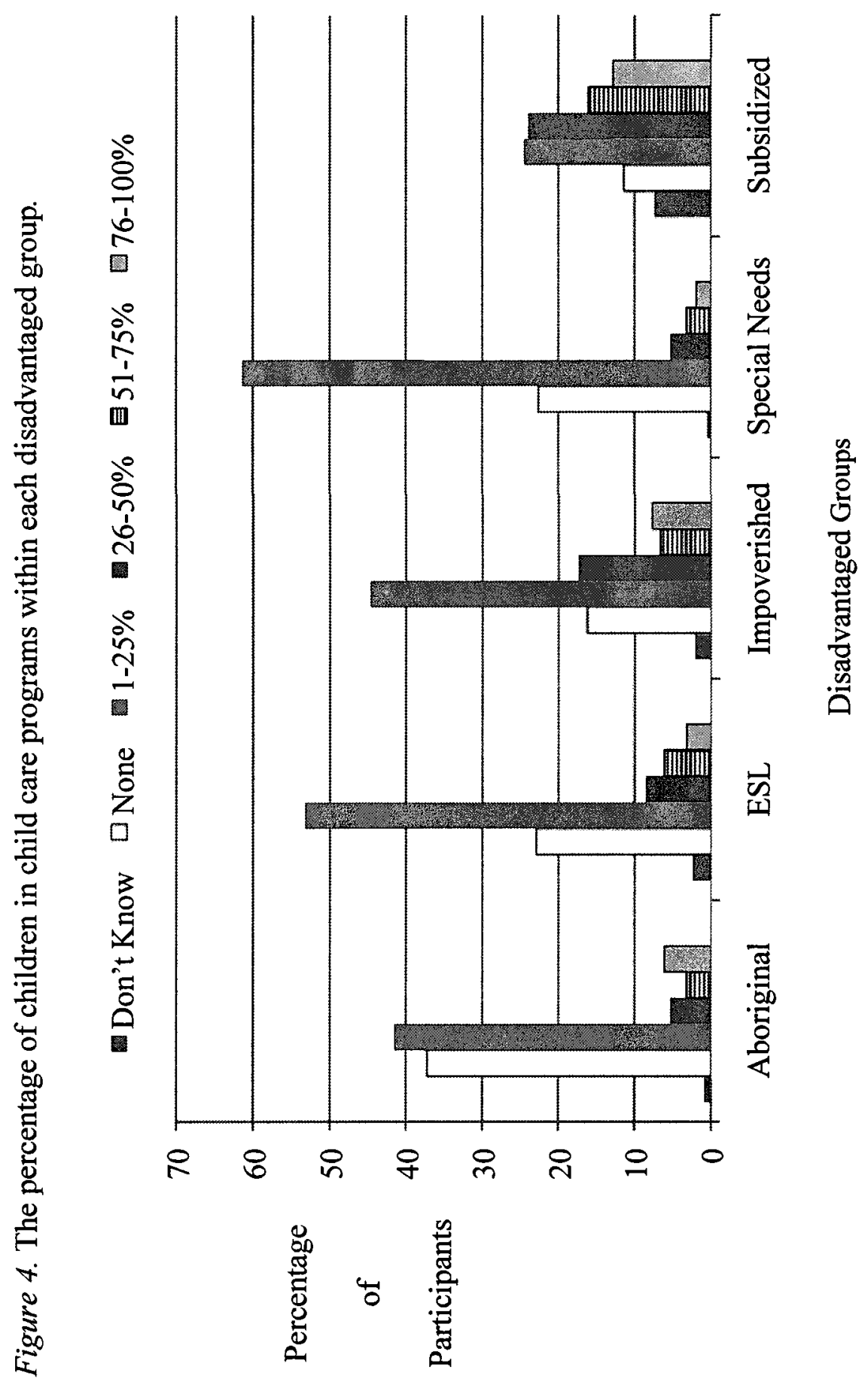




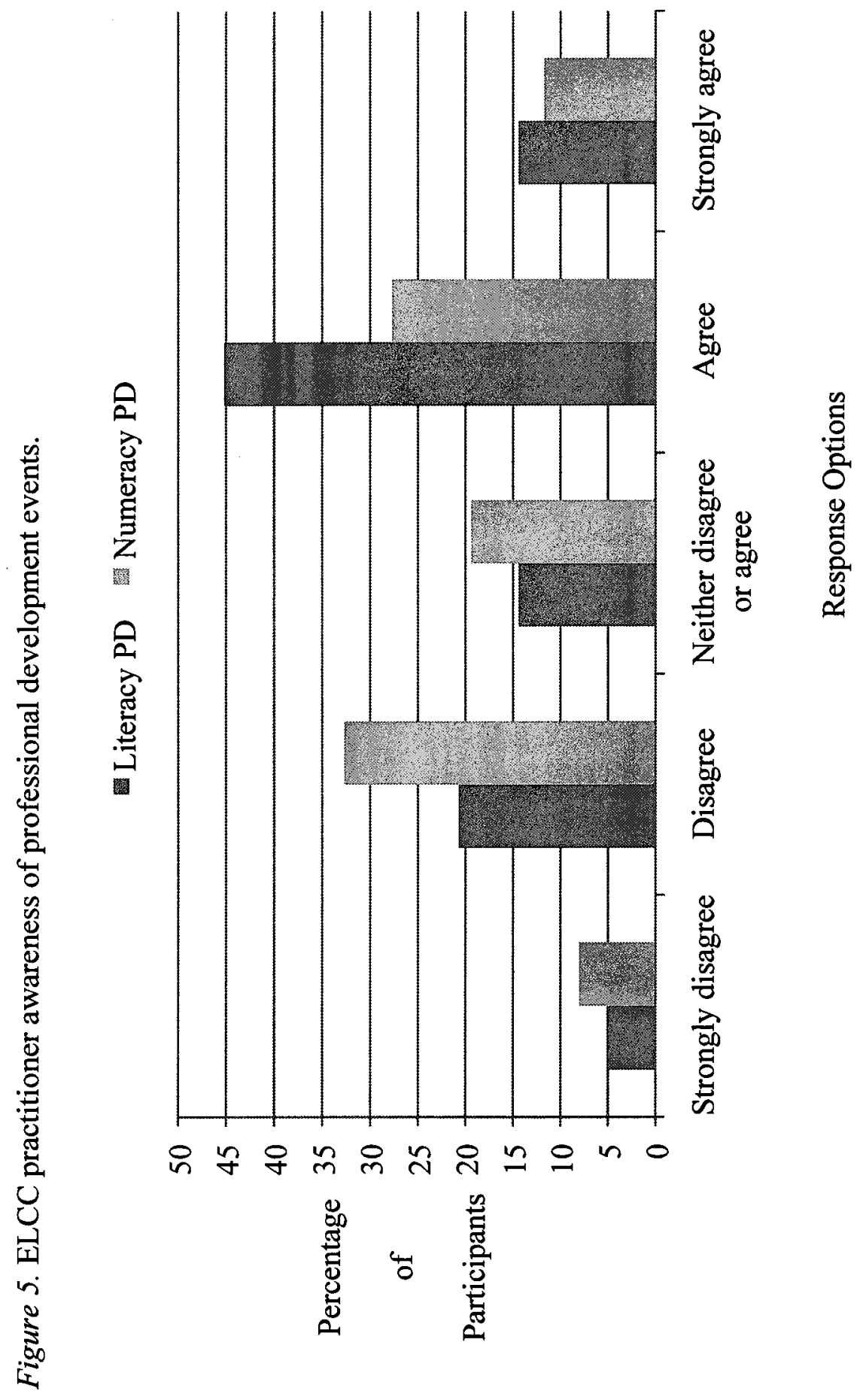


Practitioners also indicated how many professional development workshops they had attended during the last 2 years on topics such as literacy, numeracy, health and safety, etc. See Figure 6 for the proportion of practitioners attending professional development workshops by topic. Professional development topics are presented along the abscissa and percentage of participants are presented along the ordinate, thus each bar represents the percentage of participants that selected that particular response options (Zero, One, Two, and Three or more). In comparison to other professional development topics, practitioners were more likely to have missing values, or to respond that they had attended zero workshops on early numeracy and combined numeracy and literacy. For early literacy, early social skills and health, safety or nutrition topics, it was most common for practitioners to have attended one workshop during the last 2 years, and during this time approximately $70 \%$ of practitioners had attended one or more workshops on these topics. Thus, in general, practitioners seemed to be less aware of numeracy than literacy professional development events, and they had attended fewer workshops with numeracy components.

In sum, this sample involved a range of ELCC practitioners from across Canada, caring for children in a range of child care facilities and working in various capacities. The higher percentage of practitioners from Manitoba is to be expected, since recruitment was more concentrated in this province in comparison to other provinces. This sample also contains a range of level of education, years of experience, and exposure to professional development. 


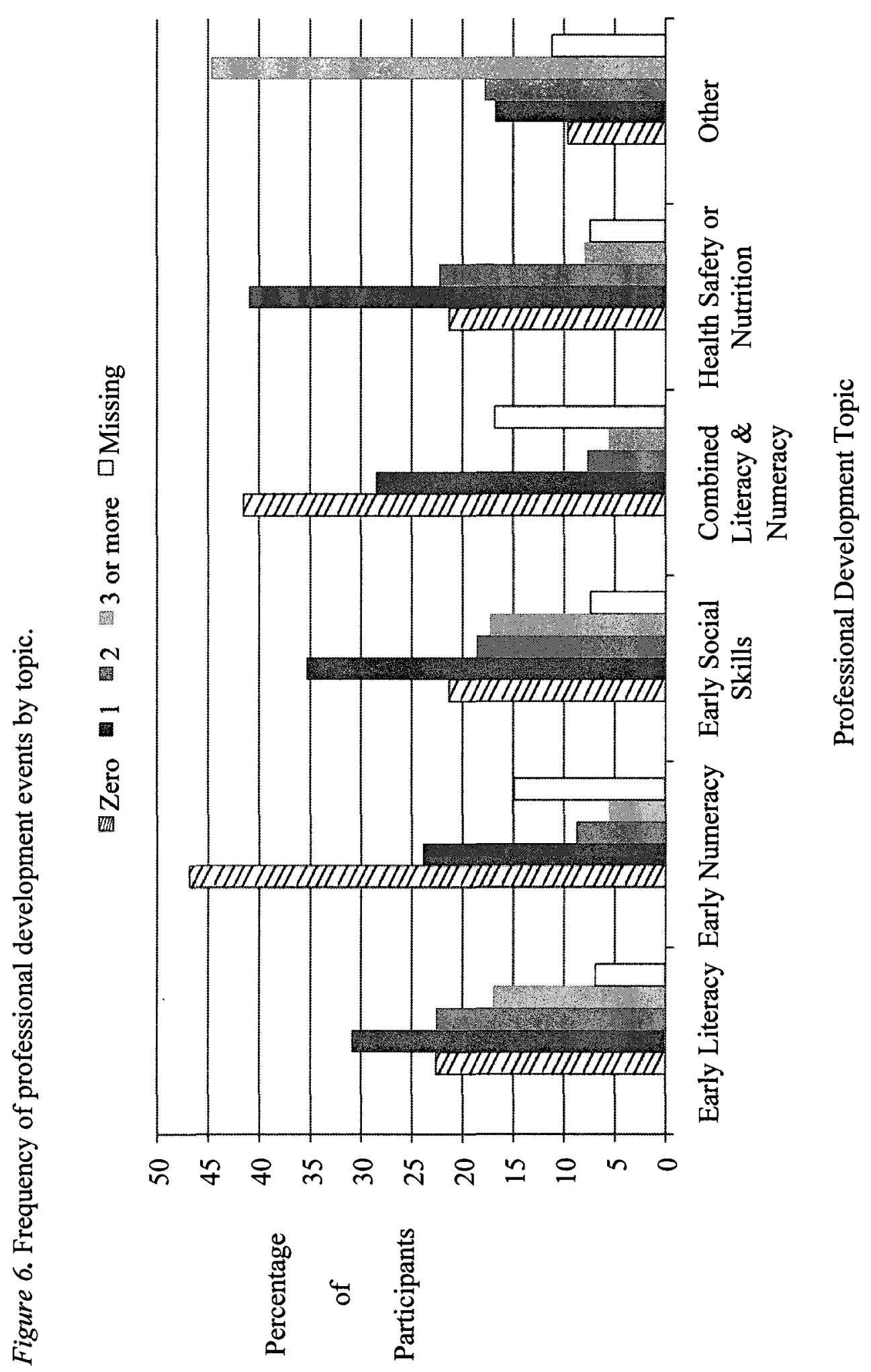




\section{Preliminary Analyses}

Expectations. An arithmetic mean was created from the expectations items for use in further analyses. An inspection of expectations items revealed that many of the items had almost no variability at all (i.e., almost all participants selected the same response) and thus the average was created using only items with some variability. See Table 11 for a descriptive summary of expectations items. The observed internal reliability of this scale was good; Cronbach's $\alpha=.87$. The mean of the composite expectations variable was $.47(S D=.93)$, indicating that on average practitioners felt these items were Neither unimportant nor important (0) to Important (1) to know before entering Grade 1.

Attitudes. Practitioner attitudes were assessed with one item for literacy and one item for numeracy ("I often avoid situations involving mathematics/writing."). These items were reversed coded so that a positive value became representative of not avoiding writing or math, therefore reflecting a more positive attitude. The mean for literacy attitudes was $1.44(S D=.79)$ and mean for numeracy attitudes was $1.12(S D=.96)$, thus, on average, practitioners disagreed (1) that they avoid situations involving writing and mathematics. 
Table 11

Summary of Descriptive Statistics for ELCC Practitioners' Expectations.

\begin{tabular}{lcccc}
\hline \multicolumn{1}{c}{ Item } & Minimum & Maximum & Mean & $S D$ \\
\hline Know some alphabet letters $^{1}$ & -2 & 2 & 1.40 & .82 \\
Print his/her name $^{1}$ & -2 & 2 & 1.21 & .90 \\
Know all 26 alphabet letters & -2 & 2 & .98 & 1.08 \\
Read a few words & -2 & 2 & .52 & 1.10 \\
Count to $10^{1}$ & -2 & 2 & 1.41 & .82 \\
Know simple sums & -2 & 2 & .25 & 1.10 \\
Count to 100 & -2 & 2 & .14 & 1.10 \\
\hline
\end{tabular}

Note. ${ }^{1}$ Not included in composite mean.

$S D=$ Standard deviation. 
Beliefs about children's capabilities. A summary of descriptive statistics for beliefs about children's capabilities is presented in Table 12. Practitioners indicated the age that most children are capable of a variety of activities $(1=$ Before age $4,2=$ Age 4 until Age 5, $3=$ Age 5 until Age 6, and $4=$ Age 6 and up), and items were used to calculate an arithmetic mean. Lower scores on this scale indicate that practitioners believe children are capable of activities at younger rather than later ages. The observed internal reliability of this scale was Cronbach's $\alpha=.84$. The mean of the beliefs about children's capabilities composite variable was $1.85(S D=.41)$, indicating that on average practitioners think that children can do these activities Between age 4 and age 5 (2).

Practices. The practices list was designed to contain both basic and advanced numeracy and literacy practices. Exploratory factor analyses (EFA) were conducted to confirm that literacy and numeracy practices grouped more or less into advanced and basic practices, as hypothesized.

Descriptive statistics for literacy practices are presented in Table 13. The literacy practice "I read a storybook aloud," was not entered into the exploratory factor analysis because it had almost no variability. Two literacy factors were requested, and an orthogonal (varimax) rotation was applied; see Table 14 for rotated factor loadings. The two factors extracted accounted for approximately $52 \%$ of the variance of the literacy practices entered. 
Table 12

Summary of Descriptive Statistics for ELCC Practitioners' Beliefs About Children's Capabilities.

\begin{tabular}{lcccc}
\hline \multicolumn{1}{c}{ Item } & Min & Max & Mean & $S D$ \\
\hline Can identify the first person in line. & 1 & 4 & 1.27 & .55 \\
Can count from 1 to 10. & 1 & 4 & 1.33 & .57 \\
Can recognize and name triangles, squares, and circles. & 1 & 4 & 1.33 & .58 \\
Can follow two-step directions. & 1 & 4 & 1.38 & .58 \\
Can count 4 items. & 1 & 3 & 1.40 & .56 \\
Can state the number after 5 by starting the count from 1. & 1 & 4 & 1.42 & .67 \\
Tells a simple story. & 1 & 4 & 1.52 & .71 \\
Makes up rhymes, including nonsense rhymes and chants. & 1 & 4 & 1.88 & .86 \\
Can state the number after 8 by starting the count from 1. & 1 & 4 & 1.88 & .79 \\
Asks who, where \& why questions, often in the past tense. & 1 & 4 & 1.72 & .76 \\
Count backward from 5. & 1 & 4 & 2.30 & .81 \\
Uses invented spelling to print words. & 1 & 4 & 2.33 & .96 \\
Tells a complete story with a beginning, middle and end. & 1 & 4 & 2.41 & .96 \\
Knows that 2 and 2 are 4. & 1 & 4 & 2.45 & .78 \\
Knows how to fairly distribute 8 candies between 2 people. & 1 & 4 & 2.51 & .83 \\
Reads and understands simple words (e.g., red, car). & 1 & 4 & 2.54 & .85 \\
\hline
\end{tabular}

Note $. S D=$ Standard deviation; Min = Minimum; $\operatorname{Max}=$ Maximum. 
Table 13

Summary of Descriptive Statistics for ELCC Practitioners' Literacy Practices.

\begin{tabular}{|c|c|c|c|c|}
\hline Item & Min & $\operatorname{Max}$ & Mean & $S D$ \\
\hline I read a storybook aloud. ${ }^{1}$ & 1 & 5 & 4.84 & .51 \\
\hline $\begin{array}{l}\text { I asked who, where and why questions while we } \\
\text { read. }\end{array}$ & 0 & 5 & 4.50 & .85 \\
\hline $\begin{array}{l}\text { I encouraged the children to write (or attempt to } \\
\text { write) their name. }\end{array}$ & 0 & 5 & 4.21 & 1.15 \\
\hline $\begin{array}{l}\text { I used nursery rhymes/rhyming games to teach } \\
\text { about sounds. }\end{array}$ & 0 & 5 & 4.19 & 1.07 \\
\hline $\begin{array}{l}\text { I used alphabet books and/or alphabets to teach } \\
\text { letters. }\end{array}$ & 0 & 5 & 3.91 & 1.22 \\
\hline I played a memory game with pictures of letters. & 0 & 5 & 3.90 & 1.00 \\
\hline $\begin{array}{l}\text { I drew children's attention to print and words } \\
\text { and their meaning. }\end{array}$ & 0 & 5 & 3.89 & 1.32 \\
\hline $\begin{array}{l}\text { I talked about words and sentences and parts of a } \\
\text { story while I read. }\end{array}$ & 0 & 5 & 3.68 & 1.50 \\
\hline $\begin{array}{l}\text { I asked a child to retell, in their own words, a } \\
\text { story. }\end{array}$ & 0 & 5 & 3.64 & 1.30 \\
\hline I encouraged practice at blending words. & 0 & 5 & 2.96 & 1.56 \\
\hline
\end{tabular}

Note. ${ }^{1}$ This item was not included in exploratory factor analyses.

$S D=$ Standard deviation; Min $=$ Minimum; Max $=$ Maximum . 
Table 14

Rotated Factor Loadings for ELCC Practitioners' Literacy Practices.

\begin{tabular}{|c|c|c|}
\hline Item & $\begin{array}{l}\text { Advanced } \\
\text { Literacy Factor }\end{array}$ & $\begin{array}{l}\text { Basic Literacy } \\
\text { Factor }\end{array}$ \\
\hline $\begin{array}{l}\text { I talked about words and sentences and parts of a } \\
\text { story while I read. }\end{array}$ & .766 & .065 \\
\hline $\begin{array}{l}\text { I asked a child to retell, in their own words, a } \\
\text { story. }\end{array}$ & .703 & .290 \\
\hline I encourage practice at blending words. & .698 & .177 \\
\hline $\begin{array}{l}\text { I asked who, where and why questions while we } \\
\text { read. }\end{array}$ & .616 & 377 \\
\hline $\begin{array}{l}\text { I drew children's attention to print and words } \\
\text { and their meaning. }\end{array}$ & .584 & .206 \\
\hline $\begin{array}{l}\text { I encourage the children to write (or attempt to } \\
\text { write) their name. }\end{array}$ & .190 & .738 \\
\hline $\begin{array}{l}\text { I used alphabet books and/or alphabets to teach } \\
\text { letters. }\end{array}$ & .134 & .714 \\
\hline I played a memory game with pictures or letters. & .224 & .682 \\
\hline $\begin{array}{l}\text { I used nursery rhymes/rhyming games to teach } \\
\text { about sounds. }\end{array}$ & .458 & .500 \\
\hline
\end{tabular}


Factor 1 was named advanced literacy because the items loading on this factor were more complex literacy activities such as practicing word blends with children and asking them to retell a story in their own words. Factor 2 was named basic literacy because items loading on this factor were rudimentary literacy practices (e.g., using alphabet books to teach letters; getting children to practice writing their own name). Composite scores were subsequently created based on these factors. Essentially, an arithmetic mean was created for each factor by summing the scores on all practices within each component and dividing by the number of items. One item ("I used nursery rhymes/rhyming games to teach children about sounds"), loaded fairly equally on each component, and thus was not included in either composite mean. Means were computed instead of using factor scores because means better facilitate the comparison of literacy and numeracy practices. Basic and advanced literacy practices were never entered into a regression model together, thus their shared variance did not pose a multicollinearity problem. The mean for advanced literacy practices was $3.73(S D=.94)$, and the mean for basic literacy practices was $4.01(S D=.85)$, thus, on average practitioners reportedly engaged in these practices At least once last week (4).

Descriptive statistics for numeracy practices are presented in Table 15. The numeracy practice "I encouraged the children to play with Lego, etc.," was not entered into the exploratory factor analysis because it had almost no variability. Two factors were requested and an orthogonal (varimax) rotation was applied. The two factors extracted accounted for approximately $55 \%$ of the variance of the numeracy practices entered.

Factor 1 was named advanced numeracy because the items included were the more complex numeracy activities for children 4 years of age, such as asking them about 
quantities and engaging in addition and subtraction. Factor 2 was named basic numeracy because the items included involved rudimentary numeracy activities such as playing games that involve recognizing printed numbers and using songs to teach counting words. Table 16 contains the rotated factor loadings for each numeracy practice included in the exploratory factor analysis. Just as with literacy practices, the numeracy factors were utilized to create arithmetic means. Basic and advanced numeracy practices were never entered into a regression model together, thus their shared variance did not pose a multicollinearity problem. One item, "I played games that involved counting items," loaded quite highly on both factors, and thus was not included in either mean. The mean for advanced numeracy practices was $3.85(S D=.93)$, and the mean for basic numeracy practices was $3.92(S D=.78)$, indicating that on average practitioners reportedly engaged in these activities At least once last week (4). 
Table 15

Summary of Descriptive Statistics for ELCC Practitioners' Numeracy Practices.

\begin{tabular}{|c|c|c|c|c|}
\hline Item & Min & Max & Mean & $S D$ \\
\hline $\begin{array}{l}\text { I encouraged the children to play with Lego, } \\
\text { etc. }{ }^{1}\end{array}$ & 0 & 5 & 4.76 & .64 \\
\hline I asked children about quantities. & 0 & 5 & 4.35 & .91 \\
\hline I played games that involved counting items. & 0 & 5 & 4.33 & .87 \\
\hline $\begin{array}{l}\text { I used songs to teach my children counting } \\
\text { words. }\end{array}$ & 0 & 5 & 4.22 & 1.06 \\
\hline I played hand/finger games with numbers. & 0 & 5 & 4.16 & 1.04 \\
\hline $\begin{array}{l}\text { I encouraged my students to sort and } \\
\text { classify objects. }\end{array}$ & 0 & 5 & 4.09 & 1.08 \\
\hline $\begin{array}{l}\text { I played games that involve recognizing } \\
\text { printed numbers. }\end{array}$ & 0 & 5 & 3.71 & 1.20 \\
\hline $\begin{array}{l}\text { I asked children to compare or combine } \\
\text { quantities. }\end{array}$ & 0 & 5 & 3.55 & 1.37 \\
\hline $\begin{array}{l}\text { I encouraged activities involving adding } \\
\text { subtracting or measuring. }\end{array}$ & 0 & 5 & 3.43 & 1.39 \\
\hline $\begin{array}{l}\text { I played a board game with a spinner or } \\
\text { dice. }\end{array}$ & 0 & 5 & 3.16 & 1.35 \\
\hline
\end{tabular}

Note. ${ }^{1}$ This item was not included in exploratory factor analyses. $S D=$ Standard deviation; Min = Minimum; Max $=$ Maximum . 
Table 16

Rotated Factor Loadings for ELCC Practitioners' Numeracy Practices.

\begin{tabular}{|c|c|c|}
\hline Item & $\begin{array}{l}\text { Advanced } \\
\text { Numeracy Factor }\end{array}$ & $\begin{array}{l}\text { Basic Numeracy } \\
\text { Factor }\end{array}$ \\
\hline $\begin{array}{l}\text { I asked children to compare or combine } \\
\text { quantities. }\end{array}$ & .802 & .213 \\
\hline $\begin{array}{l}\text { I encouraged activities involving adding, } \\
\text { subtracting or measuring. }\end{array}$ & .754 & .199 \\
\hline I asked children about quantities. & .736 & .163 \\
\hline $\begin{array}{l}\text { I encourage my students to sort and classify } \\
\text { objects. }\end{array}$ & .620 & .341 \\
\hline I played hand/finger games with numbers. & .153 & .781 \\
\hline $\begin{array}{l}\text { I played games that involve recognizing printed } \\
\text { numbers. }\end{array}$ & .094 & .671 \\
\hline I played a board game with a spinner or dice. & .341 & .639 \\
\hline $\begin{array}{l}\text { I used songs to teach my children counting } \\
\text { words. }\end{array}$ & .378 & .590 \\
\hline I played games that involved counting items. & .471 & .525 \\
\hline
\end{tabular}


Beliefs about child care. Beliefs about child care items were entered into a cluster analysis which produced three groups of practitioners named: Can't Opt Out, School Preparation, and Child-Initiated; (see Figure 6 for item means by group). All three groups tended to agree that social and emotional growth is the primary goal of an early childhood program and that teaching kids about letters, sounds and words is part of their job. The Child-Initiated group $(n=79)$ tended to believe that children should be able to opt out of literacy and numeracy activities, and that all activities should be child-initiated. The School Preparation $(n=203)$ and Can't Opt Out $(n=94)$ groups were similar in many ways - they both tended to disagree that all activities should be child-initiated and agreed that four and five year olds should be introduced to the basics of addition and subtraction. The School Preparation group tended to agree that the most important goal of an early child care program is preparation for school, while the Can't Opt Out group did not. The Can't Opt Out group was the only group that disagreed that the focus of early numeracy is counting, not math, and they also more strongly agreed that children should not be allowed to opt out of literacy and numeracy activities.

Four separate one-way between-subjects analyses of the variance (ANOVA) were conducted with practice means by beliefs about child care cluster groups; all were significant (see Table 17), thus practices means differed significantly by belief cluster group. Post-hoc comparisons revealed that, for all four outcomes, the Child-Initiated group differed significantly from the School Preparation and Can't Opt Out groups, however the School Preparation and Can’t Opt Out groups did not differ significantly from one another. In sum, the Child-Initiated group reportedly engaged in fewer numeracy and literacy activities than the School Preparation and Can't Opt Out groups. 


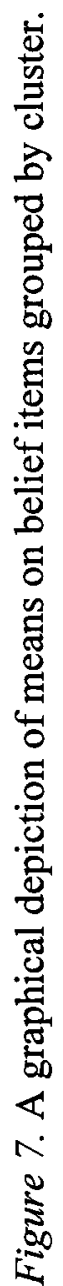

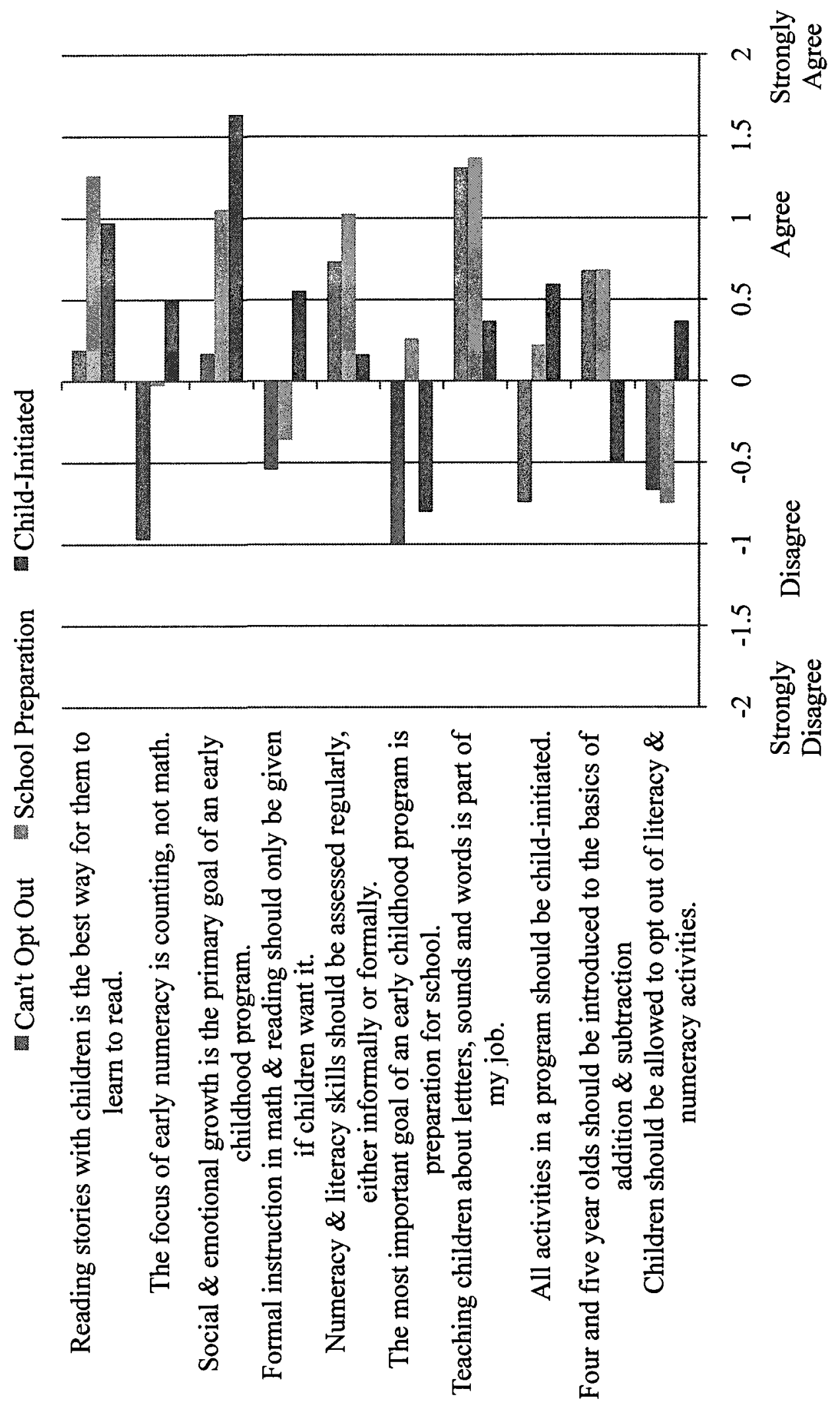


Table 17

Practices Means by Beliefs About Child Care Cluster Groups.

\begin{tabular}{|c|c|c|c|c|c|}
\hline \multirow[b]{2}{*}{$\begin{array}{l}\text { Practices } \\
\text { Outcome }\end{array}$} & \multicolumn{3}{|c|}{ Belief Cluster Group } & \multirow{2}{*}{$\begin{array}{c}\text { Simple } \\
\text { Effects } \\
F(2,373)\end{array}$} & \multirow{2}{*}{$\eta^{2}$} \\
\hline & $\begin{array}{l}\text { Child- } \\
\text { Initiated }\end{array}$ & $\begin{array}{c}\text { School } \\
\text { Preparation }\end{array}$ & $\begin{array}{l}\text { Can't Opt } \\
\text { Out }\end{array}$ & & \\
\hline \multirow{2}{*}{$\begin{array}{l}\text { Advanced } \\
\text { literacy }\end{array}$} & 3.38 & 3.83 & 3.83 & \multirow[t]{2}{*}{$7.39^{* *}$} & \multirow[t]{2}{*}{.04} \\
\hline & $(1.00)$ & $(0.92)$ & $(0.86)$ & & \\
\hline \multirow{2}{*}{$\begin{array}{l}\text { Basic } \\
\text { literacy }\end{array}$} & 3.68 & 4.13 & 4.03 & \multirow[t]{2}{*}{$8.40^{* * *}$} & \multirow[t]{2}{*}{.09} \\
\hline & $(1.05)$ & $(0.78)$ & $(0.75)$ & & \\
\hline \multirow{2}{*}{$\begin{array}{l}\text { Advanced } \\
\text { numeracy }\end{array}$} & 3.31 & 3.97 & 4.05 & \multirow[t]{2}{*}{$18.75^{* * *}$} & \multirow[t]{2}{*}{.04} \\
\hline & $(1.05)$ & $(0.87)$ & $(0.77)$ & & \\
\hline \multirow{2}{*}{$\begin{array}{l}\text { Basic } \\
\text { numeracy }\end{array}$} & 3.61 & 3.87 & 3.87 & \multirow[t]{2}{*}{$3.04 *$} & \multirow[t]{2}{*}{.02} \\
\hline & $(0.91)$ & $(0.82)$ & $(0.83)$ & & \\
\hline
\end{tabular}

Note. ${ }^{*} p<.05,{ }^{* *} p<.01,{ }^{* * *} p<.001$.

Standard deviations are shown in brackets. 
The groups formed by the beliefs about child care cluster analysis were coded for orthogonal comparisons, to be conducted during multiple regression analyses. Because there were three groups, two orthogonal comparisons were permitted. In the first comparison, the Child-Initiated group was compared to the other two groups. In the second comparison, the School Preparation and Can't Opt Out groups were compared to one another.

Mean comparisons. Paired samples t-tests were conducted to compare practitioner means on basic literacy versus basic numeracy practices, and to compare means on advanced literacy versus advanced numeracy practices. Consistent with predictions, practitioners reported engaging in basic literacy practices significantly more frequently than basic numeracy practices (4.01 vs. 3.81$), t(375)=5.42, p<.001$. Inconsistent with predictions, advanced numeracy practices occurred significantly more frequently than advanced literacy practices (3.85 vs. 3.73$), t(375)=-3.11, p=.002$. Although practitioners reported engaging in significantly more basic literacy activities than basic numeracy activities, they also reported engaging in more advanced numeracy activities than advanced literacy activities.

Another paired sample t-test was conducted to compare practitioner means on literacy and numeracy attitudes. Consistent with predictions, practitioners had more positive literacy attitudes than numeracy attitudes $(1.44$ vs. 1.12$) ; t(375)=7.94, p<.001$.

Correlates of ELCC practitioner practices. Bivariate correlations between proposed predictors and outcomes are presented in Table 18. The proposed predictors were practitioner expectations, beliefs about children's capabilities and literacy attitudes and numeracy attitudes. Outcome variables were basic and advanced literacy and 


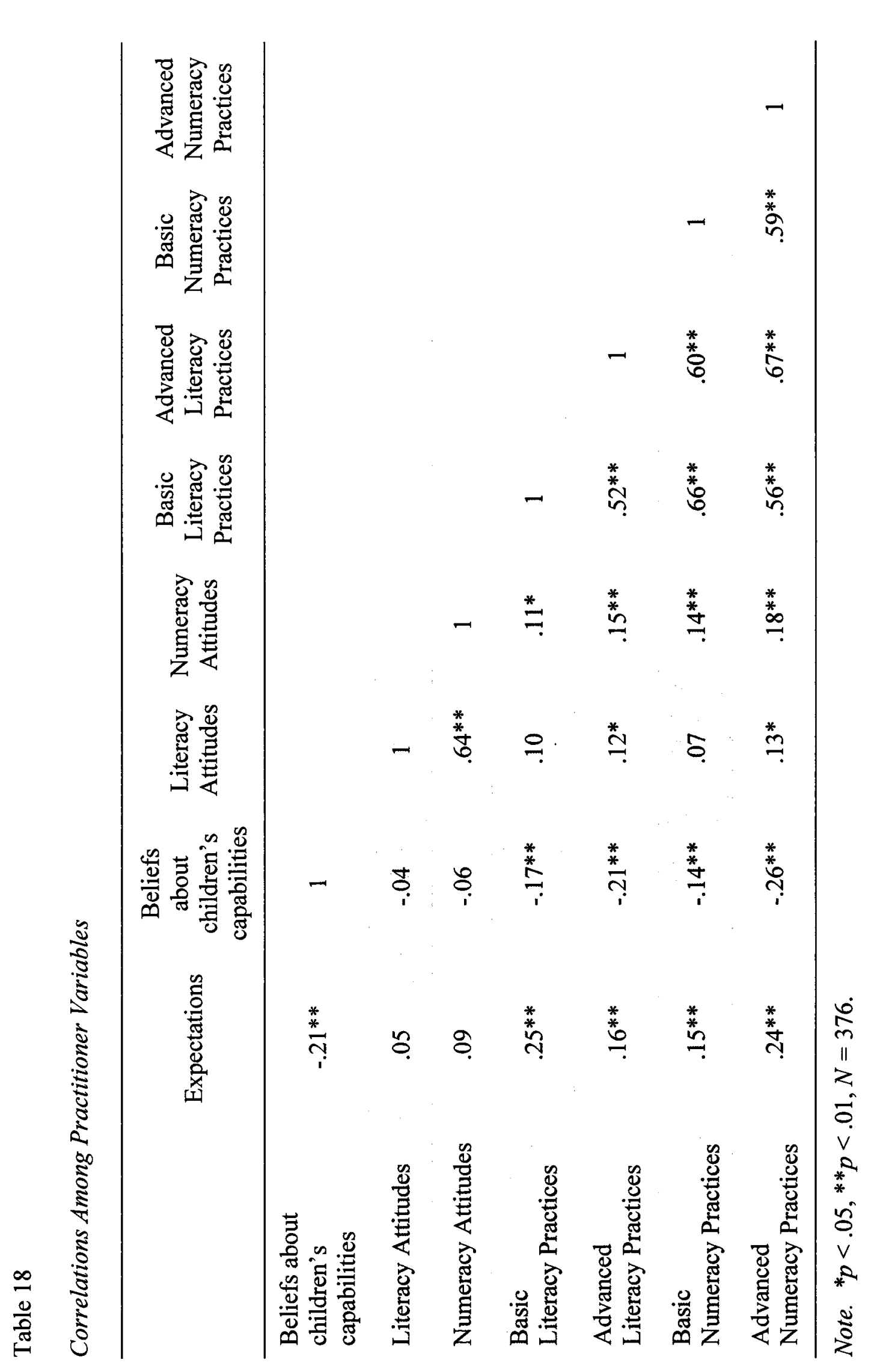


numeracy practices. Expectations were correlated with beliefs about children's capabilities and all four (both literacy and both numeracy) practices variables. Beliefs about children's capabilities and numeracy attitudes were also correlated with all four practices variables. Literacy attitudes were significantly correlated with advanced literacy practices, and advanced numeracy practices. Literacy attitudes were also correlated with numeracy attitudes. Finally, all of the numeracy and literacy practices were highly correlated with one another.

\section{Regression models for ELCC practitioners}

Basic literacy practices. Using multiple linear regression, beliefs about child care group comparisons, expectations, beliefs about children's capabilities, and literacy attitudes were entered as predictors of basic literacy practices (see Table 19 for model summaries). Consistent with hypotheses, beliefs about child care, expectations, and beliefs about children's capabilities were significant predictor of basic literacy practices. Practitioners belonging to the Child-Initiated group reported significantly less engagement in basic literacy practices in comparison to the other two groups. Practitioners with higher expectations and those that believe children are capable younger versus older also reported higher frequencies of basic literacy practices. Finally, contrary to hypotheses, literacy attitudes did not predict basic literacy practices.

Advanced literacy practices. Multiple linear regression was conducted. Beliefs about child care, expectations, beliefs about children's capabilities and literacy attitudes were entered as predictors of advanced literacy practices (see Table 19). Practitioner expectations did not predict advanced literacy practices as hypothesized. 


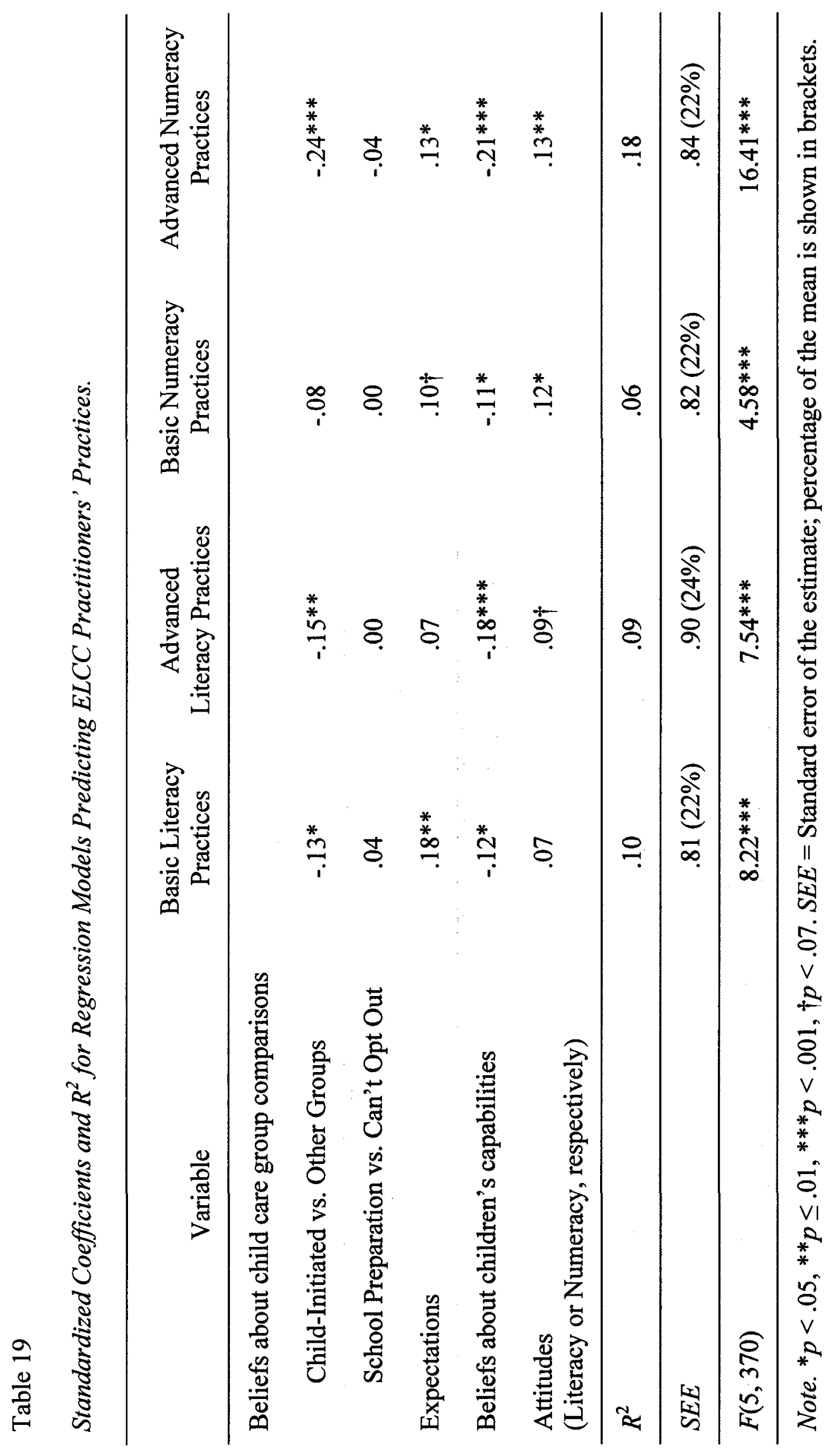

69 
Consistent with hypotheses, beliefs about child care and about children's capabilities were significant predictors of advanced literacy practices. Practitioners belonging to the Child-Initiated group reported significantly less engagement in advanced literacy practices in comparison to the other two groups. Practitioners that believe children are capable younger reported higher frequencies of advanced literacy practices. Finally, literacy attitudes marginally significantly predicted advanced literacy practices, therefore, as practitioners' literacy attitudes became more positive, their reported frequency of advanced literacy practices also increased.

Basic numeracy practices. Multiple linear regression was conducted. Beliefs about child care, expectations, beliefs about children's capabilities and numeracy attitudes were entered as predictors of basic numeracy practices (see Table 19). Inconsistent with hypotheses, beliefs about child care group membership did not significantly predict basic numeracy practices. Consistent with hypotheses, beliefs about children's capabilities significantly predicted basic numeracy practices; expectations and numeracy attitudes were marginally significant predictors of basic numeracy practices. Thus, practitioners that believed children are capable younger, that had higher expectations, and that had more positive numeracy attitudes also reported higher frequencies of basic numeracy practices

Advanced numeracy practices. Multiple linear regression was conducted. Beliefs about child care, expectations, beliefs about children's capabilities and numeracy attitudes were entered as predictors of basic numeracy practices (see Table 19). Consistent with hypotheses, beliefs about child care, expectations, beliefs about children's capabilities, and numeracy attitudes all significantly predicted advanced 
numeracy practices. When compared to the other groups, practitioners belonging to the Child-Initiated group reported significantly less engagement in advanced numeracy practices. When practitioners had higher expectations, believed children are capable younger, and had more positive numeracy attitudes, they also reported more engagement in advanced numeracy practices.

\section{Professional development as a predictor of ELCC practitioner practices.}

Originally, practitioner experience and education were considered as potential predictors of practices, however these variables did not correlate with practices and were excluded as predictors (see Table 20 for correlations). I then considered professional development (PD) as a predictor of practices because it is a form of practitioner training and is possibly more relevant for effecting changes in practitioner practices. Many practitioners were missing pertinent information about their PD, thus I included literacy and numeracy professional development as predictors of literacy and numeracy practices in separate analyses. The sample sizes were reduced from $N=376$ to $N=350$ for analyses that included literacy PD, and to $N=320$ for analyses that included numeracy PD.

A summary of all four practitioner models with professional development added as a predictor is presented in Table 21. These models will be discussed in comparison to the previous models predicting basic and advanced literacy and numeracy practices (please refer back to Table 19). Compared to the original models, the models including professional development accounted for more variance in each outcome. The $R^{2}$ change per model ranged from .02 to .06 . Although these changes seem quite small, the original $R^{2}$ s were small to begin with, thus these changes were in fact relatively large. 


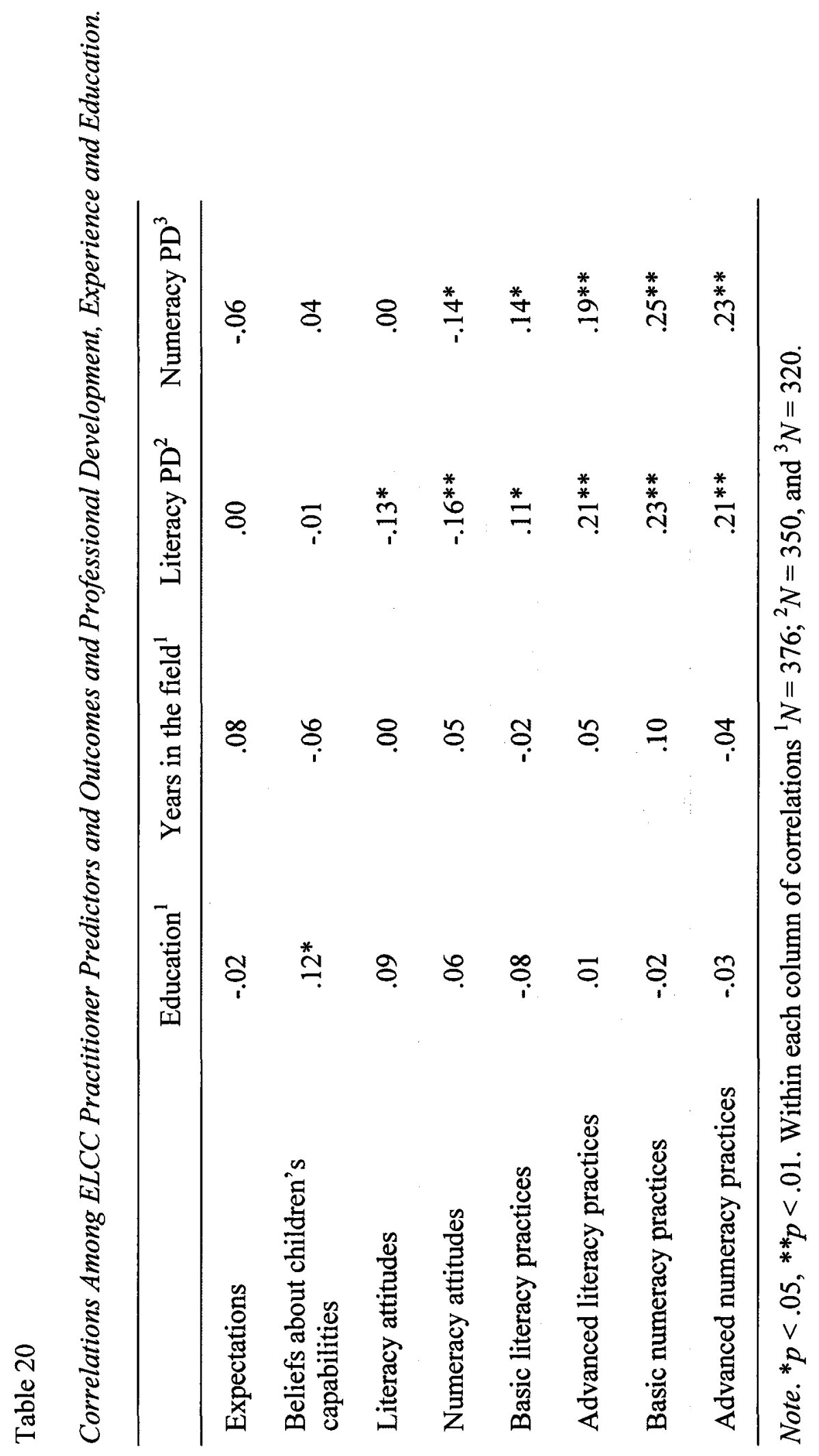




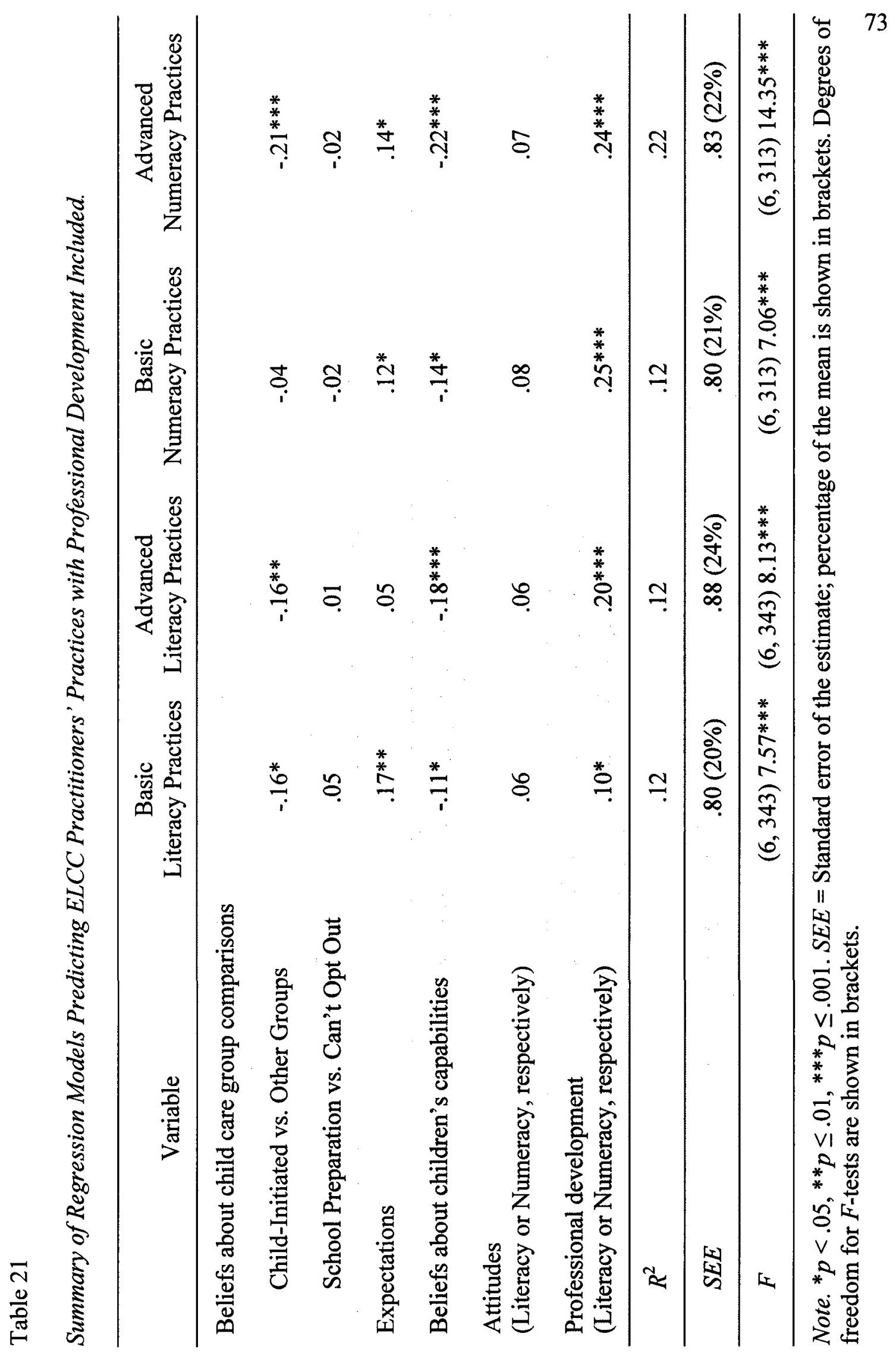


All practitioner models remained basically the same, except that attitudes became a non-significant predictor in all models, whereas professional development became a significant predictor in all models. Thus, the more often practitioners had attended literacy or numeracy professional development workshops, the higher their reported frequencies of literacy and numeracy practices respectively. Apparently, attitudes and professional development share variance that is also shared with practices. Once professional development was entered into the regression equation, attitudes no longer contributed unique variance to practices.

A comparison of models to predict ELCC practitioner practices. Tables 19 and 21 present the summaries of models predicting practitioner practices, both excluding and including professional development. Beliefs about child care group membership was a significant predictor across all models except for basic numeracy practices. The magnitude of the standardized coefficients for this variable was quite similar across the models, suggesting that beliefs about child care group membership was a relatively stable predictor across practices. In sum, belonging to the Child-Initiated group versus the other two groups was predictive of reportedly less engagement in basic literacy, advanced literacy and advanced numeracy practices.

Practitioner expectations significantly predicted all practices except advanced literacy practices. The magnitude of the standardized coefficients for the expectations variable was quite similar across models, suggesting that it was a relatively stable predictor across practices. In sum, compared to lower expectations, higher expectations were predictive of more engagement in basic literacy, basic numeracy and advanced numeracy practices. 
Beliefs about children's capabilities significantly predicted all practitioner practices. The magnitude of the standardized coefficients for the beliefs about children's capabilities variable were a bit larger for advanced versus basic practices, suggesting that it was stronger predictor of advanced practices. In sum, practitioners who believe that children are capable of relevant activities at a younger age were more likely to engage in basic and advanced literacy and numeracy practices.

Practitioner attitudes originally significantly to marginally significantly predicted all practices except for basic literacy practices. Across models, the standardized coefficients for attitudes were relatively small, suggesting that attitudes were weak predictors of practices. Once professional development was included as a predictor of practices, attitudes lost their predictive capability across all models.

\section{Descriptive comparison of mothers and ELCC practitioners}

The results for mothers and ELCC practitioners cannot be compared statistically, largely because the variables are not directly equivalent, but also due to differences in sample size. However, some interesting descriptive comparisons can be made. Please refer to Tables 10 (mothers), 19 and 21 (practitioners) for the summaries of models predicting practices.

How were mothers and practitioners the same? Expectations significantly predicted reports of both literacy and numeracy activities for both mothers and practitioners, with the exception of advanced literacy practices in practitioners. Differences between the mother and practitioner expectation scales should be noted: The mothers' questionnaire included additional items which were more advanced benchmarks. Mothers also had a higher response option-they could rate benchmarks as 
extremely important to know before starting Grade 1. Because practitioners in this study and mothers in other studies tended to rate all benchmarks as very important, the expectations scale was changed for the parent questionnaire in an effort allow for more variable responses. With that caveat, the standardized coefficients for expectations were substantially larger in the models predicting mothers' practices in comparison to the models predicting practitioner practices. Hence, both groups of adults showed relations between self-reported practices and academic expectations for children but these relations may have been stronger for mothers than for practitioners.

For both mothers and practitioners, attitudes were a weak and sometimes nonsignificant predictor of practices. Although maternal attitudes towards literacy were a significant predictor of literacy practices, mothers' attitudes towards numeracy were marginally significant predictors of numeracy practices at best. Furthermore, whether or not numeracy attitudes were predictive of mothers' numeracy practices depended on the type of practices under consideration (e.g., rich home environment, basic or direct numeracy practices). For practitioners, attitudes were weak predictors of numeracy and literacy practices with the exception of basic literacy practices. However, attitudes were no longer significant predictors of practices once professional development was added to the models as a predictor. Thus, in general, practitioner attitudes failed to uniquely predict their practices. Although mothers' literacy attitudes predicted their literacy practices, the numeracy attitudes were only weak predictors of some, but not all, numeracy practices.

Finally, both mothers and practitioners had significantly higher means for literacy attitudes in comparison to numeracy attitudes. In sum, mothers and practitioners 
expressed similar attitudes; they both reported more positive feelings towards literacy than they did towards numeracy. Attitudes may be predictive of children's outcomes for mothers because they reflect other factors. For practitioners, the relations between attitudes and professional development suggest either that more positive attitudes towards literary or numeracy might result in a greater frequency of professional development, or conversely that professional development might influence attitudes and hence practices.

How were mothers and practitioners different? An examination of the $R^{2} \mathrm{~s}$ for mother and practitioner models illustrates a key difference between mothers and practitioners-the variance accounted for in the mother models $\left(R^{2}=.23\right.$ to .35$)$ is substantially larger than the variance accounted for in the practitioner models $\left(R^{2}=.12\right.$ to .22). Thus, mothers and practitioners differed in the variance accounted for in their reported practices; mothers' practices were more strongly related to the variables in the model than were practitioner practices.

It was hypothesized that both mothers and practitioners would report engaging in significantly more literacy practices than numeracy practices. This hypothesis was supported in mothers. Practitioners, on the other hand, reported more frequent engagement in basic literacy practices than basic numeracy practices, and more frequent engagement in advanced numeracy practices than advanced literacy practices. In sum, mothers and practitioners differed in literacy practices relative to their numeracy practices. Mother reportedly engaged in more literacy than numeracy practices, whereas practitioners reported a balance of literacy and numeracy practices.

In conclusion, mothers and practitioners were similar in some ways, and different in others. Expectations consistently predicted, whereas attitudes inconsistently predicted 
both mothers' and practitioners' practices. Mothers and practitioners also shared more positive attitudes towards literacy than numeracy. However, mothers' practices were better predicted than practitioner practices, and mothers reported more literacy than numeracy practices, whereas practitioners reported equal engagement in these practices. 


\section{Discussion}

The goal of the present research was to determine whether the characteristics of mothers and practitioner were related to their reports of early numeracy and literacy practices with the children in their care. Adult characteristics examined included level of education or training, academic expectations, literacy and numeracy attitudes, book exposure (for mothers), and beliefs about child care and children's capabilities (for practitioners). These adult characteristics were used to predict the reported literacy and numeracy practices of mothers and practitioners. Overall, I found that many of the characteristics were predictive of mothers' and practitioners' practices. A summary of hypotheses and whether or not they were supported by the present data can be found in Table 22.

As shown in Table 22, comparisons were made between attitudes towards literacy and numeracy and the frequency of reports of literacy and numeracy practices. First, both mothers and practitioners reported more positive attitudes towards literacy than they did towards numeracy. This is consistent with research by Blevins-Knabe et al. (2000), who found that mothers and caregivers placed more importance on reading skills versus number skills. The present research, is to my knowledge, the only one besides BlevinsKnabe et al. to examine both parent and caregiver attitudes. 
Table 22.

Summary of Supported Hypotheses.

\begin{tabular}{|c|c|c|c|c|}
\hline Hypotheses & \multicolumn{2}{|c|}{ Mothers } & \multicolumn{2}{|c|}{ Practitioners } \\
\hline \multicolumn{5}{|l|}{$\begin{array}{l}\text { Comparisons between literacy and } \\
\text { numeracy }\end{array}$} \\
\hline $\begin{array}{l}\text { Attitudes towards literacy will be more } \\
\text { positive than those towards numeracy }\end{array}$ & \multicolumn{2}{|c|}{$\sqrt{ }$} & \multicolumn{2}{|c|}{$\sqrt{ }$} \\
\hline $\begin{array}{l}\text { Literacy practices will be reported } \\
\text { more frequently than numeracy } \\
\text { practices }\end{array}$ & \multicolumn{2}{|c|}{$\sqrt{ }$} & \multicolumn{2}{|c|}{$\mathrm{X}$} \\
\hline Potential Predictors of Reported Practices & Lit & Num & Lit & Num \\
\hline Education or experience & $\mathrm{X}$ & $\mathrm{X}$ & $\sqrt{ }$ & $\sqrt{ }$ \\
\hline Academic expectations & $\sqrt{ }$ & $\sqrt{ }$ & partially $^{\mathrm{b}}$ & $\sqrt{ }$ \\
\hline Attitudes towards literacy or numeracy & $\sqrt{ }$ & partially $^{a}$ & $\mathrm{X}$ & $\mathrm{x}$ \\
\hline Book Exposure & $\sqrt{ }$ & $\sqrt{ }$ & $\mathrm{n} / \mathrm{a}$ & $\mathrm{n} / \mathrm{a}$ \\
\hline Beliefs about child care & $\mathrm{n} / \mathrm{a}$ & $\mathrm{n} / \mathrm{a}$ & $\sqrt{ }$ & partially ${ }^{\mathrm{c}}$ \\
\hline Beliefs about children's capabilities & $\mathrm{n} / \mathrm{a}$ & $\mathrm{n} / \mathrm{a}$ & $\sqrt{ }$ & $\sqrt{ }$ \\
\hline
\end{tabular}

Note. A check mark $(\sqrt{ })$ indicates that this hypothesis was supported with the data; an X indicates that the hypothesis was not supported. Num = numeracy practices; Lit = literacy practices. Lit $=$ Literacy practices; Num $=$ Numeracy practices.

a'Mothers' numeracy attitudes only predicted direct numeracy practices as hypothesized

'Practitioners' expectations predicted basic but not advanced literacy practices.

'Practitioners' beliefs about child care predicted advanced but not basic numeracy practices. 
Second, mothers reported more literacy practices than numeracy practices (Blevins-Knabe et al., 2000). This result was not replicated for practitioners, who reported equal engagement in literacy and numeracy practices. There are many possible reasons why mothers reported fewer numeracy than literacy practices. Mothers' practices might reflect a societal emphasis on literacy, not numeracy. Mothers might have felt knowledgeable about literacy practices and less knowledgeable about appropriate numeracy practices. Practitioners might engage in numeracy and literacy practices equally because they have had specific training in both literacy and numeracy, thus facilitating their equal inclusion in the child care setting. Further, mothers and practitioners may differ in their balance of numeracy and literacy practices because some practices may occur more naturally or easily in home or child care environments. For example, reading one-on-one with a child is more likely to happen at home than in the child care setting. Similarly, numeracy practices that occur within play or games may be more likely to occur in the child care setting, the end result being a balance of numeracy and literacy activities among practitioners and more literacy than numeracy practices among mothers.

\section{Mothers}

Inconsistent with the present hypotheses, maternal education did not predict mothers' reported numeracy or literacy practices. This result differed from studies conducted in the United States in which researchers attributed poor achievement among low SES children to a lack of home learning experiences (Arnold \& Doctoroff, 2003; Campbell et al., 2001; Clements 2004; Ginsburg et al., 2008; Jordan et al., 2007; Siegler \& Ramani, 2008; Whitehurst \& Lonigan, 1998; Young-Loveridge, 1989). Links between 
SES and children's outcomes have not been well-supported by research conducted in Canada. For example, Sénéchal et al. (1996) studied Canadian mothers and their fouryear-old children and found that SES accounted for $10-14 \%$ of the variance in children's receptive vocabulary, and $7-8 \%$ of the variance in their expressive vocabulary. However, Sénéchal and LeFevre (2000) found that parental education only accounted for $5 \%$ of the variance in children's receptive language at the beginning of Grade 1, and parental education was not significantly correlated with emergent literacy or phonological awareness. It is possible that children's SES is not as variable in Canada as it is in the U.S., thus the effects on practices and achievement may be minimal. Alternatively, children's experiences at home and in child care might be more homogeneous across SES levels in Canada than in the US. It is also possible that the present sample did not contain a wide enough range of SES to allow differences in mothers' practices by SES to be detected. A study designed to specifically recruit children of low SES within Canada (e.g., families receiving subsidies) might show relations between SES, parents' reported practices and children's outcomes.

Consistent with the current hypotheses, mothers' expectations significantly predicted their literacy and numeracy practices. Mothers who agreed that it is important for their children to have learned all of the alphabet letters and how to count to 100 by the time they enter Grade 1 reported higher frequencies of literacy and numeracy practices than mothers who viewed these skills as less important precursors to Grade 1. These findings were consistent with previous research that has found links between parents' expectations and their behaviours (Blevins-Knabe, 1998; Galper et al., 1997; Hess et al., 1984; Huntsinger et al., 1997; LeFevre et al., 2002). These findings suggest that mothers' 
behaviours were in line with their expectations. Hypothetically, these home experiences would prepare children to meet mothers' academic expectations. In sum, mothers' expectations significantly predicted their literacy and numeracy practices, and as such may be important to include in future research on mothers' literacy and numeracy practices.

As hypothesized, mothers' reported literacy attitudes were positively related to their reported literacy practices. When mothers had more positive literacy attitudes, they also engaged in literacy practices more often, suggesting that parent practices were in line with their attitudes. Numeracy attitudes were not correlated with numeracy practices overall, however mothers' numeracy attitudes predicted some kinds of numeracy practices. Numeracy attitudes were negatively related to mothers' basic numeracy practices and unrelated to mothers' rich home environment numeracy practices. Mothers' direct numeracy practices increased as mothers' numeracy attitudes became more positive, thus providing some support for the hypothesized positive relation between mothers' numeracy attitudes and practices.

The mixed relations between numeracy attitudes and practices in the current study provide a potential explanation for the mixed results in past research on parental attitudes and practices. For example, LeFevre et al. (In Press) found links between Greek and Canadian mothers' attitudes and their practices, but LeFevre et al. (2009) did not. Perhaps mothers adjust their numeracy practices according to their attitudes. It is also possible that mothers with negative attitudes towards math were only comfortable engaging in rudimentary numeracy practices with their children due to a lack of their own math knowledge or dislike for the subject. Similarly, mothers with positive numeracy attitudes 
might have engaged in direct teaching of numeracy due to personal enjoyment or because they felt more knowledgeable about math in general. These findings were consistent with a study by LeFevre et al. (In Press) that found that the attitudes of Greek and Canadian parents' were predictive of similar home numeracy practices.

Why would mothers' numeracy attitudes show no relation to rich home environment practices? Perhaps mothers engage in rich home environment numeracy practices in efforts to adequately prepare their children for school, irrespective of their numeracy attitudes. Future research should work to clarify the relations between parent attitudes and different types of numeracy practices.

Book exposure also predicted mothers' literacy and numeracy practices. When mothers read to their children often and owned many children's books, they also reported more literacy and numeracy practices. The book exposure variable could be considered a measure of the quality of the home environment. Book exposure might also be a proxy measure of how much time mothers spend interacting with their children. Past research findings indicate that children learn more from activities shared with adults than they do from activities shared with peers (Mattanah, Pratt, Cowan \& Cowan, 2005; Radziszewska \& Rogoff, 1988, 1991). Adult-child interactions provide an opportunity for adults to structure and guide children's learning experiences. Interestingly, book exposure did not differentially predict literacy and numeracy. If book exposure was solely a literacy variable then it would predict literacy practices but not numeracy practices. In summary, because book exposure predicted mothers' reports of both literacy and numeracy practices, it may capture something general about mothers' didactic practices. 


\section{ELCC Practitioners}

As hypothesized, practitioners' expectations predicted basic literacy and overall numeracy practices. This finding suggests that practitioners acted in line with their expectations in hopes of adequately preparing children to meet these expectations by the time they reach Grade 1. It is unclear why practitioner expectations were not related to their advanced literacy practices. Perhaps the nature of the expectations scale can account for the lack of relation between expectations and advanced literacy practices. If the expectations scale had included more advanced items and subsequently more variability expectations might have predicted advanced literacy practices. In sum, expectations predicted almost all practitioner practices. In the future, researchers should strive to capture sufficient variability in practitioner expectations, and further explore relations between these expectations and practitioners' practices.

Consistent with the study hypotheses, practitioner beliefs about child care predicted all reported practices, except for basic numeracy. Thus, practitioners who believed direct instruction is appropriate in the child care setting reported more numeracy and literacy practices than practitioners who believed all activities had to be childinitiated (therefore not directly taught). Most of the basic numeracy practices were game and play based and did not require direct instruction, (e.g., "I played games that involve recognizing printed numbers;" "I used songs to teach my children counting words"), which may explain why beliefs about child care did not predict these practices. These findings are consistent with research by Stipek and Byler (1997) who found that practitioners acted in line with their beliefs. Therefore, practitioner beliefs about child 
care appear to be an important variable to consider when trying to predict or change practitioner practices.

Inconsistent with the current hypotheses, practitioner attitudes did not predict practitioners' literacy and numeracy practices once professional development was added as a predictor. Consistent with hypotheses, professional development predicted all practitioner practices. Professional development and attitudes seem to share some variance, however professional development stood out as a unique predictor of reported practices. It is interesting to consider the causal relations between professional development and attitudes. Do practitioners attend more professional development workshops when their pre-existing attitudes are positive? Do professional development experiences influence practitioner attitudes to make them more positive? Perhaps some third variable causes both positive attitudes and increased participation in professional development. It is also possible that professional development changes practitioners' feelings of self-efficacy to teach literacy or numeracy, thus making their attitudes towards literacy and numeracy irrelevant. In sum, professional development experience in numeracy and literacy significantly predicted numeracy and literacy practices, respectively. Future research should explore relations between attitudes, professional development and practices.

Consistent with predictions, practitioner beliefs about children's capabilities predicted all literacy and numeracy practices, although these beliefs appeared to be better at predicting advanced versus basic practices. Thus, practitioners who think children are capable of certain literacy and numeracy activities at younger ages reported higher frequencies of literacy and numeracy practices than practitioners who believed that 
children are not capable until older ages. In sum, practitioner beliefs about children's capabilities predicted their practices, warranting their inclusion in future studies of practitioner practices.

\section{Practical Implications}

Based on the findings reported here, increasing mothers' expectations and improving their literacy and numeracy attitudes might be ways to increase the frequency of their literacy and numeracy practices. Changing behaviour is often quite difficult (Pajares, 1992), however pressures over time (e.g., media, societal trends, school curriculum, interventions) may result in change eventually (e.g., VanTassel-Baska et al., 2008). At the very least, parent education and intervention efforts should take parent expectations and attitudes into account.

For practitioners, the present study suggests that altering their expectations, beliefs about child care and beliefs about children's capabilities may alter their practices. Pajares (1992) includes expectations and attitudes as forms of beliefs, and notes that all beliefs, especially when strongly held, are very difficult to alter. Adopting behaviours without changing the accompanying beliefs has been shown to result in superficial change. Most people would rather find some way to fit new evidence within their existing beliefs than change their beliefs. In sum, expectations, attitudes and beliefs seem to be important to understanding behaviours, such as literacy and numeracy practices.

Practitioner education should strive to educate practitioners about literacy and numeracy development to influence their beliefs about children's capabilities. Trying to instill in practitioners a sense that numeracy and literacy practices can be developmentally appropriate, and demonstrating that such practices occur in situations without direct 
instruction may work to change some beliefs about child care. Perhaps even practitioners who believe all activities should be child-initiated could be convinced that some literacy and numeracy practices fit with their beliefs, thus promoting literacy and numeracy practices. In sum, practitioner education and development should, at the very least, take into account their expectations, attitudes and beliefs.

\section{Limitations of the project}

This study has five main limitations. First, all parents included in the current study were mothers, thus the sample is not representative of parents. Despite attempts to recruit both mothers and fathers, very few fathers completed a parent questionnaire. In most cases a questionnaire was already completed by the mother, thus I decided to exclude fathers from analyses. Blevins-Knabe (2008) has noted the absence of fathers in home numeracy research and called for their inclusion in future. The current project lacks information about the expectations, attitudes, book exposure and practices of fathers, and thus results can only be generalized to mothers and not to all parents.

Second, because the current study required mothers and practitioners to consent and to complete surveys, it is vulnerable to participant response biases. The surveys asked many questions about literacy and numeracy and probably attracted participants that were more interested in literacy and numeracy than average. Thus, it is probable that these parent and practitioner samples have more positive attitudes towards literacy and numeracy, higher expectations, and engage in literacy and numeracy practices more frequently than the general populations of mothers and practitioners, therefore generalizations about the findings are limited. Sampling randomly from populations is a 
way to try to overcome response biases, but it is often impractical or difficult to sample in this manner.

Third, the current project relied solely on parent and practitioner reports of their characteristics and practices. Self-reports are susceptible to social desirability biases (Morsbach \& Prinz, 2006). Some mothers and practitioners may have responded as they thought they should instead of realistically reporting their characteristics and practices. Also, both mothers and practitioners were asked to recall how frequently they engaged in literacy and numeracy practices, thus relying on participants' memories. Human memory is prone to errors and inaccuracies (Schacter, 1999). In future research, time-sampled observations of parents and practitioners would objectively assess literacy and numeracy practices while minimizing social desirability and memory demands.

Fourth, although both mothers and practitioners reported their expectations and literacy and numeracy attitudes, different scales were used for each sample (items and response scales differed somewhat). Ideally, parent and practitioner expectations and attitudes would have been measured using the same items and rating scales, thus allowing their direct comparison.

Fifth, although the current project found relations between the characteristics of mothers and practitioners and their literacy and numeracy practices, these findings were correlational in nature, and thus the causal direction of these relations are unknown. Adult characteristics were used to predict adult practices, however there is no evidence that adult characteristics cause these practices. Determining causality can prove quite difficult but interventions and longitudinal studies might provide insights about the directionality of relations. 


\section{Future Directions}

Other variables to consider in future research. Future research could explore relations between parents' own math knowledge and the frequencies and types of home numeracy activities. Parent knowledge might be related to their attitudes and practices. Parents who have more experience and training in mathematics may be better equipped to teach and explain numerical concepts to their children than parents that completed few secondary and post-secondary school math courses.

Who is responsible for teaching children literacy and numeracy? Parents might think practitioners are responsible, but practitioners might think parents are responsible, and there is likely a group of parents and practitioners who think the kindergarten or Grade 1 teacher is responsible for teaching children these skills. It seems reasonable that frequencies of literacy and numeracy practices would be lower among parents and practitioners who do not think it is their job to teach literacy and numeracy. Thus, asking parents and practitioners if it is their job to teach children about literacy and numeracy may be another way to understand their literacy and numeracy practices.

The role of the child in predicting parent and practitioner practices was not explored in the current study, but is probably an important predictor of parent and practitioner practices. Parents might engage in practices more frequently when their child enjoys them or when their child's skill level is high. Because normal development is quite variable in young children, some children may not be ready for advanced numeracy and literacy activities. All of these examples illustrate ways in which the child and parent practices may interact, and it is likely that these would generalize to the child care setting 
as well. In sum, future research should examine the role of the child in predicting parent and practitioners' literacy and numeracy practices.

Throughout this project, I assumed that mothers' and practitioners' practices are important because they provide children with early experiences that help to build their literacy and numeracy knowledge. However, the current study did not assess the numeracy and literacy skills of children. Thus, future research should explore the relations between parent and practitioner practices and children's achievement outcomes. Research on mathematical development is lacking theoretical models in general. A future research direction would be to develop theoretical models of relations between variables. Presumably, the current lack of theory is attributable to the relatively small amount of research conducted in this field up until this point. In comparison to literacy, much less is understood about the development and acquisition of numeracy. The current research is founded partially in the theories of Piaget (Piaget \& Inhelder, 1956) and Vygotsky (1978). Piaget posited that children construct their understanding through their experiences. Thus, children's early experiences at home and in child care may be very important to their construction of literacy and numeracy skills. On the other hand, Vygotsky focused on the role of adults as guides, who scaffold children's learning during social interaction. According to Vygotsky, with the help of an adult, a child can engage in activities otherwise outside of his/her abilities, and gain understanding from such interactions. Parents and caregivers are probably the adults with whom children interact with most frequently, thus experiences with these adults may help children develop literacy and numeracy more quickly than they would on their own. 


\section{Conclusions}

The current study identified characteristics of both mothers and ELCC practitioners that were predictive of their reported literacy and numeracy practices. This is one of a few studies designed to systematically examine mothers' expectations and attitudes in relations to their numeracy practices. It is also one of the only studies to examine mothers' literacy attitudes in relation to their reported literacy practices (perhaps because this relation has always been implicitly assumed in home literacy research). Furthermore, to my knowledge, only one study by Green et al. (2006) has examined practitioner characteristics and literacy practices. Blevins-Knabe et al. (2000) also conducted one of the only studies of home and child care practices, however they asked mothers and caregivers about their attitudes and expectations, but did not relate these to their practices. Thus, despite some limitations, this study provides one of the first accounts of the types and frequencies of literacy and numeracy practices occurring in the child care setting, and also adds to knowledge about home literacy and numeracy practices.

The current project also points to some similarities and differences between mothers and practitioners. Although both mothers and practitioner had more positive literacy than numeracy attitudes, practitioners reported equal engagement in literacy and numeracy practices, whereas mothers reported more literacy than numeracy practices. Expectations were predictive of literacy and numeracy practices across both groups. Mothers' attitudes predicted their literacy practices, and weakly predicted some numeracy practices, whereas practitioners' attitudes were not unique predictors of their practices once their professional development was entered into the equation. Practitioner beliefs 
about child care and about children's capabilities were also significant predictors of their practices, suggesting that early childhood education and professional development workshops should take such beliefs, as well as expectations into consideration.

Future research is necessary to further explore similarities and differences between parents and practitioners. Such research should include measures of children's numeracy and literacy achievement, thus illustrating how parent and practitioner characteristics and practices relate to children's outcomes. To conclude, the problem of understanding children's literacy or numeracy achievement is quite challenging given the web of relations among potential predictors. Thus, the field of research designed to explore predictors of children's literacy and numeracy achievement is a fertile one, as many questions remain unanswered. 


\section{References}

Anderson, A., Anderson, J., \& Thauberge, C. (2008). Mathematics learning and teaching in the early years. In O. N. Saracho, \& B. Spodek (Eds.), Contemporary Perspectives on Mathematics in Early Childhood Education, (pp. 95-132). Charlotte, NC: Information Age Publishing.

Anderson, A., Anderson, J., \& Shapiro, J. (2004). Mathematical discourse in shared storybook reading. Journal for Research in Mathematics Education, 35, 5-33.

Arnold, D. H., \& Doctoroff, G. L. (2003). The early education of socioeconomically disadvantaged children. Annual Review of Psychology, 54, 517-545.

Aunola, K., Leskinen, E., Lerkkanen, M. K., \& Nurmi, J. E. (2004). Developmental dynamics of math performance from preschool to grade 2. Journal of Educational Psychology, 96, 699-713.

Blevins-Knabe, B. (2008). Fostering early numeracy at home. Encyclopedia of Language and Literacy Development, Retrieved 2009-09-07 from:

http://iteracyencyclopedia.ca/index.php?fa=items.show\&topicId $=245$

Blevins-Knabe, B., Berghout, A. A., Musun, L., Eddy, A., \& Jones, R. M. (2000). Family home care providers' and parents' beliefs and practices concerning mathematics with young children. Early Child Development and Care, 165, 41-58.

Bracken, S. S., \& Fischel, J. E. (2006). Assessment of preschool classroom practices: Application of Q-sort methodology. Early Childhood Research Quarterly, 21, 417430.

Bushnik, T. (2006). Children and youth research paper series: Child care in Canada. Canada: Statistics Canada. 
Campbell, F. A., Pungello, E. P., Miller-Johnson, S., Burchinal, M., \& Ramey, C. T. (2001). The development of cognitive and academic abilities: Growth curves from an early childhood educational experiment. Developmental Psychology, 37, 231-242.

Charlesworth, R., Hart, C. H., Burts, D. C., Thomasson, R. H., Mosley, J., \& Fleege, P. O. (1993). Measuring the developmental appropriateness of kindergarten teachers' beliefs and practices. Early Childhood Research Quarterly, 8, 255-276.

Clements, D. H. (2004). Preface. In D. H. Clements, J. Sarama \& A. M. DiBiase (Eds.), Engaging Young Children in Mathematics, (pp. ix-xv). Mahwah, NJ: Lawrence Erlbaum Associates.

Clements, D. H. \& Sarama, J. (2007). Effects of a preschool mathematics curriculum: Summative research on the Building Blocks project. Journal of Research in Mathematics Education, 38(2), 136-163.

DeBaryshe, B. D. (1995). Maternal belief systems: Linchpin in the home reading process. Journal of Applied Developmental Psychology, 16, 1-20.

Desoete, A., \& Gregoire, J. (2006). Numerical competence in young children and in children with mathematics learning disabilities. Learning and Individual Differences, 16, 351-367.

Duncan, G. J., Dowsett, C. J., Claessens, A., Magnuson, K., Huston, A. C., Klebanov, P., et al. (2007). School readiness and later achievement. Developmental Psychology, 43, 1428-1446.

Evans, M. A., \& Shaw, D. (2008). Home grown for reading: Parental contributions to young children's emergent literacy and word recognition. Canadian 
Psychology/Psychologie Canadienne. Special Issue: Literacy Development in Canada, 49, 89-95.

Galper, A., Wigfield, A., \& Seefeldt, C. (1997). Head start parents' beliefs about their children's abilities, task values, and performances on different activities. Child Development, 68, 897-907.

Gersten, R., \& Chard, D. (1999). Number sense: Rethinking arithmetic instruction for students with mathematical disabilities. The Journal of Special Education, 33, 18-28.

Gill, S., \& Reynolds, A. J. (1999). Educational expectations and school achievement of urban African American children. Journal of School Psychology.Special Issue: Schooling and High-Risk Populations: The Chicago Longitudinal Study, 37, 403424.

Ginsburg, H. P., Lee, J. S., \& Boyd, J. S. (2008). Mathematics education for young children: What it is and how to promote it. Social Policy Report: A Publication of the Society for Research in Child Development, 22, 1-23.

Ginsburg, H. P., \& Amit, M. (2008). What is teaching mathematics to young children? A theoretical perspective and case study. Journal of Applied Developmental Psychology, 29, 274-285.

Green, S. D., Peterson, R., \& Lewis, J. R. (2006). Language and literacy promotion in early childhood settings: A survey of center-based practices. Early Childhood Research and Practice, 8, 27-47.

Greenes, C., Ginsburg, H. P., \& Balfanz, R. (2004). Big math for little kids. Early Childhood Research Quarterly, 19, 159-166. 
Hess, R. D., Holloway, S. D., Dickson, W. P., \& Price, G. G. (1984). Maternal variables as predictors of children's school readiness and later achievement in vocabulary and mathematics in sixth grade. Child Development, 55, 1902-1912.

Howe, N., \& Jacobs, E. (1995). Child care research: A case for Canadian national standards. Canadian Psychology/Psychologie Canadienne, 36, 131-148.

Huntsinger, C. S., Jose, P. E., Liaw, F., \& Ching, W. (1997). Cultural differences in early mathematics learning: A comparison of Euro-American, Chinese-American, and Taiwan-Chinese families. International Journal of Behavioral Development, 21, 371-388.

Jordan, N. C., Kaplan, D., Locuniak, M. N., \& Ramineni, C. (2007). Predicting firstgrade math achievement from developmental number sense trajectories. Disabilities Research \& Practice, 22, 36-46.

Jordan, N. C., Kaplan, D., Oláh, L. N., \& Locuniak, M. N. (2006). Number sense growth in kindergarten: A longitudinal investigation of children at risk for mathematics difficulties. Child Development, 77, 153-175.

Kurdek, L. A., \& Sinclair, R. J. (2001). Predicting reading and mathematics achievement in fourth-grade children from kindergarten readiness scores. Journal of Educational Psychology, 93, 451-455.

Layzer, J., Goodson, B., \& Moss, M. (1993). Life in Preschool: Volume One of an Observational Study of Early Childhood Programs for Disadvantaged Four-YearOlds. Cambridge, MA: Abt Associates.

LeFevre, J., Clarke, T., \& Stringer, A. P. (2002). Influences of language and parental involvement on the development of counting skills: Comparisons of French- and 
English-speaking Canadian children. Early Child Development and Care, 172, 283300.

LeFevre, J., Polyzoi, P., Skwarchuk, S. L., Fast, L., \& Sowinski, C. (In Press). Do home numeracy and literacy practices of Greek and Canadian parents predict the numeracy skills of kindergarten children? International Journal of Early Years Education.

LeFevre, J., Skwarchuk, S., Smith-Chant, B. L., Fast, L., Kamawar, D., \& Bisanz, J. (2009). Home numeracy experiences and children's math performance in the early school years. Canadian Journal of Behavioural Science/Revue Canadienne Des Sciences Du Comportement ,41(2), 55-66.

Lonigan, C. J., Burgess, S. R., \& Anthony, J. L. (2000). Development of emergent literacy and early reading skills in preschool children: Evidence from a latentvariable longitudinal study. Developmental Psychology, 36, 596-613.

Mattanah, J. F., Pratt, M. W., Cowan, P. A., \& Cowan, C. P. (2005). Authoritative parenting, parental scaffolding of long-division mathematics, and children's academic competence in fourth grade. Journal of Applied Developmental Psychology, 26, 85-106.

McCardle, P., Scarborough, H. S., \& Catts, H. W. (2001). Predicting, explaining, and preventing children's reading difficulties. Learning Disabilities Research \& Practice Special Issue: Emergent and Early Literacy: Current Status and Research Directions, 16, 230-239.

Millard, R., \& Waese, M. (2007). Language and literacy, from birth...for life (Research Summary). Ontario: Canadian Language and Literacy Research Network. 
Morsbach, S. K., \& Prinz, R. J. (2006). Understanding and improving the validity of selfreport of parenting. Clinical Child and Family Psychology Review, 9, 1-21.

Musun-Miller, L., \& Blevins-Knabe, B. (1998). Adults' beliefs about children and mathematics: How important is it and how do children learn about it? Early Development and Parenting, 7, 191-202.

Pajares, M. F. (1992). Teachers' beliefs and educational research: Cleaning up a messy construct. Review of Educational Research, 62, 307-332.

Perlman, M., \& Fletcher, B. A. (2008). Literacy instruction in Canadian child care centers. Journal of Research in Childhood Education, 23, 139-155.

Piaget, J., \& Inhelder, B. (1956). The Child's Conception of Space. Boston: Routledge \& Kegan Paul.

Radziszewska, B., \& Rogoff, B. (1988). Influence of adult and peer collaborators on children's planning skills. Developmental Psychology, 24, 840-848.

Radziszewska, B., \& Rogoff, B. (1991). Children's guided participation in planning imaginary errands with skilled adult or peer partners. Developmental Psychology, 27, 381-389.

Scarborough, H. S. (1998). Predicting the future achievement of second graders with reading disabilities: Contributions of phonemic awareness, verbal memory, rapid naming, and IQ. Annals of Dyslexia, 48, 115-136.

Scarborough, H. S., \& Dobrich, W. (1994). On the efficacy of reading to preschoolers. Developmental Review, 14, 245-302.

Schacter, D. L. (1999). The seven sins of memory: Insights from psychology and cognitive neuroscience. American Psychologist, 54, 182-203. 
Sénéchal, M. (2006). Testing the home literacy model: Parent involvement in kindergarten is differentially related to grade 4 reading comprehension, fluency, spelling, and reading for pleasure. Scientific Studies of Reading, 10, 59-87.

Sénéchal, M., LeFevre, J. A., Hudson, E., \& Lawson, E. P. (1996). Knowledge of storybooks as a predictor of young children's vocabulary. Journal of Educational Psychology, 88, 520-536.

Sénéchal, M., LeFevre, J. A., Thomas, E. M., \& Daley, K. E. (1998). Differential effects of home literacy experiences on the development of oral and written language. Reading Research Quarterly, 33, 96-116.

Sénéchal, M., \& LeFevre, J. (2002). Parental involvement in the development of children's reading skill: A five-year longitudinal study. Child Development, 73, 445460.

Siegler, R. S., \& Ramani, G. B. (2009). Playing linear number board games-but not circular ones-improves low-income preschoolers' numerical understanding. Journal of Educational Psychology, 101(3), 545-560. 
Statistics Canada. (06/12/2008). Occupation - national occupational classification for statistics 2006 (720), class of worker (6) and sex (3) for the labour force 15 years and over of Canada, provinces, territories, census metropolitan areas and census agglomerations, 2006 census - 20\% sample data. Retrieved 09/07/2009, from http://www12.statcan.gc.ca/english/census06/data/topics/RetrieveProductTable.cfm? TPL=RETR\&ALEVEL $=3 \& A P A T H=3 \& C A T N O=97-559-$

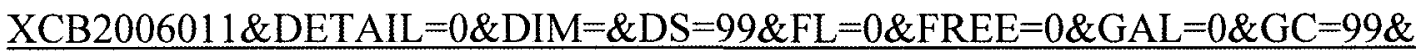
$\mathrm{GK}=\mathrm{NA} \& \mathrm{GRP}=1 \& \mathrm{IPS}=97-559-$ $\underline{\mathrm{XCB} 2006011 \& \mathrm{METH}=0 \& \mathrm{ORDER}=1 \& \mathrm{PID}=92104 \& \mathrm{PTYPE}=88971.97154 \& \mathrm{RL}=0}$ $\underline{\& S=1 \& \text { ShowAll }=\text { No } \& \text { StartRow }=1 \& S U B=743 \& \text { Temporal }=2006 \& \text { Theme }=74 \& \text { VID }}$ $=0 \& \mathrm{VNAMEE}=\& \mathrm{VNAMEF}=$

Stipek, D. J., \& Byler, P. (1997). Early childhood education teachers: Do they practice what they preach? Early Childhood Research Quarterly, 12, 305-325.

VanTassel-Baska, J., Feng, A. X., Brown, E., Bracken, B., Stambaugh, T., French, H., et al. (2008). A study of differentiated instructional change over 3 years., 297-312.

Vartuli, S. (1999). How early childhood teacher beliefs vary across grade level. Early Childhood Research Quarterly, 14, 489-514.

Vygotsky, L. S. (1978). In M. Cole, V. John-Steiner, S. Scribner and E. Soubermen (Eds.), Mind in Society: The Development of Higher Psychological Processes. Cambridge, MA: Harvard University Press. 
Wang, J., Elicker, J., McMullen, M., \& Mao, S. (2008). Chinese and American preschool teachers' beliefs about early childhood curriculum. Early Child Development and Care, 178, 227-249.

Warfield, J., Wood, T., \& Lehman, J. (2005). Autonomy, beliefs and the learning of elementary mathematics teachers. Teaching and Teacher Education, 21, 439-456.

Weigel, D. J., Martin, S. S., \& Bennett, K. K. (2006). Mothers' literacy beliefs:

Connections with the home literacy environment and pre-school children's literacy development. Journal of Early Childhood Literacy, 6, 191-211.

Whitehurst, G. J., \& Lonigan, C. J. (1998). Child development and emergent literacy. Child Development, 69, 848-872.

Young-Loveridge, J. M. (1989). The development of children's number concepts: The first year of school. New Zealand Journal of Educational Studies, 24, 47-64. 
Appendix A: Parent Survey

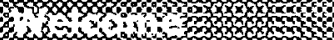

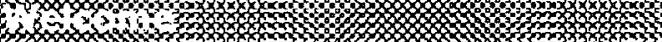

Welcome! Thank you for agreeing to participate In the Parents Count Too- a study of chlldren's home learning experiences. Please complete both sides of each page of this survey then mail it in the attached envelope. The last page asks for contact information so that you can be entered in a draw to win of 10 gift certificates from Tim Hortons ( $\$ 5$ each) and a gift basket from the Manitoba Children's Museum. For questions about the research, please contact Sheri-Lynn Skwarchuk (786-9141 or s.skwarchuk@uwinnipeg.ca).
\end{abstract}

\title{
* 1. What is your postal code?
}

2. This survey is about you and your child born in 2003. Please enter your birth dates.

Child's Birth Date

Your Birth Date

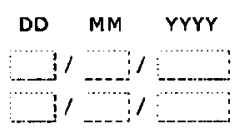

\section{What is the gender of your child born in 2003 ?}

Male

Oremaie

4. What is your relation to the child?

Mother

Father

Other (please specify)

5. If you have other children, please enter their birth years below. If you have more than 4 children, please enter the three closest in age to the 2003 child.

other Chlld

Other Child

other Child

6. Tell us about the language spoken in your home. What language is spoken MOST OF THE TIME?
Prench
Lithuanian
English
Oersian
Bangoli
$\bigcirc$ Portuguese
$O$ chinese
$\bigcirc$ Punjabi
Cilipino/Tagalog
Oromanian
German
Sign Language
$\bigcirc$ Hungarian
$\bigcirc$ spanish
Japanese
Vletnamese
Okorean
Arabic
Other (please specify) 
7. If you know the name of the school your child will attend next year, please enter it below.

8. Tell us about any and all of your child care arrangements. Check off the days per week the child attends the following options:

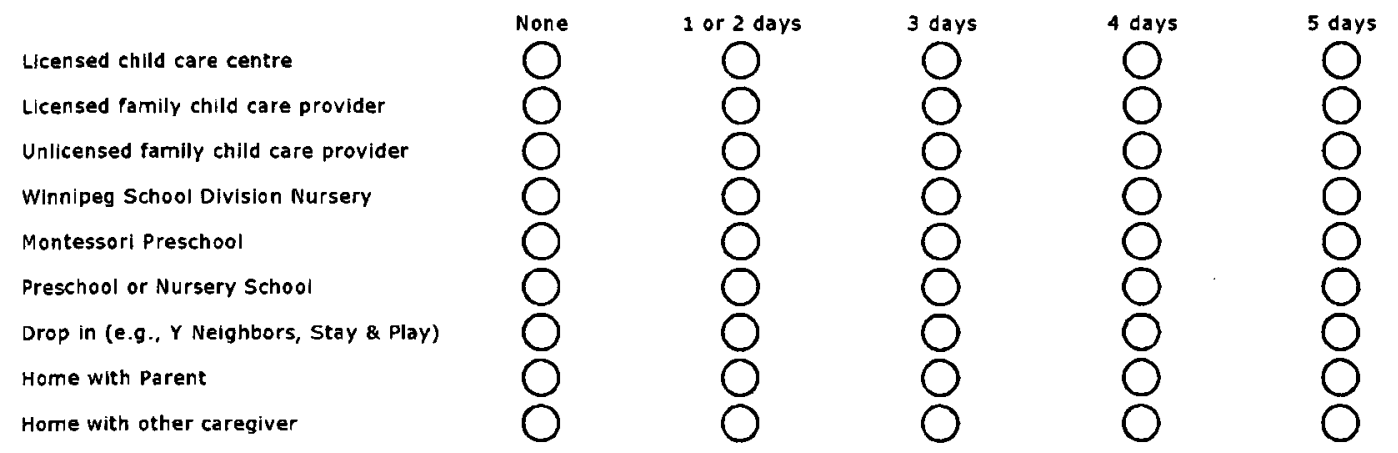

9. Do you qualify for part or full daycare subsidy?

Ores

No

10. In your opinion, how important is it for children to achieve the following benchmarks, BEFORE starting Grade 1.

Count to 10
Count to 100
Count to 1000
Read printed numbers up to 100
Know some alphabet letters
Print his/her name
Krint all 26 alphabet letters
Know multiplying (e.g., $2 \times 6$ )
Read a few words
Read simple picture books
Read chapter books


11. How often do you do the following activities with your child?

\begin{tabular}{|c|c|c|c|c|c|}
\hline \multirow{4}{*}{$\begin{array}{l}\text { We task about time wish clocks \& } \\
\text { calendars. } \\
\text { I help my child to sing/recite the } \\
\text { alphabet. } \\
\text { I encourage my child to do math in his } \\
\text { or her head. }\end{array}$} & Rarely or Never & Monthly & Weekıy & $\begin{array}{l}\text { Several days per } \\
\text { week }\end{array}$ & $\begin{array}{l}\text { Most Days pe } \\
\text { week }\end{array}$ \\
\hline & O & 0 & 0 & & \\
\hline & 0 & 0 & & ( & 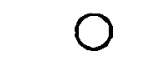 \\
\hline & $\mathrm{C}$ & 0 & & $\Omega$ & ) \\
\hline \multicolumn{6}{|l|}{ I help my child to read words. } \\
\hline \multicolumn{6}{|l|}{$\begin{array}{l}\text { I introduce new words \& their } \\
\text { defintions to my child. }\end{array}$} \\
\hline \multicolumn{6}{|l|}{$\begin{array}{l}\text { My child plays computer games that } \\
\text { involve numbers/letters. }\end{array}$} \\
\hline \multicolumn{6}{|l|}{$\begin{array}{l}\text { Invive numbers/letters. } \\
\text { we sing counting songs (e.g.,"Five } \\
\text { Little Monkeys") }\end{array}$} \\
\hline \multicolumn{6}{|l|}{$\begin{array}{l}\text { We play games that involve counting, } \\
\text { adding or subtracting. }\end{array}$} \\
\hline \multicolumn{6}{|l|}{ I teach my child the sounds of letters. } \\
\hline \multicolumn{6}{|l|}{$\begin{array}{l}\text { We make up rhymes in songs (e.g., } \\
\text { Down by the Bay) }\end{array}$} \\
\hline \multicolumn{6}{|l|}{$\begin{array}{l}\text { We sort \& classify by color, shape and } \\
\text { size. }\end{array}$} \\
\hline \multicolumn{6}{|l|}{$\begin{array}{l}\text { We time how fast an activity can be } \\
\text { completed. }\end{array}$} \\
\hline \multicolumn{6}{|l|}{$\begin{array}{l}\text { I help my child to recite numbers in } \\
\text { order. }\end{array}$} \\
\hline We play board games or cards. & 0 & & & 0 & \\
\hline I ask my child to point to words/letters & & & & & \\
\hline
\end{tabular}

when we read.

\section{How often do you do the following activities with your child?}

I ask about quantities (e.g., how many
spoons?)
I encourage collecting (e.g., cards,
stamps, rocks).
I encourage use of fingers to indicate
'how many'.

-page end. 
13. Please estimate the number of books that are available in your household.

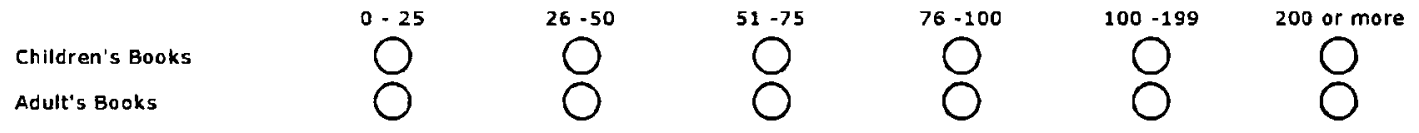

14. In a typical week, how many times do you or other members of the household read to your child?

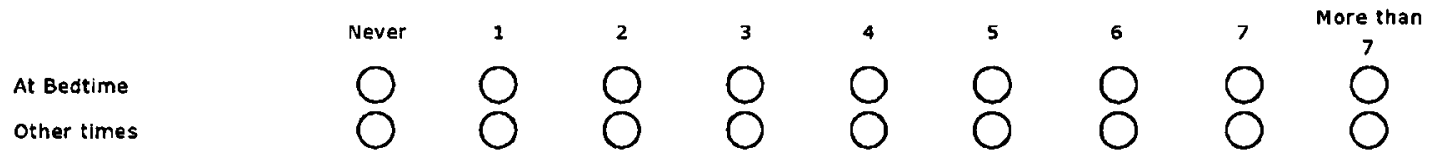

15. Below you will see a list of titles. Some of these are titles of popular children's books and some are made up. Please read the titles and put a check next to those titles which you know to be titles of children's books. Do not guess, but only check those you know. Please answer without stopping to verify the books in your home.

$\begin{array}{ll}\square \text { Alligator Pie } & \square \text { Math Fables } \\ \square \text { Animals on Board } & \square \text { Moo, Bae, La La La! } \\ \square \text { Barnyard Dance } & \square \text { Murmel, Murmel, Murmel } \\ \square \text { Big Old Trucks } & \square \text { Olivia } \\ \square \text { Brown Bear, Brown Bear, What do you see? } & \square \text { One Hundred Hungry Ants } \\ \square \text { Chicka, Chicka, 1, 2, } 3 & \square \text { Red is Best } \\ \square \text { Clarissa's Patch } & \square \text { Something Prom Nothing } \\ \square \text { Click, Clac, Moo: Cows that Type } & \square \text { Ten Apples Up on Top } \\ \square \text { Eleanor and the Magic Bag } & \square \text { Ten Little Ladybugs } \\ \square \text { Freight Train } & \square \text { Ten, nine, elght } \\ \square \text { Go Dog Go } & \square \text { The Doorbell Rang } \\ \square \text { Guess How Much I Love You } & \square \text { The Very Hungry Caterpillar } \\ \square \text { Hello Morning, Hello Day } & \square \text { The Runaway Bunny } \\ \square \text { Hippos Go Beserk } & \square \text { Tracy Tickles } \\ \square \text { In the Night Kitchen } & \square \text { Velveteen Rabbit } \\ \square \text { Love You Forever } & \square \text { We're Going on a Bear Hunt } \\ \square \text { Martha Rabblt's Family } & \end{array}$


16. Below you will see a list of games for preschoolers. Some of these are popular children's games and some are made up. Please read the names and put a check next to those games which you know to be real games. Do not guess, but only check those you know. Please answer without stopping to verify any games in your home.

$\square$ idding Armadillos
$\square$ Bouncin Tigger
$\square$ Candy Land
$\square$ Cariboo
$\square$ Crocodile Dentist
$\square$ Dominoes
$\square$ Elefun
$\square$ Exasperation
$\square$ Forage in the Forest
$\square$ Go Fish Card Game
$\square$ Go, Diego, Go 123 Game
$\square$ Guess Who

$\square$ Hi Ho Cherry-O
$\square$ Hungry, Hungry Hippos
$\square$ Insey Winsey Spider
$\square$ Monkey Madness
$\square$ Monopoly Junior
$\square$ Mr. Bucket
$\square$ Operation
$\square$ Perfection
$\square$ Picking Peppers
$\square$ Scrabble Junior
$\square$ Snakes \& Ladders/Chutes \& Ladders
$\square$ Trouble

17. What are your child's favorite activities? Indicate how often your child would CHOOSE (if you let them) to spend his or her free time on each activity below.

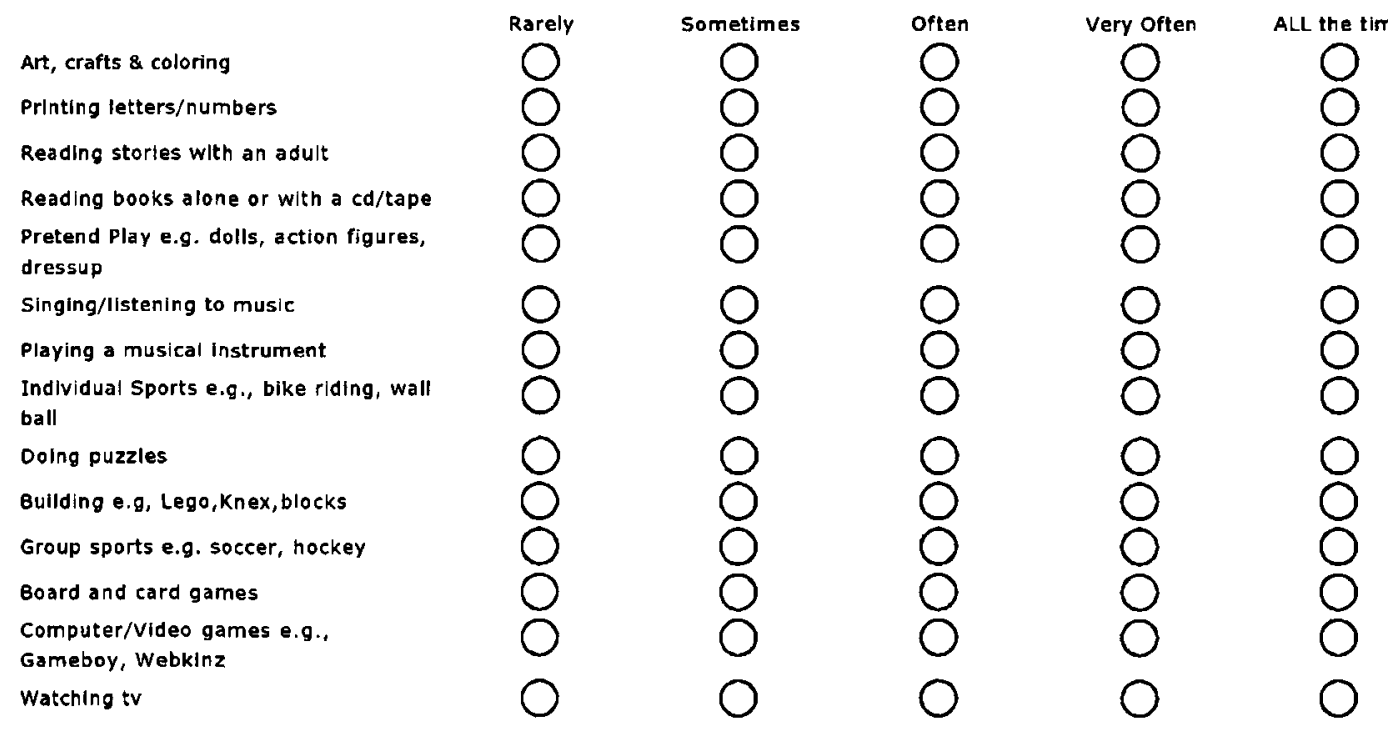


18. Please rate how strongly you agree or disagree with the following statements.

When I was in school, I was good at
mathematics.

19. When cooking with your child, rate how often each of the items below occurs.

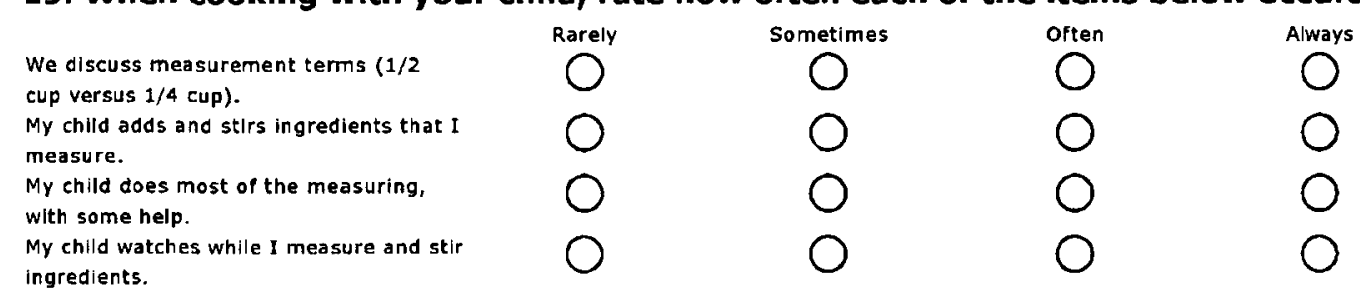

\section{When we do Valentines or Birthday cards:}

My chlld chooses cards and decorates
them.
I do most of the printing \& discuss
spelling.
My chlld makes the card his/herself.




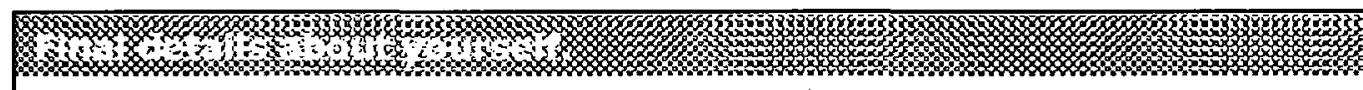

21. Tell us about your education.

\begin{tabular}{|c|c|c|c|c|c|}
\hline $\begin{array}{l}\text { four highest level of } \\
\text { education } \\
\text { ther parent's highest } \\
\text { evel of education }\end{array}$ & $\overbrace{}^{\text {High School }}$ & $\bigcirc^{\text {College Cert|ficate }}$ & $\bigcirc^{\text {College Diploma }}$ & $\bigcirc^{\text {University Degree }}$ & $\bigcirc^{\text {Graduate Degree }}$ \\
\hline
\end{tabular}

level of education

22. Tell us about your current employment status:

Full Time

Part Time

Not Employed

23. Please tell us about your occupation. Select the best-fitting industry. What industry do you work in?
Accomodation/Food Services
Information/Culture/Recreation
Agriculture
manufacturing
Business/Building support
Other Services
Child-care
Professional/Scientific/Technical Services
construction
Publle Administration
Education-Teacher/Professor
Social Assistance
Education - Other
Trade
O Finance/Insurance/Real Estate
Transportation
Forestry/Mining/Energy
Unemployed
Health Care
utillties
Homemaker

\section{What industry does the other parent work in?}
Accomodation/Food Services
Information/Culture/Recreation
Agriculture
Manufacturing
Business/Building Support
Other Services
Child-Care
Professional/Scientlfic/Technical Servlces
construction
Public administration
Education-Teacher/Professor
Social Assistance
Education - Other
Trade
Finance/Insurance/Real Estate
Transportation
Forestry/Mining/Energy
Unemployed
Health Care
utilities
Homemaker

Thank you for completing this survey. 


\section{Appendix B: Early Learning and Child Care Practitioner Survey}

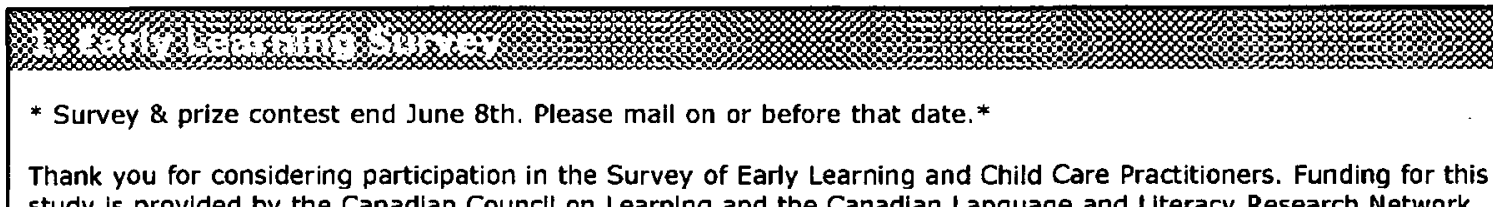
study is provided by the Canadian Councll on Learning and the Canadian Language and Literacy Research Network.

This brief (about 10 minutes) survey is about early learning beliefs and practices. Participation in this survey is anonymous. The questions in the survey address your work with children. You are free to exit the survey at any time and you can omit any questions you feel uncomfortable answering.

This study has been approved by the Carleton University Ethics Committee for Psychological Research. The data collected in this study are strictly confidential and will be made available only to researchers associated with this project and their students. There is no risk to participating in the study.

If you have any questions related to this study and/or concerns as a result of participation in this study, please feel free to contact me directly (Dr. Jo-Anne LeFevre, Professor, Department of Psychology, Carleton University, 613520-2600 ext. 4574, jlefevre@connect.carleton.ca). Should you have any ethlcal concerns about this study, please contact Dr. A. Parush (Chair, Carleton University Ethics Committee for Psychologlcal Research, avi_parush@carleton.ca, 613-520-2600, ext. 6026) or Dr. A. Bowker (Chair, Dept. of Psychology, psychchair@carleton.ca, 613-520-2600, ext. 2648).

Once all the data have been collected and analyzed, a summary of the findings will be published in the Canadian Child Care Federation's Interaction magazine.

At the end of the survey, a separate page (to keep this survey anonymous) will be provided for you to enter your email address into a draw to win one of 4 gift certificates. Each prize is redeemable for $\$ 75$ in learning materials.

Thank you for your time and consideration.

\section{I consent to participate in the Early Learning \& Child Care Practitioner Survey. O AGREE.}

\section{What is your postal code?}

\section{How would you describe your current work with children?}
O Directly with children in a child care centre or program.
O As a director or administrator in a child care centre.
As a family or home child care provider
O In a family resource program or other part-time program
O In a nursery school or preschool program, where parents are not present. where parents are also present.
O As an instructor of Chlld Care and Early Learning practitioners
Other (please specify)

\section{In this role, how much of your time do you spend directly with the children?}
$100 \%$
about $50 \%$
less than $25 \%$
about $75 \%$
about $25 \%$ 
5. Does your program follow a specific philosophy?
O No
O Yes - Bank Street
O Yes - (Aboriginal) Head Start
O Yes-Montessori
O Yes - High Scope
O Yes - Second Language Immersion
O Yes - Reggio Emilia
O Yes - Religious
O Yes - Academic-school preparation
O Yes - Walderf
O Yes - Emergent Curriculum
O Yes \& No-Some elements of a specific philosophy.

For 'Yes \& No', please describe which philosophy(ies) you include

\section{Where is your program located?}
$O$ In a dedicated private facility
O In a private sehool, as part of the school
O In a community or recreation centre
In a public school, as part of the school
$O$ In a church
O In a publlc school, run by a separate organization
O In my home
Other (please speclfy)

7. Think about the children in your program. Tell us about how many of the children fall into the following categories.
Aboriginal
Speak a language other than french or English at home
Live in impoverlshed or diffleult
circumstances
Have special needs (eg. physical
disabillties)
Qualify for government subsidized care

$\begin{array}{cc}\text { None } & 11025 \\ \square & \square \\ \square & \square \\ \square & \square \\ \square & \square \\ \square & \square\end{array}$

8. In this survey, we'll use the term LITERACY to refer to language and reading abilities. Similarly, we'll use NUMERACY to refer to number and math abilities.

During the last TwO (2) years, how often have you attended the types of professional development listed below?

$\begin{array}{lcccc} & \text { Not at All } & \text { once } & \text { Twice } & \text { Three times or } \\ \text { more }\end{array}$


9. Please rate how strongly you agree or disagree with the following statements.

I feel I am sufficiently knowledgeable about early
literacy.
I feel I am sufficlently knowledgeable about early
numeracy.
I am aware of Professional Development events
about early numeracy In my local area.
I am aware of Professional Development events
about early literacy in my local area.
I often avoid situations involving mathematics.
I often avoid situations involving writing.

$\begin{array}{cc}\begin{array}{c}\text { Strongly } \\ \text { Disagree }\end{array} & \text { Disagree } \\ 0 & 0 \\ 0 & 0 \\ 0 & 0 \\ 0 & 0 \\ 0 & 0 \\ 0 & 0\end{array}$

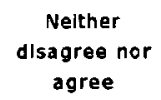

0

0

0

0

0

0
Agree

$0 \quad 0$

10. Tell us about your education.
Highest level of education
High School
College Certificate
College Diploma
University Degree
Graduate Degree
Early Chlldhood Programs
$\square$

11. Please rate your agreement with the following statements.

\begin{tabular}{|c|c|c|c|c|c|}
\hline & $\begin{array}{l}\text { Strongly } \\
\text { disagree }\end{array}$ & Dlsagree & $\begin{array}{l}\text { Neither } \\
\text { disagree nor } \\
\text { agree }\end{array}$ & Agree & Strongly Agree \\
\hline All activitles in a program should be chlld-Initlated. & 0 & 0 & 0 & 0 & 0 \\
\hline $\begin{array}{l}\text { Formal instruction in math \& reading should only be } \\
\text { given If children want it. }\end{array}$ & 0 & 0 & 0 & 0 & 0 \\
\hline $\begin{array}{l}\text { Teaching children about letters, sounds and words is } \\
\text { part of my job. }\end{array}$ & 0 & 0 & 0 & 0 & 0 \\
\hline $\begin{array}{l}\text { Children should be allowed to opt out of literacy \& } \\
\text { numeracy activities. }\end{array}$ & 0 & 0 & 0 & 0 & 0 \\
\hline The focus of early numeracy is counting, not math. & 0 & 0 & 0 & 0 & 0 \\
\hline $\begin{array}{l}\text { Reading stories with chlldren is the best way for } \\
\text { them to learn to read. }\end{array}$ & 0 & 0 & 0 & 0 & 0 \\
\hline $\begin{array}{l}\text { Numeracy \& literacy skills should be assessed } \\
\text { regularly, either informally or formally. }\end{array}$ & 0 & 0 & 0 & 0 & 0 \\
\hline $\begin{array}{l}\text { Soclal \& emotional growth is the primary goal of an } \\
\text { early ehildhood program. }\end{array}$ & 0 & 0 & 0 & 0 & 0 \\
\hline $\begin{array}{l}\text { Four \& five year olds should be introduced to the } \\
\text { basics of addition \& subtraction. }\end{array}$ & 0 & 0 & 0 & 0 & 0 \\
\hline $\begin{array}{l}\text { The most important goal of an early childhood } \\
\text { program is preparation for school. }\end{array}$ & 0 & 0 & 0 & 0 & 0 \\
\hline
\end{tabular}

12. Every child develops at his or her own rate. In your opinion, how important is it for children to achieve the following benchmarks, BEFORE starting Grade 1.

\begin{tabular}{|c|c|c|c|c|c|}
\hline & Very Unimportant & Unimportant & $\begin{array}{l}\text { Nelther } \\
\text { un important nor } \\
\text { important }\end{array}$ & Important & Very Important \\
\hline Count to 10 & 0 & 0 & 0 & 0 & 0 \\
\hline Count to 100 & 0 & 0 & 0 & 0 & 0 \\
\hline Know some alphabet letters & 0 & 0 & 0 & 0 & 0 \\
\hline Know all 26 alphabet letters & 0 & 0 & 0 & 0 & 0 \\
\hline Print his/her name & 0 & 0 & 0 & 0 & 0 \\
\hline Know simple sums (e.g., $2+2$ ) & 0 & 0 & 0 & 0 & 0 \\
\hline Read a few words & 0 & 0 & 0 & 0 & 0 \\
\hline
\end{tabular}


13. Tell us about an early literacy activity that you find particularly enjoyable or successful.

(1)

14. Tell us about an early numeracy activity that you find particularly enjoyable/successful.

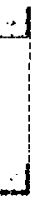

15. Tell us about literacy or numeracy activities that you have stopped doing because they weren't enjoyable or successful.

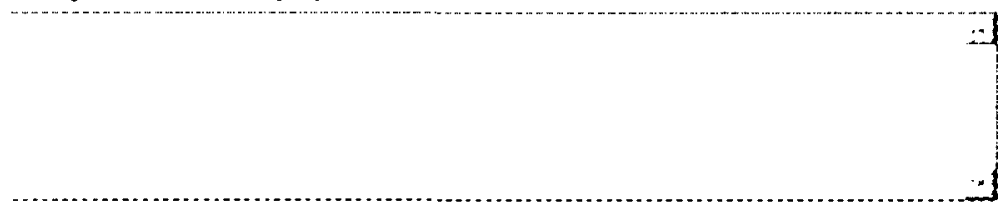

16. For the next set of questions, we'll ask you to focus your answers on a particular age group of children. Please select the age group below with whom you spend most of your time or which represents most of the children in your care.
Infant (under 12 months)
0 School-age $(5$ and 6 year olds)
Toddler ( 1 and 2 year olds)
Ofter-School (6+)
O Preschool ( 3 and 4 year olds)

** IF YOU PICKED PRESCHOOL OR OLDER, PLEASE SKIP TO QUESTION 18.** 
17. Please answer this set of questions if you picked Infant or Toddler as the age group with whom you spend most or your time. **IF YOU PICKED PRESCHOOL OR OLDER PLEASE SKIP TO THE NEXT PAGE.**

How often did you do the following activities with the children in your care?

Never with this Not in the last Sometimes butAt least once in At least once Most days last

I read a storybook aloud. age group

year

not last month the last month

last week

week

0

0

0

0

0

manipulatives (e.g., puzzles, blocks,

0

0

O

0

0

O

toys with buttons that press)

I encouraged pretend or real

conversations and turn taking.

I recited nursery rhymes.

I labeled the colors and shapes of

objects.

I drew attention to comparisons with

words like small, bigger, first, last.

I encouraged children to share toys.

I asked questions while we read.

I engaged children in conversation about

quantity (e.g., How many are there?)

I played games with cause and effect

(e.g., hiding and finding a object)

I used alphabet books.

I encouraged chlidren to use manners.

I counted fingers and toes and food

during daily life activitles.

I encouraged children to notice patterns

(e.g., red, blue, red).

l engaged children in musical activities.

I pointed out some words, letters and/or

letter sounds while $I$ read.

I encouraged drawing and scribbling.

I pointed out rhymes and sounds in

words and songs.

I cuddled with chlldren.

I pointed out words and print around the

room.

I used baby sign language to

communicate with children.

I encouraged children to sort and classify

objects (e.g., Let's pult out alt the

hearts).

I read stories with numbers.

I watched a video/tv show with my

children.

I sang songs/played finger games with numbers (e.g., Five Little Monkeys, Alice

O

0

0

0

0

0

0

O

0

0

0

$\mathrm{O}$

0

0

0

0

0

0

0

0

0

0

0

0

0

0

0

o

0

0

0

0

0

0

0

0

0

0

0

0

00

0

0

0

0

0

0

0

0

0

0

0

0

0

0

0

0

0

0

0

0

0

0

0

0

0

0

0

0

0

0

0

0

o

0

0

0

0

0

0

0

0

0

0

0

$0 \quad 0$

0

0

0

0

0

0

0

0

0

0

0

0

0

0

0

0

0

0

0

0

0 
18. **PLEASE ANSWER THIS SET OF QUESTIONS IF YOU PICKED PRESCHOOL OR OLDER AS THE AGE GROUP WITH WHOM YOU SPEND MOST OF YOUR TIME.** If you picked Infant or Toddler, please answer the set of questions on the previous page only.

\section{How often did you do the following activities with the children in your care?}

Never $w /$ th this Not In the last Sometimes butAt least once in At least once Most days last

I asked children about quantities (e.g., age group year not last month the last month last week week

how many are there?)

$$
\text { O }
$$

O

0

O

O

O

letters.

I encouraged activities invoiving adding, subtracting or measuring.

I drew chlldren's attention to print and words and their meaning.

I played hand/finger games with numbers (one potato, two potato).

I talked about words and sentences and parts of a story while I read.

I played a board game with a spinner or dice.

I used alphabet books and/or alphabets to teach letters.

I encouraged children to use gestures or songs in their dramatic play.

I encouraged practice at blending words (for example, cow-boy, foot-ball). I played games that Involve recognizing printed numbers (e.g., Bingo)

I asked children to Include another child in a game or activity.

I asked who, where and why questions while we read.

I used nursery rhymes and/or rhyming games to teach about sounds.

I read a storybook aloud.

I played games that involved counting iterns.

I encouraged the children to write (or attempt to write) their name.

I used songs to teach my children counting words.

I encouraged the children to play with Lego, puzzles, peg-boards and blocks. I helped children to use words to express their feelings.

I asked a chlid to retell, in their own words, a story that I had read aloud. I encouraged my students to sort and classify objects (e.g., types of dinosaurs).

I encouraged chlldren to use colours and shapes in thelr drawings.

I played games that involved

cooperation and sharing.

0

o

O

O

0

0

O

0

O

0

0

0

0

0

O

0

0

O

0

0

0

0

0

0

O

0

0

0

0

0

0

0

0

0

o

0

0

0

O

0

0

0

0

0

0

0

0

0

00

0

0

00

0

0

0

0

0

o

0

$\mathrm{O} O$

$\mathrm{O}$

0

0

0

0

0

o

0

I asked chlldren to compare or combine

quantities (e.9., you have 2 and $I$ have

0

0

0

0

0

0

one; how many altogether)? 
19. Below you will see a list of titles. Some of these are titles of popular children's books and some are made up. Please read the titles and put a check next to those titles which you know to be titles of children's books. Do not guess, but only check those you know. Please answer without stopping to verify the books in your centre.

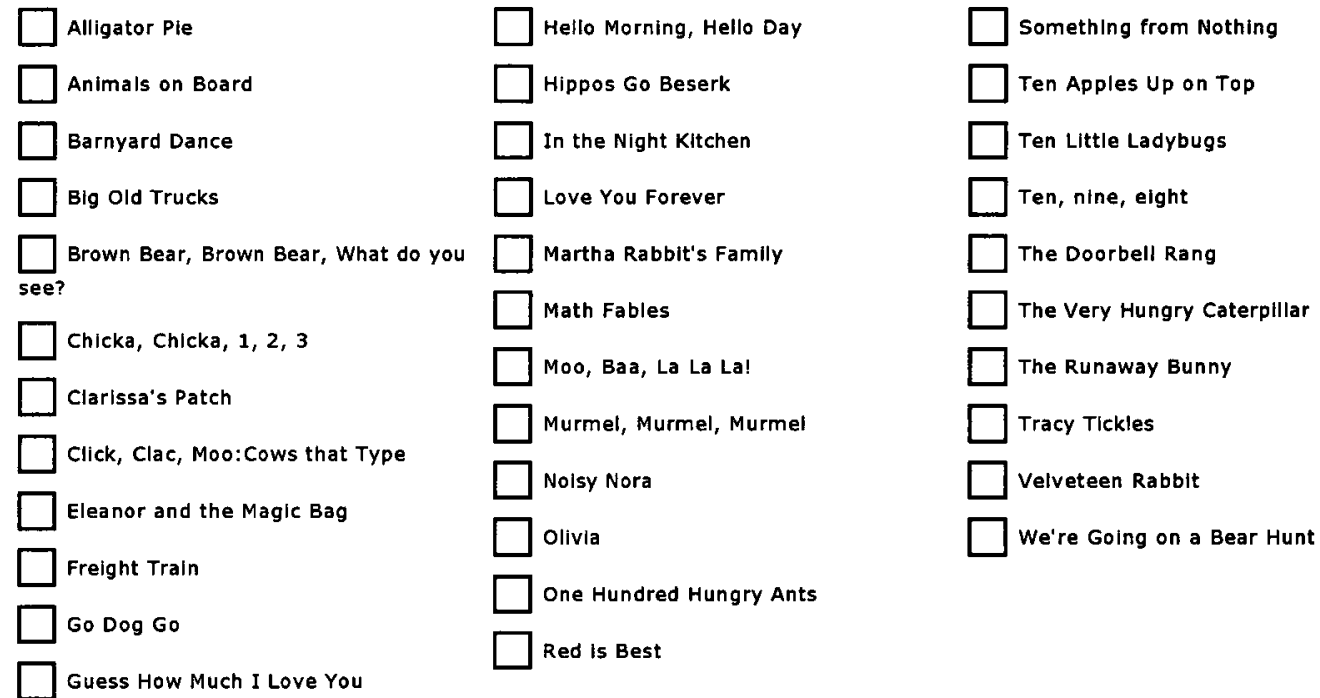

20. Below you will see a list of games for preschoolers. Some of these are popular children's games and some are made up. Please read the names and put a check next to those games which you know to be real games. Do not guess, but only check those you know. Please answer without stopping to verify any games in your centre.

\begin{tabular}{|c|c|c|}
\hline 123 Parakeets & Forage in the Forest & Mr. Bucket \\
\hline Adding Armadillos & Go Fish Card Game & Operation \\
\hline Bouncln Tigger & Go, Dlego, Go 123 Game & Perfection \\
\hline Candy Land & Guess Who & Picking Peppers \\
\hline Cariboo & Hi Ho Cherry-o & Scrabble Junior \\
\hline Crocodile Dentist & Hungry, Hungry Hippos & Snakes \& Ladders/Chutes \& Ladders \\
\hline Dominoes & Insey Winsey Splder & Trouble \\
\hline Elefun & Monkey Madness & \\
\hline asperation & Monopoly Junior & \\
\hline
\end{tabular}


21. Every child develops at his/her own rate. However, we can often identify an age range at which most children are capable of certain activities. Please select the age group at which you think children are CAPABLE of achieving the following:

Uses Invented spelling to print words.
can state the number after 5 by starting the count from 1 .
Can follow two-step directlons, even when the desired object is in
another room.
Tells a complete story with a beginning, middle and end.
can ldentify the flrst person in line.
Can recognize and name trlangles, squares, and circles.
Knows how to fairly distribute 8 cancles between 2 people.
Can state the number after 8 by starting the count from
Cant backward from 5 .
Reads and understands simple words (e.g., red, car).
Can accurately count 4 items in a collection.
Makes up rhymes, including nonsense rhymes and chants.
Asks who, where \& why questions, often in past tense
Tells a simple story.
Knows that 2 and 2 are 4 .

\section{How old are you, in years?}

Age

23. Please select your gender.

Female 


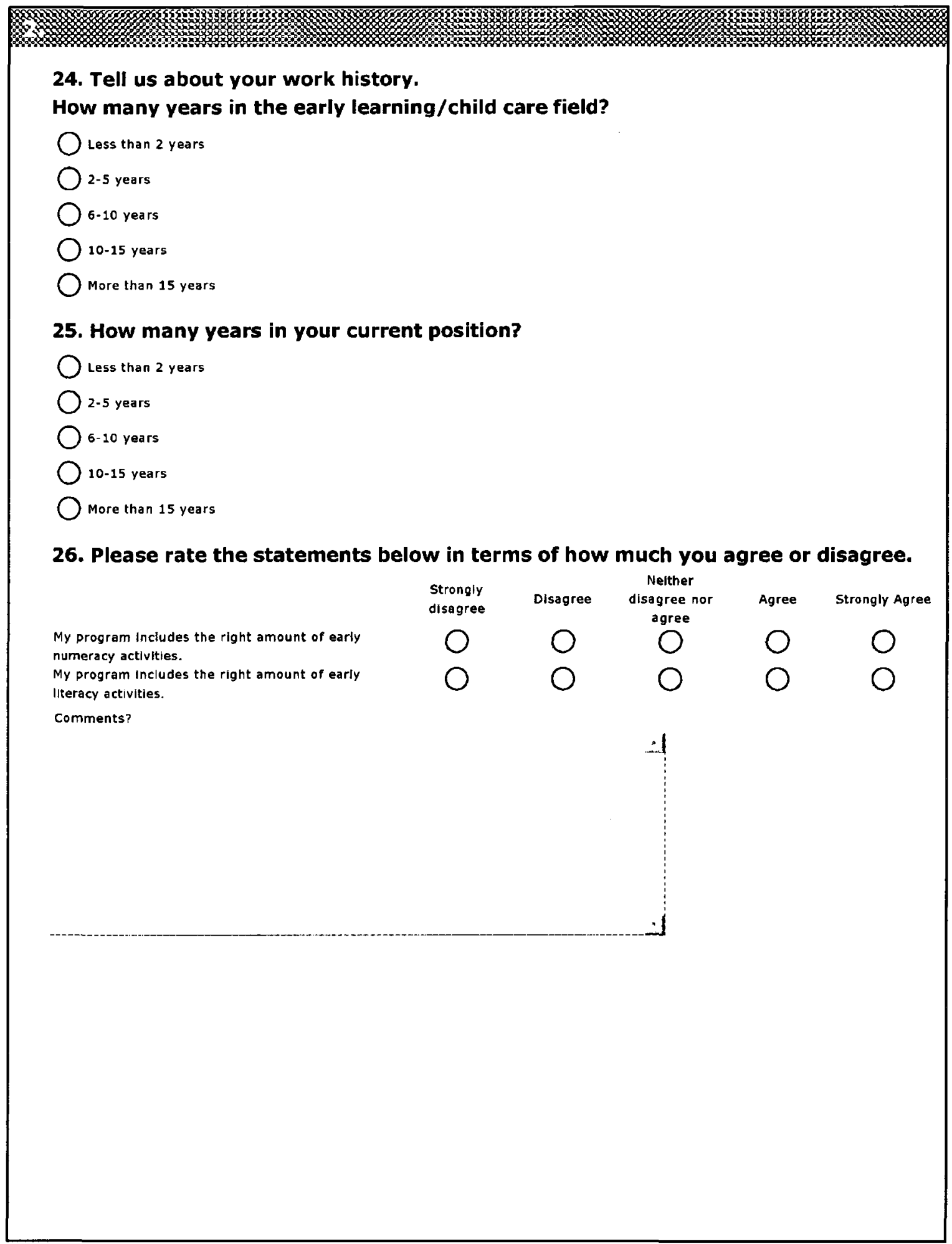


Appendix C: ELCC Practitioner Program Philosophies

\begin{tabular}{lr}
\hline \multicolumn{1}{c}{ Program Philosophy } & Percentage \\
\hline None & $28.2 \%$ \\
Montessori & $1.6 \%$ \\
Reggio Emilia & $2.3 \%$ \\
Waldorf & $.3 \%$ \\
High Scope & $4.0 \%$ \\
Religious & $1.1 \%$ \\
Emergent Curriculum & $16.0 \%$ \\
(Aboriginal) Head Start & $3.5 \%$ \\
Second Language Immersion & $.3 \%$ \\
Academic-school preparation & $9.8 \%$ \\
Some elements of a specific philosophy & $14.6 \%$ \\
Child Directed & $.5 \%$ \\
Play based & $1.6 \%$ \\
Theme based & $.8 \%$ \\
Emergent Curriculum and Reggio Emilia & $1.6 \%$ \\
Some Emergent Curriculum & $4.0 \%$ \\
Some academic/school preparation & $1.9 \%$ \\
Combination of two of more philosophies & $4.8 \%$ \\
Other philosophy & $1.3 \%$ \\
Aboriginal other & $.5 \%$ \\
\hline Note. ${ }^{1}$ Missing cases = 5. & \\
\hline
\end{tabular}




\section{Appendix D: Ethics Approval}

\section{Fwd: Ethics final approval}

From: Jo-Anne Lefevre (jeferre(connectrarleton,a)

Sent: August 13, $20099: 49: 21$ AM

To: Carla Sowinskl (carls_sowinskiehotma

Ethics Approval ElCC study (see below). This was before thay had anything in the ongine system.

Cheers, Jo-Anne

So-Anne LeFovie, Ph.D.

Director, Inatiaute of Cogritive Science

Asactiato Editor. Journal of Experimental Chidd Peychology

Cartoton University

Room 2201. Dunton Tower

1125 Colonel By Dive

Otawra, ON K1S 580

613-520-2600 x. 2893 FAX: 613-520-3985

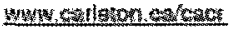

www. cartenon.cosmi

Begin forwarded meassage:

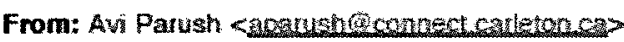

Date: May 22, 200823008 PM GMT-04.00

To: "lo-Anne LeFevre" >llefevreQ 0 comectcarleson.cas

Cc: Au Paushisicaletons

Subject: Ethics final approval

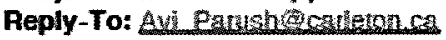

The Carleton University ethics committee for psychology research has approved your study: "Who's counting? Numeracy and Literacy Practices of Early Leaming and Child care practitioners*

The study number is $07-241$.

This approval is valid until August 31, 2009. At that time, you will need to submit a progress report indicating that the research is either complete or that it is ongoing and you require a renewal.

Good luck with this research,

Avi

Avi Parush, Pho

Chais - Committe for Ethics in Psychological Research

Department of Psychology

Carletan University. Ottawa, ON. Canada

Home Pane

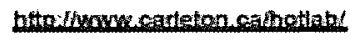


Dejattrent o Paycology

Ethes Conntitiee tor Psycholugy Researth whth Human Participants

\section{Certificate of Ethics Approval}

\begin{tabular}{|c|c|c|}
\hline Principal Investigator & Department & 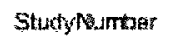 \\
\hline & & 09-060 \\
\hline Institution/si where resear & ted: & \\
\hline University of Wir & & \\
\hline Co-lnuestigators and oher & & \\
\hline Researchor & Study Role & Position \\
\hline Wo-jure Leferte & Faoulty sponser & Faculy \\
\hline
\end{tabular}

Sidv Tite: Renewal and Addendum to 07-254 "Parents count too: An investigation of children's home numoracy oxperiences"

Aaproval Date: $\frac{03 / 03 / 2009}{\text { Submitted Date Study Conponent }}$ Appovial Typo:

Commentis:

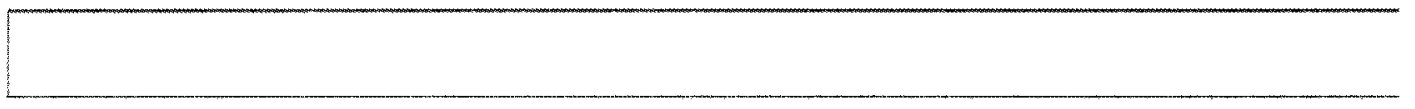

Cerification

The potocol descriting the atowe-narted proiect hes heen reviewed ty the Conmitlee for Ethica in psyohology Restarch ard the research procedires were ound to to acceplate cn ettical grounde fer research invotwing tumar participarts.

\section{No Siproakure}

Chair, Etrics Committes for Psychology Reseanth

This Certifeate of Approwal is valid for the atove tem provited there is no change in the research procedures. 